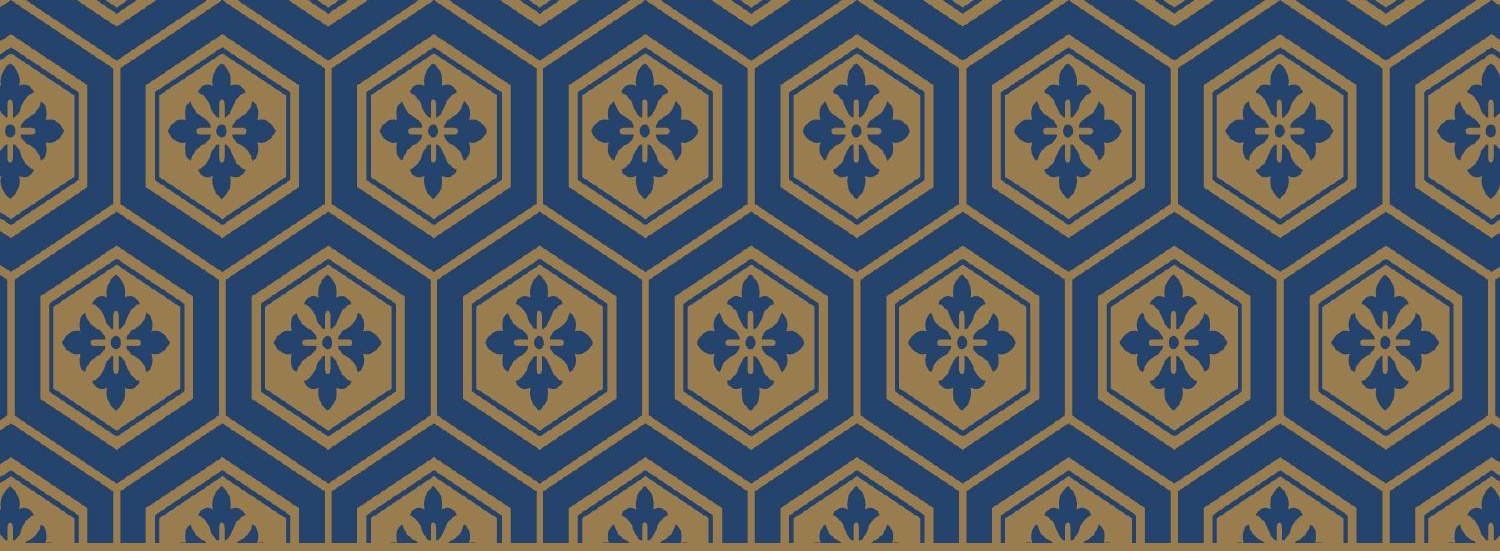

\title{
The American Automobile Industry
}

REBIRTH OR REQUIEM?

Robert E. Cole, Editor

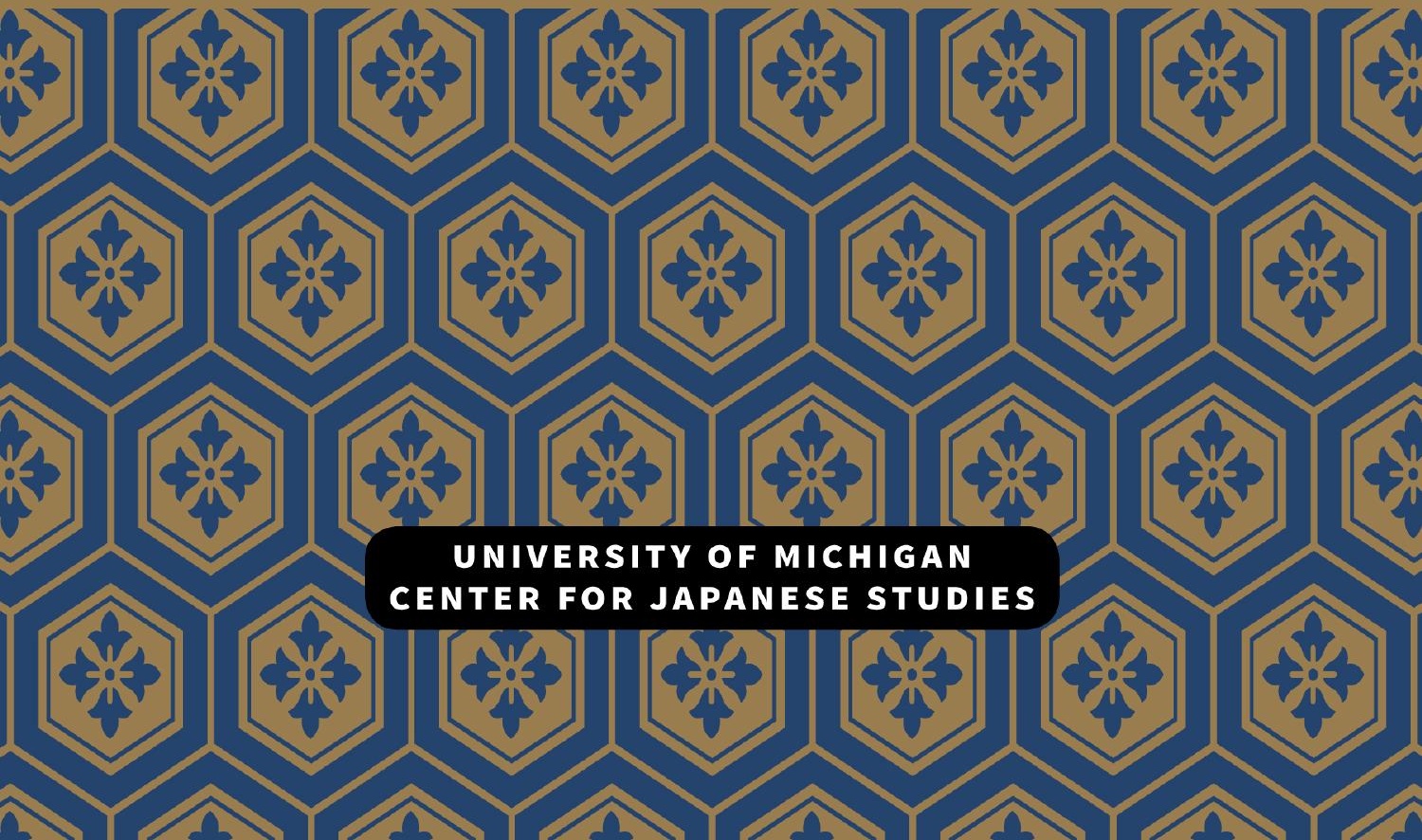


THE UNIVERSITY OF MICHIGAN CENTER FOR JAPANESE STUDIES

MICHIGAN PAPERS IN JAPANESE STUDIES

NO. 13 


\section{MICHIGAN PAPERS IN JAPANESE STUDIES}

No. 1. Political Leadership in Contemporary Japan, edited by Terry Edward MacDougall.

No. 2. Parties, Candidates and Voters in Japan: Six Quantitative Studies, edited by John Creighton Campbell.

No. 3. The Japanese Automobile Industry: Model and Challenge for the Future?, edited by Robert E. Cole.

No. 4. Survey of Japanese Collections in the United States, 1979-1980, by Naomi Fukuda.

No. 5. Culture and Religion in Japanese-American Relations: Essays on Uchimura Kanzō, 1861-1930, edited by Ray A. Moore.

No. 6. Sukeroku's Double Identity: The Dramatic Structure of Edo Kabuki, by Barbara E. Thornbury.

No. 7. Industry at the Crossroads, edited by Robert E. Cole.

No. 8. Treelike: The Poetry of Kinoshita Yüji, translated by Robert Epp.

No. 9. The New Religions of Japan: A Bibliography of Western-Language Materials, by H. Byron Earhart.

No. 10. Automobiles and the Future: Competition, Cooperation, and Change, edited by Robert E. Cole.

No. 11. Collective Decision Making in Rural Japan, by Robert C. Marshall.

No. 12. The Sting of Death and Other Stories by Shimao Toshio, translated by Kathryn Sparling. FORTHCOMING.

No. 13. The American Automobile Industry: Rebirth or Requiem, edited by Robert E. Cole. 
THE AMERICAN AUTOMOBILE INDUSTRY:

REBIRTH OR REQUIEM?

edited by

Robert E. Cole

Ann Arbor

Center for Japanese Studies

The University of Michigan

1984 
Open access edition funded by the National Endowment for the Humanities/ Andrew W. Mellon Foundation Humanities Open Book Program.

$$
\text { ISBN } \quad 0-939512-21-1
$$

Copyright () 1984

Center for Japanese Studies

The University of Michigan

108 Lane Hall

Ann Arbor, MI 48109

\section{Library of Congress Cataloging in Publication Data}

The American automobile industry:

(Michigan papers in Japanese studies; no. 13)

Proceedings of the Fourth U.S.-Japan Automotive Industry Conference held at the University of Michigan in 1984.

Includes bibliographical references.

1. Automobile industry and trade-United StatesCongresses. 2. Automobile industry and trade-JapanCongresses. I. Cole, Robert E. II. U.S.-Japan Automotive Industry Conference (4th: 1984: University of Michigan). III. Series.

HD9710.U52 A65 $1984 \quad 338.4^{17629210973} \quad 84-17041$ ISBN 0939512-21-1

Printed in the United States of America

$$
\begin{gathered}
\text { ISBN 978-0-939512-21-8 (paper) } \\
\text { ISBN 978-0-472-88009-6 (ebook) } \\
\text { ISBN 978-0-472-90206-4 (open access) }
\end{gathered}
$$

The text of this book is licensed under a Creative Commons Attribution-NonCommercial-NoDerivatives 4.0 International License: https://creativecommons.org/licenses/by-nc-nd/4.0/ 


\section{CONTENTS}

Illustrations

Preface

Robert E. Cole

\section{PART I: PUBLIC FORUM}

Introduction

Billy E. Frye

Opening Statement

Paul W. McCracken

The Case for a U.S. Auto Policy

Owen Bieber

The Japanese Auto Industry: Its Development and Future Problems

Shohei Kurihara

Industrial Policy

Michael A. Driggs

Responses of Conference Panelists to Audience Questions

Revolution at Ford: All Roads Lead to Quality

Harold A. Poling

Evolving Manufacturer-Supplier Relationships

Edward J. Hayes

Responses of Conference Panelists to Audience Questions 
A Compact for Automotive Revitalization (C.A.R.)

Gerald Greenwald

\section{PART II: ISSUES FOR DEBATE}

Industrial Policy for the U.S. Auto Industry:

Recipe for Success or Failure?

The Japanese Tax System and Automobiles

John Creighton Campbell

Currency Misalignments: The Case of the Dollar and the Yen

Shafiqul Islam 


\section{ILLUSTRATIONS}

Sources of Tax Revenues, 1980

Real Exchange Rates

Changes in Exchange Rates and Competitiveness:

Aggregate Economy (1983) and Manufacturing (1983-II)

Budget Deficit and the Current Account: 1970-84

Real Short-term Interest Rates 



\section{PREFACE}

Amid the gloom, indeed the despair, that prevailed among auto industry spokesmen during early 1981, we held the first U.S.-Japan Auto Conference. With all the uncertainty that accompanies a march into new territory, the conference very much resembled a call to arms as industry, union, and government officials sought to comprehend and respond to the Japanese challenge. In the subsequent two conferences in 1982 and 1983, the concerned parties displayed an impressive willingness to roll up their sleeves and get on with creating the conditions for a renewal of the industry. Yet success seemed to elude their efforts, and frustration mounted as the national recession lengthened and deepened.

It was not until our March 1984 conference that a definite change in tone became apparent. By this time, it was clear that the industry was beginning to reap the fruits of its efforts. As Paul McCracken notes in his remarks, the market for new cars was manifesting its traditional high-geared response to improved business conditions, and the voluntary trade restraints were contributing to the ability of the industry to take advantage of this renewed prosperity. In addition, those who know the industry well knew that major improvements in quality and productivity had been made, and many of the changes responsible for these improvements seemed unlikely to be reversed.

All this was much on the minds of speakers and participants during our March conference. As I write this preface in early September, relatively little has occurred to diminish this return to prosperity. Two of our speakers, Mr. Bieber and Mr. Greenwald, cautioned against overreacting to this marked improvement in the industry's performance and reminded the audience of the permanent loss of jobs and the weakened financial conditions of the firms. But such cautions could hardly outweigh the sense of relief at the improvement in industry performance. The various speakers presented an image of people who thought that they were pretty much on the way toward addressing successfully their internal problems of productivity, quality, and marketing. All that remained was to dispose of the external factors that prevented them from competing on that well-known if elusive "level playing field." As one of the speakers put it (and he might just as well have been speaking for a number of the others), two thirds of the still significant manufacturing cost difference is accounted for by the yen-dollar imbalance and the tax differential between the U.S. and Japan. 
This industry interpretation is quite at variance with the typical conclusions drawn by outside observers. In Part II of these proceedings, James Womack is quite representative when he states that American auto industry efforts to become competitive in the world auto industry largely reflect what does or does not happen within the industry. He goes on to conclude that government policy will play, at best, a supportive role. One can make a persuasive argument, for example, that the industry indulgence in awarding high bonuses to top executives did more to harm its competitive position-by demoralizing middle management, creating an expectation of business as usual among employees and the UAW, and damaging popular support for the domestic industry-than any disadvantage created by differing tax systems.

Before speculating on the reasons for the differing interpretations of industry leaders and most outside observers, particularly academics, we need to reflect on the validity of industry claims. To facilitate this process, we have broken with our past practice and included in the proceedings a section for which we have commissioned new papers and reprinted existing papers that we judged particularly relevant and timely in light of the topies of discussion at the conference. These papers deal with the potential contribution of industrial policy, U.S.Japanese tax structures, and the yen-dollar exchange rate. In keeping with the role of the University community in sponsoring this conference, we seek to use this section to heighten discussion and bring into play differing perspectives. I have also broken with past practice in treating this preface less as a place to provide an introduction and more as an opportunity for specific discussions that are intended to enhance more thoughtful interpretations of the subsequent materials.

The vehicle for my efforts will be to share some reflections on the typical use of the phrase "level playing field." ${ }^{1}$ The phrase is consistent with the fondness Americans display for the use of sports rhetoric. Such metaphors have great power in American culture. The imagery of an uneven playing field conveys the sense of a fundamental lack of fairness in the rules governing international trade and in the behavior of our competitors. The game of competition is being tilted in "their" favor. Proponents using such terminology generally conclude with a rousing statement to the effect that if these rules were just equalized, then we would have little trouble competing!

Let us consider these claims. Undoubtedly, the rules governing international trade do not have random effects on all trading partners but will favor one party over another at given points in time. It can be argued that throughout the early postwar period the rules favored the United States, and, predictably of subject.

${ }^{1}$ I am indebted to Adrian Tschoegl for stimulating my thoughts on this 
course, we did not complain too much. Industry officials of ten explained our behavior in terms of altruism. For example, while much of the American auto industry's successful decision to invest abroad in the postwar period (there was, of course, some pre-World War II experience as well) and the Japanese failure to do so can be explained in terms of capital-rich America and a strong dollar versus capital-short Japan and a weak yen, we preferred more elaborate explanations. Thus, we talked about the need to serve foreign markets through building local facilities that would create jobs and contribute taxes to the local economy. These remarks are not meant to discredit American behavior; the industrial leaders of every nation engage in the practice of seeking to present their actions in the most favorable light. It may well be, however, that the international rules that served us so well in the early postwar period are now working against us. This is the argument put forward by those who cite an imbalance in the yen-dollar exchange rate (typically, they refer to a weak yen rather than a strong dollar) and differential tax practices between Japan and the U.S.

There can be no doubt that the strengthened dollar and the weakened yen have imposed a heavy burden on U.S. producers in the marketplace. It has created a very difficult situation in which producers correctly believe they are being hurt by forces beyond their control. This added burden has imposed real problems, problems that extend well beyond the auto industry. In this sense, one can speak of "fairness" or the lack thereof. That is, we can question the fairness of having U.S. producers compete with added burdens imposed on them over which they have no control. Yet, when we try to determine the meaning of fairness, it is not all that clear what constitutes fairness. Fair to whom? Is the current situation fair to consumers, producers, employees, shareholders? A strong dollar, for example, reduces prices for the American consumer. However difficult it is to sort out the varied meanings of fairness as applied to the various constituencies, it is clear that U.S. producers have been hurt. But the phrase, absence of a level playing field, tends to convey more than this. In the context in which it is usually presented, it tends to convey a notion of fault.

Even if the rules governing international trade favor Japan over the U.S. today, we cannot assume that someone is at fault and that the fault lies with unfair action on the part of our trading partners. In principle, whatever fault that does exist could just as well be attributed to the failure of the U.S. government to put its own house in order. In practice, though, the fault is usually seen as lying with our trading partners.

Strong accusations have been made; these accusations are all the more remarkable given that the evidence to date is so ambiguous. In the case of the yen-dollar exchange rate, the initial charge was that the Japanese were intentionally manipulating rates. There was such a paucity of evidence for this view that the charge is no longer being made. But the argument quickly shifted to other 
"failings" of the Japanese, such as their low interest rates and the lack of financial liberalization. Presumably, when financial liberalization fails to produce the desired outcome-as is most likely the case, at least in the short run-still other culprits will be found. Yet, as Shafiqul Islam suggests in Part II, there is ample basis for arguing that the problem lies with an overvalued dollar rather than an undervalued yen; the dollar has appreciated just as much or more against Western European currencies as it has against the yen. Even if the yen-dollar exchange rate does not reflect the true international strength of the yen, there is no evidence to suggest that Japanese leaders are taking specific action to produce this outcome. But this is just what the rhetoric of an uneven playing field suggests-it invokes images of someone at work rigging the system.

It is only natural that inequities in trading practices exist given the patchwork quality of the postwar development of trading rules and national practices, as well as the different interests of the parties to these rules. Under these conditions, it is naive to think that we could have an equalization of the basic conditions of all trading partners. Use of the sports metaphor, level playing field, trivializes the complexities of international economic competition. Sport is an activity in which individuals/teams maximize physical performance under a completely arbitrary set of rules. It has no consequences beyond the elation and depression it produces in the participants and spectators. Economic competition, on the other hand, is a discovery process aimed at finding the lowest cost way of producing and the most effective way of marketing. It has major consequences for the nature of industrial activity, its location, and people's standard of living. The danger of the sports metaphor is that it ignores these differences and in so doing trivializes the problem. But as with any effective symbol, this is precisely its source of strength-its ability to simplify a very complex issue.

We cannot assume that the corrective action needs to be taken primarily by our trading partners. As noted above, the dollar has strengthened against the currencies of all our major trading partners. On the issue of taxes, we may indeed rely more on direct taxes compared to most of our major trading partners, who have turned more to indirect taxes and, particularly, consumption taxes. John Campbell argues in Part II, however, that the differences in this regard are much greater between the United States and Western Europe than they are between the United States and Japan, whose tax systems are really quite similar in this respect. He further argues that existing reports that maintain there are lower taxes on Japanese cars are based on faulty methodology. Mr. Driggs notes in his remarks that the government has been unable to conduct a thorough comparison of the respective tax systems because of the complexity of the matter and the difficulty of developing comparable data. Again, we see strong accusations being made with a paucity of evidence. Without taking a position on the presence or absence of significant differences in tax burdens, I would simply note that exchange rates tend to adjust to all kinds of differences in economic systems, including differences in tax structures. 
Even ignoring this point, our analysis suggests that corrective action may more properly lie in the hands of the U.S. government rather than the Japanese government. It is in principle far easier to change our own government policies than compel changes in those of our major trading partners-indeed, if we are the cause of the problem, it would seem far "fairer"-although in practice it is often easier for us to pressure our trading partners for changes. However, if fairness is the issue, then we would do well to remind ourselves that it is of ten the case in matters such as tax policy that we attack Japan for what are standard international practices. It is we who are often "odd man out." Yet, since we are being hurt by the Japanese, we tend to single them out as the culprit.

Finally, as suggested earlier, it is unlikely that corrective actions on the part of Japan would change their basic competitive advantage in small-car production. This is because productivity differences (including the related problem of wage differentials) and quality differences are still the major contributing factors. It is not my intention to dismiss the disadvantages the Japanese derive from a strong dollar; as Vice President Frye points out in the Introduction, biology teaches us that even marginal advantages or disadvantages may in the long run make the critical difference in determining success or failure. Yet for the moment, it is clear that productivity differences and quality differences have been the major determinants of the Japanese advantage in small-car production.

If the matter is so clear cut as I suggest, why is it that U.S. industry leaders have persisted in their claims of a lack of a level playing field as the major source of their problems. The answer is multiple. Clearly, most industry leaders fully understand the nature of the competitive disadvantage and its roots in productivity and quality differences. In their corporate policy initiatives over the last five years, they have acted to address many of these problems. Yet, their public rhetoric gives far more weight to the external factors that we have been discussing. Why this discrepancy?

First, as Georg Simmel noted at the turn of the century, a stress on "outsiders" as the cause of one's problems is effective both in diverting attention from one's own failings and as a motivator for action among "insiders." Second, the industry desperately needed to buy time to realign its product offerings and to hold its ground during our deepest postwar downturn. This time could only be bought by government action, and an effective way to build public sentiment for new public policy was seen as presenting our most powerful competitor as engaging in unfair practices. Such tactics are hardly the invention of the auto industry, nor has their use been confined to the Japanese (though the more "foreign" the competitor, the easier it is to create mistrust over their motives). Moreover, it is clear that many Japanese postwar trading practices have been restrictive, and their protectionist period lasted far longer than the "infant-industry" defense should have allowed. Such practices, while now largely in the past (at least in the 
auto sector), nevertheless provided an ample basis for American indignation and the raw material for industry complaints. Speaking as one who favored the voluntary trade restraints based on the rationale that our industry needed time to become more competitive and that the Japanese had a responsibility not to flood our market at a difficult time, one can still question the tacties used to mobilize political support in the U.S.

The dangers are twofold. First, in pursuing claims of a lack of a level playing field, the industry takes the chance that its claims of inequities will be shown to be wrong by outside experts. Under such circumstances, they risk losing their overall credibility and therefore damaging the legitimate case they had (and may continue to have) for buying time. Second, there is the national and indeed international cost of contributing to a poisoning of U.S.-Japanese relations. There is a sufficient basis for frictions between the world's two major market economies without needlessly adding to them. We have enough trouble working on our legitimate problems, whether in auto or elsewhere, and we do not need to exacerbate them with needless charges of unfairness and a questioning of each other's good faith.

Success in managing our interdependent economies requires considerable cooperation; these larger goals should not be jeopardized by blowing up beyond reason legitimate industrial-sector conflicts. Industry leaders do have good reason to be concerned about the impact of the strong dollar on their competitive position, and it is appropriate for them to seek redress in Washington. One would hope, however, that they understand the full range of competitive problems and that they not seek scapegoats for them. (None of this is meant to diminish Japan's strong obligation to make major contributions to resolve our mutual problems.) It is my hope that you will keep these considerations in mind as you read and evaluate the various discussions.

Robert E. Cole

Professor of Sociology

The University of Michigan

and

U.S. Project Director

The International Auto Industry Forum 
PART I: PUBLIC FORUM 



\section{INTRODUCTION}

Billy E. Frye

I am pleased to have a moment to welcome you to The University of Michigan and to thank you for coming to the Fourth U.S.-Japan Automotive Industry Conference. I would especially like to thank the speakers and the other visiting participants on the program. In addition, I want to express a special word of appreciation to The University of Michigan faculty, staff, and students who have organized and are participating in this conference.

I am not an economist, so I feel that I have little real understanding of the problems that the automotive industry faces and, thus, little useful to say. But in a way, those of us who are involved in university administration in this day and age face many of the same classes of problems that the industry faces:

1. the need to increase productivity in the face of rising costs;

2. increasingly severe competition for our share of the market;

3. the desire to maintain and improve the quality of our product in the interest of public responsibility as well as our own long-term self-interest;

4. the need for responsible public policy, policy that provides an adequately supportive environment without depriving us of our invaluable autonomy and individuality;

5. the responsibility to cooperate with other institutions and organizations in the state, the nation, and the world in order to promote the overall well-being of our profession, without abandoning, at the same time, our self-interest and uniqueness; and

6 . the need to discover and continually revise management and planning strategies and tactics that enable us to cope with the shortterm exigencies and opportunities that we face without neglecting or undercutting our long-term needs and goals.

Billy E. Frye, former Dean of the College of Literature, Science and the Arts, is Vice President of Academic Affairs, The University of Michigan. 
In other words, universities and the automotive industry are both in a period of unusually vigorous change, driven by changes in our environment that include:

1. changes in local, national, and global economic conditions;

2. changes in public attitudes, expectations, and desires;

3. changes affecting our "marketplace," such as demographics;

4. intrinsic changes in the properties and content of our product and in the technology through which it is produced; and

5. changes in the arena in which, and the rules under which, our profession or business is practiced.

I would be the last to want to push this parallel too far, but if our experiences do have these classes of problems and concerns in common, I can better understand the challenges that the industry faces. In short, both the University and the automobile industry are in a period of "dynamic change" occurring in both ourselves and our environment. As the subtitle, "Rebirth or Requiem?" suggests, we are right to be concerned about survival. In that regard, I would like to make just a brief comment or two from my own vantage point as a biologist. Biology teaches (or confirms) a number of obvious lessons about those factors that may affect the outcomes of periods of epochal change such as those we are going through. Let me mention four:

First, even marginal advantages or disadvantages-often seemingly slight-may in the long run make the critical difference in success or failure in the world of "tooth and claw."

Second, our individual interests, on the one hand, and our collective interests, on the other, while very distinctive from one another, are also inextricably interconnected. Success, therefore, hinges upon a dependable balance between competition, on the one hand, and cooperation, on the other, a balance governed by clear, though perhaps unwritten, rules.

Third, survival depends upon adaptability, the ability to change as our environment changes. In business as in biology, rigidity is the certain path to extinction over the long haul.

Fourth, and finally, the greatest-indeed the universal-source of adaptability in the long run is cross-fertilization, whereby gene pools, and hence individual competencies, are shared and explored in new and sometimes stronger combinations. 
Now, it was not my intent by this reference to biological parallels to bring this conference around to the subject of "sex" in three short minutes. Having done so, however, let me conclude on this theme by noting that one of the most central functions of the university is to encourage the free exchange of ideas. We are especially pleased, therefore, to have this opportunity to be the boudoir for what I am sure will again this year be a most seminal exchange of ideas.

Finally, let me note that we at the University are acutely aware that the well-being of all of us depends upon the good health of the automobile industry, and we are grateful to you for coming here today to discuss how the well-being of this industry can be further assured over the long run. I wish you every success in your conference. Indeed, as I look at the turnaround in the industry that has occurred in the three or four years since the first of this series of conferences, I have no doubt of a successful outcome! 



\title{
OPENING STATEMENT
}

\author{
Paul W. McCracken
}

The years of these conferences have been an era of turmoil for the automobile industry. With the second so-called oil shock, in 1979, the American market ran to the small-car side of the deck. This was a 180-degree turnabout, for the years following 1973 had seen a discernible shift in market preference back toward the larger cars. While some theologized about this shift during the $1970 \mathrm{~s}-$-seeing it as another indication of the sinful ways of consumers when left to exercise their own preferences-it was actually a quite rational response to the generally declining price for gasoline, in real terms, after 1974 .

Then came the 1979 earthquake in the world oil market, with a sharp jump in gasoline prices, and with uncertain and erratic supplies that spawned fillingstation queues. All the gears began to clash. There was a mismatch between cars the market then wanted and what the industry was producing. There was a congealing conviction on the part of consumers that, in any case, cars produced here at home were inferior in quality relative to those produced abroad, particularly relative to those from Japan. Costs of producing a car here were higher than those prevailing in Japan $-\$ 1500$ per car being a conventional estimate of the differential. And in 1979 we were on the threshold of a 30 percent increase in the trade-weighted real exchange rate of the dollar. Providentially, those in the industry did not then know this, or queue lines might have shifted from gasoline stations to hospitals for the emotionally disturbed.

Finally, these draconian adjustments had to be managed with severely adverse conditions in cash flow and profits. Profits in this industry from 1969 to 1972 accounted for 12.2 percent of those in all U.S. manufacturing; they were only 0.2 percent a decade later. (Even the better profits of 1983 were only 9.9 percent of total manufacturing profits, well below what history would suggest to be the normal share.) Seldom in history has an industry been required to accomplish such

Paul W. MeCracken is Edmund Ezra Day Distinguished University Professor of Business Administration, The University of Michigan. 
a massive transformation in so short a time and with such constrained financial capability (all with apologies to Churchill).

It is now 1984. Where are we? The industry has now had a decade for this task of Herculean transformation. It may not be a long period measured against the time requirements of product planning, but it is a considerable span of time in terms of political and public patience. In a way, the results are remarkableremarkable almost to the point of being miraculous. Consumers are casting a decidedly affirmative vote. During the first year of the current expansion, real GNP rose 6 percent (about normal) while so-called Auto GNP in real terms rose 45 percent (about double the normal cyclical response). New-car sales in 1984 will be about 11 million, up 20 percent from last year's pace. Moreover, there is a large potential market for years to come. Since 1979, if normal market forces had prevailed, new-car sales would have been at least 10 million units more than what actually occurred. There must be, in short, a substantial backlog of demand.

Those in the industry who have accomplished these near miracles and who now confront a strong basic market cannot, however, take time off for selfcongratulation. The industry has survived the rapids, but it must now assure its seaworthiness for the ongoing voyage. Decisions made now will be critical to its future. The American industry must, in short, have as its objective the ability to survive and prosper when fully exposed to open international competition. In the final analysis, the amount of employment and production for the American industry will depend on whether cars can be produced here with product quality and costs that are fully competitive in an industry where inexorable forces are producing a rapid internationalization. It is important that, when 1984 moves off stage, we can look back on a year during which further progress was made in closing the competitive gap.

Thus, the horizon for concerns in this year's conference is inevitably less preoccupation with short-term survival and more with how to be fit for the long voyage. One of my favorite poets, Robert Service, put it well:

This is the Law of the Yukon, that only the Strong shall thrive;

That surely the Weak shall perish, and only the Fit survive. 
To introduce my topic-the U.S. auto industry in search of public policy-I looked for a way to describe the condition of our North American motor-vehicle sector. Remember the emperor strutting before his subjects in his birthday suit. Well, this image conveys our condition quite well for a couple of reasons. First, the tailors and valets of the auto industry-in this case, the people who crunch the numbers, tote up the earnings, and project the sales volume-have assured the emperor that he is well turned-out. Second, the members of the imperial court-in this case, the shareholders and Wall Street generally-are sufficiently pleased by the sovereign's rich gifts that they loudly applaud his progress despite any private misgivings about his appearance. In fact, the only people who are not hiding their shock and surprise at the emperor's nakedness are the common people of the town-in this case, the auto workers and their union. Precisely because of their love for the emperor and loyalty to the realm, they would wish to see him clothed in the appropriate robes of sound public policy.

The point of this story is that, unfortunately, not everyone connected with the industry is interested in public policy considerations. We in the UAW, however, are intensely interested, not only because our jobs are on the line, but also because we take seriously our civic responsibility to encourage public debate on issues that will have such an enormous impact on the way Americans live in the decades to come. We understand the applause the emperor is receiving at the moment. We understand that the industry is a little starved for praise and that industry leaders have a vain tendency to see the results of their own actions as positive-a case in point, the massive cost-cutting in recent years. Never mind that the good news may not survive much beyond the next election if we do not see a change in policies. Never mind that 1984 domestic car and truck sales are still expected to be two and one-half million units below 1978 levels. Never mind that the core industry today provides 170,000 fewer jobs-not counting massive employment losses in supplier and other auto-related sectors-than it did in 1978.

Owen Bieber is President, International Union, United Automobile Workers. 
Never mind that imports have a solid hold on one-fourth of our market and would have had an even stronger hold were it not for the voluntary restraint agreementwhich Secretary Baldridge and Trade Ambassador Brock have said should not be renewed.* Most of all, never mind the growing evidence that the North American auto firms are about to turn small-car production into a kind of offshore franchise operation-this despite warning signs in the Persian Gulf and elsewhere that suggest that the big-car gold rush could come to a screeching halt in the not-toodistant future.

Naturally, it is this accelerating move to offshore small-car and parts production that concerns us most in the UAW, and it should be of critical concern to anyone who cares about the kind of society we are building for the future. To put the question bluntly, Should profitability be all we seek from our auto industry? What about jobs, incomes, community stability, safety; technical innovation? What about preserving the industry's critical linkages to other industries, or the need to improve fuel economy and environmental quality? I think the right answers for the country are pretty obvious. Yes, we want more than profits. Yes, we also want jobs, incomes, stability, and a diverse industrial base that generates high living standards for our people.

The real question is, then, whether we are going to see any of these benefits if we leave all the investment and planning decisions to a handful of executives meeting in private, whether in Detroit or Tokyo.

It is clear to me that we are not, and it is also clear that traditional macroeconomic remedies will not, in and of themselves, guarantee the social benefits that ought to flow from a healthy auto industry. Macropolicies are to the economy as sound health practices are to the human body. They are needed to stay fit and trim. But if the body is severely damaged in an accident, more specific treatment other than a good diet and lots of rest and exercise is needed for recovery. I submit that the U.S. auto industry's problems are sufficiently acute to require specialized policies as well.

The policies required will not flow from private decision making because private cost-benefit calculations simply do not make any reference to public costs and public benefits, even though it may be these items that matter most to the majority of Americans who do not own a lot of auto-company stock. Furthermore, private market-based decisions do not now-and never have-accounted for all the outcomes in our industry. For example, in 1982 the UAW made unprecedented contract adjustments not only to save jobs, but also to improve the competitive position of the major U.S. firms. Yet, in terms of reducing the Japanese

*Editor's Note: Secretary Baldridge announced in mid-1984 that he was withdrawing his earlier opposition and reserving judgment pending developments in the industry. 
advantage in landed costs-whatever figure you want to put on that-the effect of our adjustments was negated by the run-up in the value of the dollar. That is a clear case of events outside the industry overwhelming internal adjustments. Nor are the recent profits solely the outcome of management decisions. Management would like to say that the profits resulted from much lower break-even points. That is partly the case, but these profits are also the product of cheaper oil and the 1981 Reagan Tax Act. Lower pump prices have given bigger cars a new lease on life, while extra disposable income in the upper brackets gives an extra boost to the sales of luxury models. Even the recent boom in the building of engine plants in Mexico is not strictly a market decision based on cost considerations. It is also a response to public policy-in this case, the trade policy of the government of Mexico.

We can project two scenarios for the auto industry in 1990 , one in which the U.S. continues to lack a public policy for the auto sector, and the other in which it has such a policy in place. In the first scenario, most of the small-car market and a growing part of the large-car market is supplied from abroad. The import share is 40 percent. Fully 20 percent of the parts in vehicles assembled here come from abroad, where governments do pursue targeted auto-sector policies, in part to meet the social goals mentioned earlier. Having developed a growing dependence on foreign technology, the U.S. auto industry not only sheds jobs by the hundreds of thousands but no longer generates nearly as many technological spin-offs. Thus, U.S. production costs rise in many industries. The upper Midwest becomes a vast welfare client and a drain on the nation's resources.

In the second scenario, however, the U.S. finally drops its ideological freemarket blinders and catches up with the rest of the world. The Domestic Content Bill has been enacted. The auto industry's market share and employment may continue to decline, but only slowly and predictably as part of a managed process. Investment here is made a condition of market access for high-volume sellers, as it is almost everywhere else in the world. The auto industry remains dynamic across the entire product line, supporting not only its own work force but also another 1.7 million jobs in supplier industries as well. It continues to underpin the nation's crucial metal-working base and provides a vast market for everything from paint to steel and computer-controlled machine tools.

In the first scenario, only about 500,000 blue- and white-collar core auto employees will be left in the United States-about half the 1978 number and 200,000 fewer than in 1982 . In the second projection, however, there will be about 735,000 workers-fewer than today's figure, but a decline that is manageable without horrendous costs to society.

So which path do we choose? Do we adopt an explicit industrial policy in general and a coherent auto policy in particular? Do we stabilize the import share? Do we let it rise, but at a rate no faster than we can retrain and reemploy 
dislocated workers? Do we act to maintain U.S. production, or do we simply wave goodbye as the U.S.-based firms pack up small-car and parts production and ship it off to their foreign franchises? Do we and other industrialized nations reduce work time in relation to rising productivity, or do we let new technology run pellmell over the need to preserve industrial employment? These are some of the hard choices we face. Many prefer not to face them, but, in my opinion, we can and must make the decision to determine our own economic future in a democratic fashion.

What would the world look like if a socially accountable policy for the auto sector were in place? Export restraints, a currently controversial issue, provides an example for the effect of such a policy. If our government were behaving proactively and not reactively to the import surge, it would have demanded something in return from the U.S. companies when it negotiated the voluntary restraint agreement with the government of Japan. It is my understanding-and, I think, an accurate one-that those export restraints were supposed to buy time for the U.S. firms to develop competitive product lines. Last year, GM registered profits of $\$ 3.7$ billion, and even higher profits are projected for 1984. Yet there is not much evidence that GM has devoted more resources to domestic small-car production. There is the Saturn Project, of course, and we are solidly behind that if it means jobs in this country, but the big story in the small-car segment is not Saturn-at least, not yet. The big news is that GM is looking to its affiliates in Japan and Korea for about 400,000 small cars a year. Although GM is leading the parade, Ford also plans to import cars from Europe starting late next year and has committed itself to importing cars from a new $\$ 500$ million plant in Mexico, using substantial parts from its Japanese partner, Tōyō Kögyō. Chrysler has yet to announce its small-car game plan, but it is obvious that they may decide to build replacements for the Omni and Horizon models abroad.

The universal justification for moving to offshore production is, of course, the famous $\$ 1500$ advantage in landed cost supposedly enjoyed by Japanese small cars. We in the UAW were skeptical about that figure-and the reasons for itfrom the start. Nevertheless, we had it shoved up every part of our anatomy by the enemies of domestic-content legislation and by free-trade hit men in the media.

Now, thank God, the final report of the Joint U.S.-Japan Automotive Study (conducted at the University of Michigan) notes what it calls "analytic problems" in most of the many studies that show U.S. small-car production costs so far above the Japanese. The report indicates that sometimes the authors of the other studies engaged in an arbitrary "allocation of labor-content cost differences to productivity differences-and to wage-rate differences." Sometimes, too, they did not bother to notice that the true cost of Japanese auto labor tends to be understated because of the fact that a great deal of Japanese compensation comes in 
the form of "payments in kind"-housing and the like-which may show up on the books as overhead rather than direct labor costs. In short, the reports were sloppy and did a lot of damage. Finally, however, the truth is out that the U.S. remains a viable site for the production of the small vehicles that will dominate the U.S. market in the decades ahead.

All that is now needed is for government to send a signal that it wants a domestic small-car industry - a signal that would redirect the energy now going to line up outsourcing deals and focus it instead on producing high-quality, low-cost small cars. Enactment of the domestic-content legislation would certainly send that message. Unfortunately, never in my memory has such an enlightened and carefully crafted piece of legislation been so feverishly attacked and brutally misrepresented as has the auto-content proposal. Even Tom Wicker, that guardian of prudence and tempered judgment, betrayed an unquestioning acceptance of the retaliation theory in a recent column. This theory presupposes that our enactment of an auto policy would represent the first shot in a new trade war-as though in the world today there were such a thing as free trade in autos, steel, textiles, or food and fiber. Contrary to Wicker, an auto-content requirement would not insulate the domestic industry from competition. Rather, it would invite competition while imposing fair ground rules on all contestants. Nor would a content law freeze the industry in its present state or fix the number of jobs it provides. The industry has changed massively and will continue to do so.

We want the industry to change, but we just do not want it to shrink precipitously and at immense social cost in terms of employment, income generation, technology gains, productivity, and regional dislocation. Most of all, in advocating this legislation, we want the public to recognize that it can get us off the path of deindustrialization that must necessarily lead us to national ruin.

We are proposing, instead, that the nation select a path that gets us to a dynamic, vital, competitive industrial base while minimizing costs incurred along the way, whether those costs are borne by companies, workers, or various units of government. In fact, unlike quota arrangements, the domestic-content approach has a number of the elements that would emerge from meaningful, tripartite industrial-policy negotiations. First, in return for imposition of investment requirements on foreign competitors, the U.S.-based producers would be forced to accept limits on their own foreign sourcing. Second, consumer choice and competition would be retained, as no favoritism would be shown the domestic companies versus foreign firms producing here. American consumers would continue to be assured the substantial benefits of competition among U.S. and foreign-based producers with regard to product quality, manufacturing methods, and price, while the public would be protected against the risk of massive dislocation costs.

If we examine the central elements of a sound U.S. auto policy, we find it has three key pieces: (1) U.S. investment commitments, (2) a trade policy linked 
to the rate at which displaced workers can be reemployed, and (3) technology, training, and democratization programs to allow all parties to share in the industry's gains. Domestic content addresses the first of these, plus part of the second. We are committed to maintaining and expanding our job security and retraining programs in this summer's auto negotiations, and we also plan to take a run at the whole question of sourcing by the U.S. firms. But, as was mentioned above, what we are able to accomplish within the industry can always be overwhelmed and subverted by developments in the realm of international and domestic public policy. Thus, we must have a clear and comprehensive public policy committed to a strong auto sector. For the sake of decency and a secure future for our industry, we must work together to fashion a respectable wardrobe for the emperor. 
THE JAPANESE AUTO INDUSTRY:

ITS DEVELOPMENT AND FUTURE PROBLEMS

\author{
Shohei Kurihara
}

It is indeed an honor for me to have been granted the opportunity to present my views on the development of the Japanese automotive industry and its outlook for the future. Two major themes that thread their way into the discussion are government policies that affected the industry after the war and the current disagreement between the U.S. and Japan over auto import levels.

\title{
The Development of Japan's Auto Industry
}

Japan's current advantage in the automotive industry is, generally speaking, the result of two factors. First, on a macroeconomic scale, the industry obtained access to expanding markets. In the $1960 \mathrm{~s}$, the industry benefited greatly from the expansion of the domestic market, which was caused by a rapid switch to the auto for transportation. In that decade, Japan's domestic market grew at an annual average rate of 18.4 percent. Then, in the 1970 s, export demand increased briskly at an annual average rate of 14 percent. This increase was the result of the oil crisis and the concomitant shift from full-size to smaller cars. Second, on a microeconomic scale, Japan's auto industry markedly improved its international competitiveness in the areas of price and quality. This improvement resulted largely from the automotive industry's own efforts to inerease productivity through ambitious investment in factories and equipment, technological innovation, and the use of the Japanese style of management. The competitive advantage of the automotive industry was, however, not solely due to its own efforts. Developments in related industries, such as steel, also played an important role.

Opinion differs, even in Japan, over what the driving force was that enabled the Japanese automotive industry to attain its competitive advantage in

Shohei Kurihara, former Vice Minister for International Affairs at the Ministry of International Trade and Industry, is an advisor to the president of the Bank of Tokyo and to the minister of MITI. 
such a short time. The manufacturers themselves and the majority of industrial analysts stress that success was due to the manufacturers' aggressive entrepreneurship and the vitality of the private sector, in which there was stiff competition. As an ex-MITI official, one might think that I would overvalue the role played by MITI. Yet I would agree that the industry's accomplishments were largely the result of its own strenuous efforts. The government merely maintained a supportive position that concentrated on introducing environments favorable to the automotive industry.

Government policies protecting Japan's domestic market were almost nonexistent until the mid-1950s because the U.S. car industry was, at that time, a leviathan too big to challenge. In the postwar period, passenger cars were considered luxury items, and they enjoyed little priority in government industrial policies. The only policy of any significance dealt with how to economize the precious foreign currencies needed for car imports.

The industrial importance of the automotive industry only began to be recognized in the late 1950 s and the 1960 s, at which time various policies (involving capital procurement and taxation) were put into effect. Such measures, however, mainly affected parts suppliers. Then, in 1965, car imports were liberalized following the rules of GATT and IMF, and, in 1968-71, the influx of capital was opened up following the codes of OECD. Prior to such liberalization measures, MITI attempted to consolidate car manufacturers, which were thought to be too numerous, but this policy met with little success. It is a well-known fact that, at that time, the capital participation of America's Big Three in Isuzu, Mitsubishi, and Toyō Kōgyō later took place because all of the latter were experiencing some difficulties.

\section{0 - a Watershed}

During the 1970s, luck smiled on the Japanese automotive industry, with perhaps part of the industry's advantage not due to its own efforts. In particular, the first oil shock of 1973 and the second one of 1978-79 caused world demand for small cars to increase and provided windfall export markets for Japanese car manufacturers, who already enjoyed a comparative advantage in small-car production. The favorable situation did not last long, however, when the worldwide economic recession soon caused international trade conflicts to develop.

The second oil shock triggered an economic recession throughout the industrialized nations of the world. Automotive industries suffered seriously in those countries whose markets were already saturated. In the U.S. market, in particular, the economic recession, high interest rates, and high car prices drastically reduced demand, especially for full-size models, delivering a strong blow to the U.S. car industry. During this period, though the sales of imported cars to the 
U.S. market increased, the increase did not contribute significantly to the decrease in total demand. (During 1977-80, sales of imported cars increased by 330,000 units, but total demand fell by 2.8 million units.) The difficulties encountered by the U.S. automotive manufacturers did not result primarily from the increase of imported cars but from the recession, which lowered overall demand. This was also the opinion of the International Trade Committee. Regardless of the cause, because the U.S. automakers suffered large deficits four years ago and laid off workers in ever increasing numbers, the situation became a national political issue. As a result, the government, the industry's management, and unions all started to unite in their efforts to promote recovery.

Considering the situation from the broader perspective of safeguarding the free-trade system and fostering further development of economic relations between the two nations, the Japanese government started a three-year voluntary restraint program on car exports to the U.S. in April 1981. This decision was based upon the assumption that the U.S. automotive industry would attempt to restructure. In my opinion, it was not the best solution, but it was a necessary preventive measure. Over the course of the past three years, during which time the voluntary restraints have been in effect, the U.S. recovery has become an established fact. Although the recovery developed more slowly than expected, the recent profits of the U.S. automotive industry indicate a remarkable turnaround. Concurrently, the joint efforts of management and labor to become more competitive have been pursued strenuously and have brought gratifying results.

The continued recovery of the U.S. auto industry has, of course, influenced the present political discussion over whether or not to end the voluntary restraints. When Trade Ambassador Brock visited Japan last November, an agreement was reached to extend those restraints for another year, with the ceiling for the 1984 fiscal year raised to 1.85 million units from the previous ceiling of 1.68 million units. This agreement is understood to provide a transitional period, which, it is hoped, will avoid market confusion in the U.S. that might possibly result from an abrupt discontinuation of the voluntary restraints. I, for one, hope that the continuing U.S. business recovery in 1984 and the U.S. qutomotive industry's self-help efforts will create a situation in which voluntary restraints will be unnecessary and can be eliminated.

\section{The Outlook for Japan's Automotive Industry}

Deteriorating market conditions in the industrialized nations have been pushing Japan's automotive industry onto a new course. Markets in developed countries are narrowing, while higher growth is expected in the markets of developing nations. Yet problems of market stability also exist in the developing countries, such as policies favoring domestic production and their of ten heavily 
overextended financial position. Not much further growth is expected in the domestic market, as it is already almost completely saturated. Replacement demand is currently 85 percent of total demand.

These circumstances have narrowed the freedom of the Japanese automotive industry to determine its own future. When not much can be expected from either domestic or export markets, a third alternative for further growth would be expansion of production activities overseas. When production facilities are established abroad, local procurement of parts and components and the transfer of technology cause the foreign firm and the host nation to become interdependent, which lessens the problems of international trade. With regard to Japanese relations with the U.S., Nissan and Honda have already established their own production facilities here, and a joint venture between GM and Toyota has materialized. Nissan has also decided to begin production in the United Kingdom. Although these developments are welcomed by both the host and guest nations, they present many problems for the manufacturers themselves.

In the field of overseas production, Japanese car manufacturers are far behind their U.S. counterparts in experience and know-how. Consequently, they are very concerned about the investment risks. These risks, however, are unavoidable if the transformation into truly international companies is to be effected. As overseas production increases, domestic production naturally slows down. A slowdown will affect the productivity, costs, and labor relations of domestic operations, and Japan's automotive industry will have to face the challenge of adjusting to such conditions.

When seen from a broader international viewpoint, the world's automotive industry in the latter half of the 1980s will see the coexistence of competition and cooperation. On the one hand, interdependence in production and technology will deepen among certain groups of manufacturers; on the other hand, competition will increase between others. Each company will be required to outperform others in particular areas, such as cost reduction, quality, and technical innovation, and a company's bargaining power in both cooperative and competitive ventures will rest upon excellence in those areas. For Japanese car manufacturers, whether or not they can attain that excellence (and in what field) depends solely upon each company's determination and choices.

\section{Future U.S.-Japan Relations}

Political and economic relations between our two nations are continually improving. Yet, even though close and interdependent economic relationships exist, occasional trade conflicts are not necessarily precluded. We must stress, however, our determination not to allow such trade conflicts to develop into political antagonism. Mike Mansfield, U.S. Ambassador to Japan, whom we are 
privileged to count among our most respected friends, has repeatedly said in public, "There is no bilateral relationship more important than that between the United States and Japan." Any disruption in our relations is not only unfortunate for both, but also detrimental to the free world as a whole. Thus, all trade disagreements must be solved by mutual cooperation, and as early as possible.

Finally, I would like to stress the importance of the role played by the U.S. in the maintenance of free world trade. Nations that express their desire to maintain free trade are numerous, but only the United States actually possesses both the will and power to do so. Should the U.S. opt for protectionism, the world is destined to suffer from a repetition of the disasters of the 1930s. For this reason, I am deeply worried about the recent movements toward local-content legislation. I have no intention of officiously presenting the disadvantages that would be suffered by the U.S. through the enactment of such legislation. It is sufficient to say that this legislation would not only imperil the dynamism of the world automotive industry but also cause chain reactions in other key industries and, very possibly, result in uncontrolled protectionism all over the world. I am not trying to place responsibility solely upon the U.S. for the maintenance of the free-trade system. I am fully aware of the numerous responsibilities and duties that Japan-in full cooperation with the U.S.-must fulfill to safeguard free trade. Fortunately, the world economy is enjoying a promising recovery, and it is my sincere hope that our confidence in the free-trade system will be strengthened by maintaining close cooperation between the U.S. and Japan. 



\title{
INDUSTRIAL POLICY
}

\author{
Michael A. Driggs
}

Everywhere you turn these days, someone is either calling for or attacking the concept of a national industrial policy. Perhaps future historians will refer to this period as the era of the great industrial policy debate. The problem with this debate is that much of it is form without substance. Nevertheless, there are critical issues that must be discussed. I shall address the issue of what the debate is about and how it relates to international industrial competitiveness.

Industrial policy, as a national concern, has seemed to emerge in only the last couple of years. The worldwide recessions since 1979 have made it clear-as nothing else could do-that the U.S. is an integral part of a global market. Although we have been part of a world market for a long time, we could not see our weaknesses until recently. The proponents of a national industrial policy are deeply concerned about the international competitive situation.

The administration welcomes the growing concern about our international trade position. It is perhaps the greatest benefit to come out of the industrial policy debate. Even if we do not like the answers, trade is no longer the neglected sector of our economy.

To begin my discussion of industrial policy, it will be helpful to briefly outline the current international economic situation. It is the product of several trends over the past twenty years-some positive, others negative. The most important has been the growing role of trade in our economy. In 1960, exports represented only 3.9 percent of our gross national product. By 1980 , they had more than doubled-reaching 8.2 percent. Imports have, of course, followed the same trends. The last several years have seen a minor reversal in these trends, with both imports and exports dropping. This decline reflects the impact of the

Michael A. Driggs is Deputy Assistant Secretary for Automotive Affairs and Consumer Goods at the U.S. Department of Commerce. He also served as Executive Director of the Chrysler Corporation's Loan Guarantee Board at the Department of Treasury. 
1981 and 1982 recession and the continuing slow growth abroad. I am confident, however, that we will see imports and exports grow relative to our national income as the economy continues to improve.

Not only has trade grown relative to the rest of our economy, but worldwide trade has grown faster than output. It has been the engine of growth both in Europe and in Asia. This vast expansion of trade has been possible because of the enormous reduction in trade barriers since World War II. Starting with GATT in 1947 and continuing through the Tokyo Round negotiations, there has been sterdy. progress in eliminating trade barriers. Perhaps at no time in history has international commerce been so free.

Despite these trends, international trade receives little attention in the United States, except when there is really bad news about our deficit. While some companies actively seek to expand their exports, many do not try at all. We estimate, for example, that only a thousand firms account for over 60 percent of our exports. This relative indifference to trade has been a problem not just in the business world, but in government as well. In the last twenty years, the federal government has taken a number of actions that have impaired our ability to export. This is in spite of the positive actions being taken elsewhere to improve the international environment. Some of these negative actions are directed specifically at trade, but others are the inadvertent effects of legislation or regulations intended to serve some other purpose.

In earlier years, little concern was voiced when new impediments to our exports were created. The United States was dominant in the global economy, and our technological and industrial leadership was considered unchallenged. Actions that made our products a little less competitive were considered trivial. Our position was strong, and we could afford to sacrifice in the trade area in return for supposed benefits in other areas.

Unfortunately, we can no longer afford to be so cavalier. Our share of world manufactured exports is now down to 19 percent from 21 percent in 1970 and 25 percent in 1960. Our technological dominance is being challenged. Our share of the high-technology export market has fallen from 27.4 percent in 1965 to 23.9 percent in 1980 . In 1974 , for example, imports of machine tools amounted to less than 13 percent of our domestic consumption. By 1982, imports were up to almost 27 percent, a more than doubling of market share. Japanese successes, such as the $64 \mathrm{~K}$ RAM, hardly need to be mentioned. By 1983, our total trade deficit had reached a record $\$ 58$ billion. Even more disturbing, our traditional trade surplus in manufactured products had been transformed into a deficit that last year reached $\$ 31$ billion.

It is indeed time that American complacency about trade should be shaken. While I disagree with much that has been proposed under the banner of 
"industrial policy," the emergence of this debate is a welcome sign that our period of complacency about our international competitiveness is coming to a close.

Our deteriorating international trade position is not, of course, the only reason for the emergence of industrial policy as a topic of national debate. Increased unemployment due to the overall state of the economy in 1981 and 1982, while cyclical in nature, was a factor. Also a factor is our constantly evolving industrial structure. Demand for traditional industrial products, such as steel, has lessened as new materials and processes appear. Nor is it surprising that a characteristic of many proposals on industrial policy is an emphasis on supporting traditional industries. The increasing rate at which technology, and hence industry, is changing leads to insecurity and demands for actions to slow these disruptive changes.

I have already used the term industrial policy a number of times without in any way describing what it is. There is a good reason for that. There is no commonly accepted definition for the term "industrial policy," and I do not intend in these remarks to attempt one. Rather than define the term, I would like to go beyond the rhetoric and examine the various proposals themselves.

Recently, the Department of Commerce reviewed many of the industrial policy proposals, and what we found were vast differences. Some of the proposals imply a major increase in government intervention in the market, while others, in fact, could result in less federal involvement. To the extent that these proposals require increased government intervention, I believe they should be opposed. This is especially true of proposals that involve "picking winners and losers," an expression generally used to characterize proposals that involve the government in allocating credit to specific industries or firms and protecting their markets. The mechanism for allocating this credit in virtually all of the proposals is some type of "National Development Bank." Funds would be directed in two ways: to assist older, so-called sunset industries to modernize or adjust and to encourage and support the development of emerging industries, new technologies, and innovation. Such proposals may have superficial appeal. They are supposed to compensate for perceived failures by the private capital market, but, on closer inspection, a number of problems can be seen.

Support for declining industries is popularly viewed as a way to save jobs, but it would, in fact, result in taking capital away from and destroying jobs in other, more competitive industries. A national bank would substitute the judgments of a few officials in Washington for those of millions of investors in the private market. Perhaps, worse, it would almost be inevitable that political rather than economic criteria would determine how credit was allocated. I have personally been involved in the two times this country has tried to do this: the bankruptcy of the Penn Central and the near collapse of Chrysler. Despite theory, this process just will not work in practice. 
Is the federal bureaucracy and Congress in a better position to choose new or emerging technologies than the market? There is no reason to believe that the government can do a better job than the market place. Let's face it, government -even with the best minds-cannot process the information necessary to make the thousands of intelligent investment decisions the market demands. Innovation and change comes from the individualistic and entrepreneurial spirit of our freemarket system. The role of government should be to foster an environment conducive to change and innovation, not to take over the responsibility of making individual investment decisions.

The federal government has an appropriate role in fostering new technologies through its support of basic research, and this administration has increased funds for research. To spur innovation, we have put into place tax credits for $R \& D$, proposed legislation to facilitate joint $R \& D$ by the private sector, and strengthened the patent process. Proposals for a national development bank, however, would involve an enormous increase in government intervention in the economy. Other proposals appear to be more limited in scope-for example, those calling for increased cooperation and communication between government, business, and labor--but even with proposals of this kind we need to exercise caution. For example, there are proposals for a national commission, complete with its own bureaucracy, to review actions of the legislative and executive branches. We all want to see better communication and understanding between business, labor, and government, but this must be in the context of preserving and enhancing our basic private-market system. Creation of a new federal agency, supposedly representing business, labor, and government, to determine our economic strategies and have oversight over the rest of the government is a frightening prospect to me. It has implications not just for our private-market economy but also for our democratic institutions and the process of forming national goals.

We must also be concerned that communication and consensus do not replace competition. Even in Japan, where consensus on many issues and mutually shared goals are so important, competition among individual firms remains fierce. We must be cautious, therefore, in our judgments about proposals for increased communication and consultation. Well meaning as they may appear, there are risks.

Protectionism, one of the most obvious forms of industrial policy, lurks in the shadows of many industrial policy proposals. Yet, government intervention in the market to restrict imports is usually designed to benefit a particular industry, almost always at the expense of the rest of the economy. Once you start down the road of providing help to specific industries, it becomes very difficult to then resist the demands of other industries. We would soon have an inefficient economy hiding behind walls of trade restrictions. 
An argument often made for a national industrial policy is that the United States needs one if it is to compete with other nations that have such policies. Many industrialized, so-called free-market economies do have industrial policies, giving help to specific industries in one form or another. Although we must be greatly concerned with the industrial policies of other nations, there is no validity to the commonly drawn inference that because our competitors have interventionist industrial policies, we should also adopt them. The fact is that the results of industrial policies in other countries are not all that impressive. This is especially true in Europe. In France, for example, the government has sought to create its own national computer industry, the "Plan Calcul." But after a number of years of government support of all kinds, it still has not succeeded. The socialist government of France has also tried to protect jobs by supporting traditional industries. They now are reversing that policy, however, in order to try to stay competitive and again become profitable. In Great Britain, a great deal of money was poured into traditional industries, such as autos, during the 1970 s with little if anything positive to show for it.

Even in Japan, government targeting has not always been effective. Industries such as shipbuilding, petrochemicals, and aluminum, which previously were targeted by the government, are now being phased down. Most people are now aware that, initially, the Japanese Ministry of International Trade and IndustryMITI-did not think that Japanese auto companies would be able to compete in world markets and, thus, tried to get them to merge. Even if industrial policy were completely successful in Japan, however, that would not imply that the United States should adopt a policy. We must make our own decisions in terms of our own traditions, customs, and society.

If we do not adopt our own industrial policy, then how do we deal with nations that do? The fact that the industrial policies of other countries have not always been successful does not mean they have not had negative effects for us in the trade area. Thus, we do need to take action. The proper way to respond to these policies, however, is through the use of our trade laws and our rights under international trade agreements. If foreign nations provide subsidies, we have the means to deal with them. If they protect their markets, we have the right and responsibility to open these markets. This is precisely what this administration has been doing. In Japan, for example, we have recently negotiated an agreement that further opens up the Japanese telecommunications market. We took action against European steel producers where they were getting government subsidies. We have no intention of using our trade laws to protect inefficient industries in the United States, but we do intend to see that U.S. companies have a fair opportunity to compete.

Overall, this administration has not been indifferent to the concerns that have provoked demands for an industrial policy. We agree that U.S. industry needs 
to invest more, that the time horizons of managers must be extended, that $R \& D$ and innovation must be increased, and that national productivity must be improved. The difference is that we see the solutions in making the private market work better by establishing the proper environment for free-market forces to direct resources to their best uses, not by introducing more government.

Since taking office, the Reagan Administration has taken a number of steps to achieve these goals. I have already mentioned actions to increase $R \& D$ and innovation. We also are working to reduce burdensome regulations and government intervention in the marketplace that has stifled competition. Most important, however, have been our overall economic policies designed to reduce inflation and increase savings, leading to higher investment and economic growth. The fruits of these policies can already be seen in our much lower inflation rate, lower interest rates, and strong economic recovery.

The way to increase the time horizon of our managers is to give them more confidence in the future. We do this by maintaining consistent economic policies and getting away from the stop-go policies of the past twenty years, not by involving the federal government in investment decisions. Obviously, much remains to be accomplished, but we have built a foundation upon which we can continue to set in place those policies that will give us long-term, noninflationary growth and ensure our future competitiveness. 


\title{
RESPONSES OF CONFERENCE PANELISTS TO AUDIENCE QUESTIONS
}

\author{
Panelists for the first question and answer session were Owen \\ Bieber, Shohei Kurihara, and Michael A. Driggs. The moderator was \\ Paul W. McCracken.
}

McCRACKEN: The time has now come for the audience to interrogate our speakers. Looking over these questions, it seems to me that there are a good many potential members of doctoral committees sitting out there in the audience who would do a very good job putting the rest of us through our paces. We have a great many more questions than we will actually have time for. Of course, many of the questions focus on the same issue, industrial policy. To Mr. Driggs: Should we not protect certain industries that are essential to the national defense, such as steel, computers, and, I presume, automobiles?

DRIGGS: We clearly have to act to protect industries that are victims of illegal or unfair trade practices. We have laws in place that will do that, and we will enforce those laws vigorously. The question of national defense is also equally important, but there the decisions must be based upon very specific criteria for individual companies or industries.

MCCRACKEN: Well, let us take a specific industry. How about the auto industry?

DRIGGS: The automobile industry sells to the consumer, and the consumer never benefits from protectionism. Even though temporary measures may well be appropriate to help an industry buy time in extraordinary circumstances-as have existed in last three years-these should clearly be the exception, not the rule.

MCCRACKEN: Mr. Bieber: In light of your remarks about offshore franchise operations, what is the UAW's position on the GM-Toyota venture?

BIEBER: In the public hearings that have been held before the FTC, the UAW did not take a public position either in support of or in opposition to the GM-Toyota joint venture. However, I would point out to this audience that the UAW has 
negotiated a tentative agreement with the joint-venture company that provides, if the FTC approves the venture, that the employees of the former GM operation will be given preference to the jobs in the new company and that the UAW will be recognized as the collective-bargaining agent for those employees.* We have actually worked out a three-part agreement: (1) a temporary agreement that establishes those things I have just alluded to; (2) an interim agreement during the time in which the employees would be hired-and that is about to begin; and (3) negotiations on a regular collective-bargaining agreement shortly after the cars begin rolling off the assembly line. I am very happy to say that we are delighted with the fact that we were able to sit down with the representatives of that joint venture, primarily the representatives of the Toyota Motor Company, and work out that agreement.

MCCRACKEN: Mr. Kurihara: What is your reaction to Mr. Bieber's position that the Japanese cost advantage is attributable to (1) the yen-dollar imbalance and (2) the absence of a commodity tax on Japanese exports to the U.S.?

KURIHARA: I believe that a strong dollar has contributed to the Japanese advantage in selling automobiles in the United States, and I think the reason for that strong dollar lies mainly in the problem of high interest rates in the United States. As for the second aspect, the lack of a commodities tax on Japanese exports to the U.S., the commodity tax is equivalent to the sales tax in the United States. It is natural, therefore, for exported cars to be exempted from taxation. If a Japanese car is sold in the United States, there are other taxes that come into play. Thus, I do not think the difference in taxation has contributed to the Japanese advantage.

MeCRACKEN: Mr. Driggs: Should GATT be amended to allow the U.S. to impose import duties equivalent to the corporate income tax burden borne by U.S. manufacturers and to forgive that equivalent on exports?

DRIGGS: One of the cornerstones of GATT is that one trading partner should be treated no differently than any other trading partner. That is a concept that must be preserved, regardless of how GATT may or may not be modified. Whether or not it is appropriate to use the income tax burden as a mechanism for doing this I do not know. We have looked at a number of different studies and talked to a good number of people to try to understand what the relative tax burden is on the Japanese auto producers compared to that on the U.S. auto companies, but the tax systems of the two countries and the accounting practices of the two industries are so different that we cannot come up with a firm answer.

*Editor's Note: The FTC has since approved the joint venture. 
MeCRACKEN: Mr. Bieber: Do you believe that imposition of a domestic-content requirement would cause any rise in the price of small cars to U.S. consumers? If so, approximately how much would you estimate the price increase would be?

BIEBER: Let me make a couple of points in answer to this question. First, it has been indicated here-if not downright stated-that this is a protectionist bill. Let us clear the air once and for all. The auto-content legislation that we are proposing is not protectionist. We are not advocating that the Japanese companies not sell in this market. What we are saying is that, if they want to participate in our market to the extent that they are, they should locate their plants in this country, provide jobs for American workers, and pay taxes to American communities. American companies have always located in those countries where there is a substantial market. Second, although the argument has been made over and over, it is not true that the cost of the automobile will increase if domestic-content legislation is enacted. The same argument was made when we discussed the question of the voluntary restraints, yet the median increase in automobiles for the last year was 3.4 percent, which was below the 3.8 percent inflation rate that we had in this country.

Even if we assume that auto content would, in fact, result in some increase in automobile prices, do we not have to consider the total disadvantages as well? General Motors has openly stated that they want to import 200,000 Isuzus, 100,000 Suzukis, and now upwards of 100,000 Daewoos. If this trend at GM continues, Ford and Chrysler say they will follow it. The net result will be that we will not have a small and subcompact car market in this country, a situation that will drastically affect our total economy. If we do not have a robust auto industry in this country, we will not have industries such as steel, rubber, plastics, electronics, mining, and textiles. Even the high-tech industry will suffer-30 percent of the robots produced in this country today are utilized in the American auto industry.

The auto industry is a basic industry in this country, and without its success we cannot continue to have the type of living standard and economy that we have enjoyed in this country, which, I think, is one of the richest nations on the face of the earth. Nor can we ignore the human suffering or the welfare cost that will occur when these plants go offshore, when these jobs disappear. Communities must continue to operate; governments and school systems must continue to be funded. All these costs must be factored into the total picture when we get concerned about the price of the automobile.

MeCRACKEN: Mr. Kurihara: You have indicated that Japan favors free trade with no import restrictions or local-content requirements. Does this not contradict the import restrictions in Japan on beef and cigarettes? 
KURIHARA: It is true that there are Japanese restrictions on imported beef and cigarettes, but, although this may sound like an excuse, agriculture is a very sensitive issue in every country. The Japanese and U.S. governments are negotiating right now to ease these restrictions as much as possible. In the future, the Japanese market will be more open to imported beef and cigarettes.

MeCRACKEN: Mr. Bieber: Will the UAW request a seat on the Chrysler Corporation board of directors after Doug Fraser retires?

BIEBER: Yes, but not request, retain the UAW seat on the Chrysler board.

MeCRACKEN: Mr. Driggs: Do you think it is important for the U.S. to maintain small-car production capability, and, if so, what government policies would you advocate to insure that this will occur? If it is not important, why is it not important?

DRIGGS: It is very important that we maintain an ability to compete in every segment of the market. Since we taught, and are still teaching, the rest of the world how to build cars, there is no reason why we cannot be successful ourselves. The best government policy, however, is a policy that creates an environment that gives the consumer the confidence that he is going to have a job and, therefore, the money to buy a car. The U.S. government cannot enter the marketplace and design the cars or second-guess the investment decisions. One specific example will make my point. The federal government pays some 90 percent of the costs of all buses used by cities for intracity transportation. Since there are no standardized plans for buses, the cost is more than it otherwise would be because each city custom designs its own bus. It is very logical to assume that standardization would bring the cost down. This was tried in the early 1970s-the buses were then costing about $\$ 30,000$ to $\$ 40,000$ apiece. The government assembled a committee, and they produced a pretty nifty bus for $\$ 180,000$ apiece. In short, the best policy is to create an environment of economic confidence and prosperity, and that is what we are trying to do.

MCCRACKEN: Mr. Bieber: What is wrong with out-sourcing if it offers reduced costs and better quality? Suppliers are also unionized.

BIEBER: I think I answered the first part of that question-the cost issue-in my response to the question concerning domestic-content legislation. Regarding quality, there are two points I would like to make. First, I am a little bit concerned with Mr. Driggs's reply to that last question. It implies that government is all bad and that if we would rid ourselves of government, everything would be rosy. I would agree that the government should not tell the auto industry how to build a car. But I would point out that because of government regulations over the 
last few years, today we have a better designed, safer, and more fuel-efficient car. This progress did not just happen. It came about because there were certain government provisions set forth that the auto companies had to meet. It is not fair to say, therefore, that government does not and should not play a role.

Second, it is true that in the 1970s the American auto manufacturer and the American auto worker, in some cases, became sloppy. But today the American car does not have to take a back seat to any car produced in the world. It is a fine, high-quality car, and we continue to strive to make it better. I am not saying that the Japanese car is not a quality car-it is-but the American-made car is also a fine, quality car.

MeCRACKEN: There are two dimensions to out-sourcing. One would be of fshore, and the other out-sourcing within the United States.

BIEBER: There has always been a certain amount of parts that go into the American-made car that are not produced by the primary builder. In the case of Chrysler or Ford, in particular, they produce less parts in-house than General Motors. The UAW has not taken the position that there cannot be any outsourcing, but we have stressed to the companies that it is acceptable only if there is a need. In the case of Chrysler, for example, they do not have enough capacity to produce all the parts that they require. In this instance, we tried to influence that company to seek the most highly qualified source for those parts, and we believe very strongly that the most highly qualified sources are those companies whose workers are UAW workers.

MCCRACKEN: Mr. Kurihara: Should the Japanese government take action to change the yen-dollar exchange rate in order to achieve a better balance? If so, what actions should it take?

KURIHARA: As I have said before, I think the imbalance between the yen and the dollar is due to high interest rates in the United States. Japan does not have the means to rectify the value of the yen directly. Currently, there is negotiation between the United States and Japan on how to liberalize the financial system in Japan. Financial liberalization is a very difficult problem-even in America it took ten years-but the Japanese government is very serious about moving in that direction. I personally do not think, however, that financial liberalization will necessarily cause the value of the yen to increase.

MCCRACKEN: Mr. Bieber: What role will there be for profit sharing in the American automobile industry?

BIEBER: Our union has long advocated profit-sharing programs-they were one of Walter Reuther's goals-and we were finally able to incorporate them into the 
collective-bargaining agreement of 1982. We will go to the table in 1984 fully intending to maintain those profit-sharing programs. However, it never was the intent, nor did we ever advocate, that profit sharing become the only means through which the employees can share in the abundance of their particular company. Reuther indicated that basic wage increases must be fixed first, and then there ought to be a means through which the workers "could stand at the end of the bake oven and wait for that enormous pie." Profit sharing is a way to share in that pie, and we will continue to negotiate on and improve those programs. However, we will also talk about other items that rightfully belong on the collectivebargaining table, including annual improvement wages.

MeCRACKEN: Mr. Driggs: Don't we currently have a de facto industrial policy -for example, import restrictions on steel and motorcycles-and should not this policy be more coordinated in order to obtain systematic rather than ad hoc decisions?

DRIGGS: The question, I think, illustrates as forcefully as anything can the confusion we have when we just toss out a slogan like "industrial policy," since it can mean just about anything to anyone. Of course we have policies for our industries. They have developed over time, not always in a very organized fashion, and sometimes in conflict with each other. That kind of development, however, is a product of our social, cultural, and political system. Rightly or wrongly, the price one pays for democracy is some inefficiency. Yet, creating a government agency to substitute for decisions in Washington will not make the situation better but, in my opinion, much worse.

MCCRACKEN: We are deeply indebted to the members of the panel and the speakers for the first half of the afternoon. Thank you. 


\title{
REVOLUTION AT FORD: ALL ROADS LEAD TO QUALITY
}

\author{
Harold A. Poling
}

The American automobile industry has been wrestling with more than its share of problems these past four years. But, in a sense, we have been strengthened by the experiences of this period and have emerged better able to face the formidable worldwide competition of the present and the future. There has been a dramatic turnaround in the attractiveness of our products, in our costs, in our employee relations, and, most significantly, in our quality and productivity.

The American automobile industry is not a "smokestack" industry but a "catalyst" industry, leading other U.S. industries in the creation of higher levels of quality, new technology, and a better-educated work force. The driving force has been quality improvement. It is my objective to describe (1) Ford's past, present, and future strategy for achieving leadership in quality-of course, efforts to improve quality are taking place throughout the U.S. qutomobile industry-and (2) what these changes in the U.S. auto industry mean in the larger context of American industrial competitiveness in the world market.

Although the scope of my remarks includes only what the U.S. auto industry is doing to solve its own problems, it must be understood that, despite the fact that the industry has asserted control in the areas within its grasp, there are still unresolved problems crucial to its success that are not within its control. For example, the single biggest problem facing the industry is unfair international competition, the effects of which are reflected in the huge, unreasonable trade imbalance with Japan. The problem stems from two factors: the undervalued yen and the differences in U.S. and foreign tax structures. It is the federal government that must find reasonable solutions to these problems. They are too urgent and too critical for us to stand by while our industrial strength is sapped. Here, however, I will restrict my remarks to one of the issues the domestic industry is facing and facing well: quality.

Harold A. Poling is Executive Vice President, North American Automotive Operations, Ford Motor Company. 
The key to Ford's quality strategy can be summed up in our phrase: "Quality is Job \#1." But it is not merely a slogan; it is at the heart of the turnaround that has taken place at Ford over the past four years.

By the late $1970 \mathrm{~s}$, consumers had become increasingly quality-conscious in all manufactured goods, not just cars, and in all aspects of their lives. We and the other American carmakers realized that the public's increasing sophistication and its heightened threshold of expectation demanded even higher quality than we had attained in the past. This meant that American manufacturers had to turn their backs on the clichés of the past, clichés that said:

1. Production is the first priority, and quality is expensive to achieve.

2. Defects cannot be prevented, only detected.

3. Quality is the responsibility only of the quality-control department.

4. Production employees can contribute only with their hands and backs. They do not care about the company, and they are to blame for poor quality.

5. Worry only about your own job; do not get involved in someone else's.

6. Stockpile enough supplies to replace bad parts.

Not everyone believed these clichés, but certainly a great number of people did.

In 1979 , Ford decided that we could not afford to have anyone thinking along these lines. We decided that we must make sure that each one of us would be committed to the belief that quality is, and would remain, Ford's number one priority. And quality truly became Job \#1 every step of the way, throughout the entire system. It starts with vehicle design and continues through engineering development and the manufacturing process. It follows the vehicle from the end of the assembly line to the dealer's showroom and service bays. Today, the quality philosophy at Ford Motor Company is based on these fundamental beliefs:

1. Quality is our first priority, and the commitment to quality starts at the top.

2. Quality means satisfying the customer, and his expectations are a moving target, always rising.

3. Defect prevention is better than defect detection.

4. Quality reduces costs.

5. There is extraordinary potential in all people.

6. Quality is the responsibility of all employees.

7. Teamwork is more effective than baton-passing. The days when the design engineer told the plant manager, "I've done my job; now it's your turn," are gone. 
8. If quality is built into the product, there is no need for plants to stockpile redundant parts inventory.

9. Use the highest-quality supplier, and try to use fewer suppliers.

That is the way Ford is committed to doing business today and in the future.

(1) Quality is our first priority, and the quality commitment starts at the top. In 1979, the senior management of Ford Motor Company established quality as our number one policy objective. We stressed that the company's future success depended on the quality reputation and performance of its vehicles. Our objective was to build the highest-quality cars and trucks in the world-and to have the world know it. That is a simple statement, but it is also a firm commitment by our hourly and salaried employees, whether they work in sales offices, executive offices, engineering centers, or on plant floors. We will never stop trying to get better. To us, quality is a moving target, so our quest for quality is unrelenting, unyielding, and unforgiving.

It is interesting to note that the mission of North American Automotive Operations used to be described as, first, providing a satisfactory return on investment and, second, producing high-quality cars and trucks. Today, those goals are reversed, and our mission is described in formal company documents as one of producing high-quality products first. That is because we know that, if we do that, we will provide a satisfactory return on investment to our stockholders-a subtle but important change in our mind-set. We are confident that high quality will generate strong customer acceptance, higher productivity, and lower costswith the end result being improved competitiveness.

(2) Quality means satisfying the customer. Quality includes reliability on the highway and durability over the long run-and advanced technology where it supports those attributes. It includes visual appearance-styling and attention to details-the sound of the door closing, the feel of the interior, the performance, and the features of the car. Everything must be right, must work the first time, and must keep on working. We believe that we are responding.

But not only must we design and build products the customer demands, and produce them with high quality, we must also treat our customers with the kind of respect they deserve when they come into a Ford or Lincoln-Mercury dealership to buy a vehicle or have it serviced. We strive to make quality Job \#1 in every contact that our sales and service personnel have with the customer.

(3) Defect prevention is better than defect detection. It is much more costly and time-consuming to fix a product after mistakes have been made. Therefore, our objective is to prevent quality concerns at every stage of the process by designing and building quality in, rather than expecting the next person in the system to catch problems and correct them. And we are seeing that a good 
heavy dose of this preventive medicine is doing wonders for the health of our quality reputation and market share.

In our manufacturing and assembly plants, statistics alert us to potential or existing problems in time to react with preventive measures. An increasing number of employees are evaluating their quality capability by means of statistical process control (SPC) to improve uniformity and quality.

(4) Quality reduces costs. It has been said that "the best things in life are free." Well, we have come to recognize that improved quality is one of them. This is ironic but true. Improved quality increases productivity, lowers manufacturing and warranty costs, and improves profitability through increased market share. If you design it into the vehicle, it is virtually free.

(5) There is extraordinary potential in all people. Our production employees have a wealth of knowledge and experience about the best way to design and build a product. Because we did not encourage them to share that knowledge with us in the past, we did not take advantage of it. That has changed, and now our employees in our plants are encouraged to assist our design and manufacturing engineers and, in fact, can be credited with a large number of production and design engineering ideas.

In 1979, the UAW and Ford jointly adopted a process we call Employee Involvement. In simple terms, Employee Involvement (EI) affords employees the opportunity to participate in workplace decisions, to offer suggestions and get answers, to communicate and be heard. The program is based on the principle that people have a great deal more to offer than just their physical labor: that, when given the chance, they can and want to contribute positive ideas that solve work-related problems and improve the work environment. Employee Involvement recognizes that employees are the experts at their jobs and that their suggestions can make the product and their jobs better.

Today, virtually all of our North American facilities have voluntary EI teams, and more than 50 percent of our employees have received EI training. Plant employees regularly review the prototype vehicles more than two years before production begins, and they submit suggestions to change the vehicle design and manufacturing plans to optimize quality and productivity. For example, employees at our Kansas City Assembly Plant suggested more than 650 design and manufacturing changes for the Ford Tempo and Mercury Topaz. More than threequarters of those suggestions have been implemented.

One idea came from an employee who works in the plant's small-parts crib. He noticed on the prototype that the two bolts holding the front-door handle were different from the two holding the back-door handle, even though both door handles and bolt sizes were identical. He asked the engineer why. Upon looking 
into it, the engineer learned that one designer had had responsibility for the front door, another for the rear door-and the two people had never talked with one another. So, they ended up with two different fasteners where there could have been one. Needless to say, identical fasteners are used on the production models, resulting in cost savings, easier installation, and the tracking of fewer parts.

(6) Quality is the responsibility of all employees. We recognize that not only management but also our salaried and our hourly employees want to produce quality products-our jobs and our future depend on that. Quality requires a cooperative effort between management and employees.

(7) Teamwork is more effective than baton-passing. It used to be the case that the development engineers would present a new product to the manufacturing engineers and say, in effect: "There, our job is complete; now it's your responsibility." Each group looked only at its own task, completed it, and passed it on to the next group, with little interaction. We do not design, develop, or manufacture new products that way anymore. Now, reliability teams exist for each of the hundred or so major subsystems on a car or truck, such as the steering or braking system. Each team consists of representatives from manufacturing, development engineering, planning, sales, finance, service, and our suppliers. The team members break down organizational barriers so that there is less of a "my turf/your turf" syndrome and more "our turf." Members work together to assure that we design quality in at the drawing board, so that it can be built in on the line. In fact, we have added additional time to the early development part of our newvehicle programs for better "before-the-fact" prevention of quality concerns. Numerous other examples of productive teamwork underscore our belief that people working together can accomplish more than people working alone in their own operational "chimneys."

(8) If quality is built into the product, there is no need to stockpile supplies. This boils down to three letters, J.I.T., just-in-time, kanban in Japanese. The system originated in the Rouge manufacturing complex in Dearborn, built and organized by Henry Ford.

Today, our quality gains have enabled us to reduce "just-in-case" inventories that protected us from the consequences of inefficient manufacturing practices. They have allowed us to work on implementing a cost-saving just-in-time system, whereby inventory levels are significantly lowered and parts are delivered by suppliers almost on-demand as they are needed. We can do this only because of our plants' high-quality output. Just-in-time has saved millions of dollars in unnecessary expense. For instance, the Cleveland Engine Plant has reduced average on-hand inventories to about a seven-day supply, generating annual ongoing savings of about $\$ 30$ million.

(9) Our quality strategy demands that we use as few, and the highest quality, suppliers of a specific part as possible. Because suppliers contribute about half 
of the average content of Ford vehicles, the quality of their parts is vital. Thus, in August 1981, we launched an innovative program to recognize component suppliers who consistently meet Ford's quality standards. The recognition is in the form of a "Q1 Preferred Quality Award." To qualify for the award, a supplier must have an excellent Ford quality rating and an effective quality-assurance system that includes process control and the use of statistical control techniques. In return, the supplier is given preferential treatment, including long-term contracts and the privilege of self-certification. The supplier now has responsibility for his own quality and is more closely integrated into the preliminary stages of new-product programs in which he will play a major part. Furthermore, restricting ourselves to high-quality suppliers allows us to use fewer suppliers, which increases the uniformity of the parts.

As a result of this quality focus at Ford, our product quality has improved dramatically. Nationwide marketing research surveys of thousands of vehicle owners indicate that the quality of 1984 model cars and light trucks is 55 percent and 59 percent, respectively, better than the quality of our 1980 models.

Where do we go from here? Our next task is to broaden our quality focus to excellence in every organization in our North American Operations. This concept, "Total Operational Excellence," is a strategy for improving quality and productivity in all aspects of the business, both product and nonproduct related. Its objective is to marshal the total work force in the effort to satisfy the customer by improving the quality of every business element-not only engineering and manufacturing, but finance, personnel, sales, marketing, and administration. It requires every organizational entity to identify the best way that its function can be performed by a business, to adopt that method, and then to improve on it. It replaces managing by instinct with managing with facts. That is the next goal we have set for ourselves-an expansion of "Quality is Job \#1" to every job in every organization.

To sum up, Ford has achieved a major quality turnaround as a result of a number of major changes in our corporate thinking-and we expect to continue changing in the future. As I noted at the outset, many of these changes are taking place throughout the U.S. auto industry, but their significance extends to all American industry and every American. The automotive industry has been called a "smokestack industry," a "sunset industry," a dying industry. Nothing could be further from the truth. It should be rechristened a "catalyst industry": It is a catalyst for improving the skills of America's work force, for the development of new technology and new applications of existing technology, and for improved quality in the country's supplier base.

First, we are seeking employee input into new product design and manufacture, and we are depending on employees to identify potential quality problems through the use of SPC. We are also providing more training and retraining for 
our people than ever before. In the past year, Ford's active salaried and hourly employees spent more than two million hours in formel training. More than 117,000 hours were spent in training Ford's skilled tradesmen in new technologies. The Ford-UAW contract negotiated in 1982 allocated five cents for each hour worked by hourly employees toward certain training, retraining, and development activities for both active and laid-off hourly employees retaining seniority. More than 8000 hourly employees nationwide, including 3000 displaced by plant closings, have participated in one or more forms of counseling, training and other services since these activities became available. A considerable training effort has also been developed for our suppliers. Since 1981, we have conducted 114 five-day seminars in SPC for 4500 Ford supplier personnel. At the dealership level, service technicians at Ford and Lincoln-Mercury dealerships received 653,000 hours of training in the past year. So, we are increasing the knowledge and training of employees at all levels in our industry and supplier industries.

Second, the industry is also a catalyst for the development of new technology and new applications of existing technology. We have completed the first stage of the massive retooling and facilities' changes that downsizing necessitated. The U.S. auto industry is now fine-tuning the technology of its plants and vehicles, as well as the components and parts it produces. At Ford, for example, we are introducing the latest technology into automobile manufacture:

Computers: We can go from car design to tool and die manufacture on outer-body panels entirely on the computer-aided design system. This bypasses physical models (except for the prototype) and thus substantially improves accuracy and productivity.

Robots: Ford will have about 2500 robots in use worldwide by the end of this year-about half in the U.S. They will be welding and painting auto bodies and performing other less desirable manufacturing operations.

Lasers: In Ford plants, laser beams are now welding steel transmission assemblies with previously unattainable levels of precision. In addition, we are installing six laser welding systems for a new, hightechnology, four-speed automatic transaxle that will be in some of our future car lines.

Machine vision: Machines in Ford plants now employ infrared, ultrasonic, and cathode-ray technologies and compare production assemblies of automobile bodies, electronic circuit boards, and clocks with computerized images of the desired component configuration. 
Finally, the American automobile industry is a catalyst for improved quality in the country's supplier base. Our quality standards, and the requirements of SPC and just-in-time inventory systems, are reflected in our suppliers' newly raised quality levels. These improved quality levels will have a ripple effect throughout the manufacturing sector, raising the quality of the output not only of the automobile industry but also of other industries that our suppliers serve.

These three factors indicate that the American automobile industry can play a key role in the regeneration of all American industry. The long-term viability not only of the auto industry but of all American industry is at stake. And, with the stakes so high, we cannot afford to fail. I believe that American industry has the courage, the knowledge, the creativity, and the determination to meet whatever is ahead.

This is a changing world, and we intend to change with it. Hopefully, all American industry-management and labor-as well as our government that controls trade policies, will join us in changing enough to allow us to compete in today's global market. Given a fair opportunity to compete, I am confident that American industry can do so successfully. 
EVOLVING MANUFACTURER-SUPPLIER RELATIONSHIPS

Edward J. Hayes

There are great changes taking place in manufacturer-supplier relationships in the U.S. auto industry. Being an executive of Fruehauf, which is an OEM, and also of Kelsey-Hayes, which is a well-known supplier, I am able to see two sides of this picture concurrently. In the context of our subject, however, it does not really matter on which side of the desk one sits. At this point in time, we are all participants in events that promise to change the entire face of the industry. When we consider those changes, and what factors brought them about, we automatically think of Japan and the new wave of industrial change in which they have played such a vital role.

After the crippling effects of the war, Japan turned to the U.S., England, and others for financial aid and technological support to revitalize their industries. There were probably few who envisioned the forces being set into motion. The money was carefully invested, and the technology was not only used, but soon improved. Japan's success in this Herculean effort is certainly borne out by their leadership in many areas of industrial technology. We might say that the student is beginning to instruct the teachers.

We have to take into consideration, however, that our cultures, work ethic, and socioeconomic structures are totally different. We hear about the way Japanese laborers are committed to producing nothing but defect-free products, and I would agree with that if I did not know that Japanese manufacturers have also had their share of recalls. Since the Japanese had so little in the way of raw materials and energy supplies, they have had to become very proficient at manufacturing quality products at a low cost in order to survive. That is exactly the situation that the American suppliers find themselves in today. We must manufacture a higher-quality, lower-cost product than the OEMs themselves can produce.

Edward J. Hayes is Vice President of Research and Development for Kelsey-Hayes and Fruehauf Corporation. He has developed more than twenty-five patents, including a disc brake that is now used on 90 percent of all vehicles worldwide. 
The Japanese success has also been dependent upon their discovery of working relationships, which are inherent in everything they have accomplished. The evolution of manufacturer-supplier relationships in this country is certainly an expression of our growing interdependence. No-holds-barred ingenuity is turning our industrial problems around and putting us squarely back on the right track.

Kelsey-Hayes has often worked in close cooperation with its customers to achieve a common goal. For example, we found that to make a disc brake feel really smooth, we had to have tolerances that were better than aircraft tolerances $-a$ runout less than one-half of one thousandth of an inch. Furthermore, this had to be accomplished at automotive prices. There were many times when we had to stay up all night at our Kingsway Plant to accomplish this, and our customers, Lou Veraldi and Max Jerosik, were there with us. We feel that in our relationship with our customers we are an extension of their engineering arm.

Since as far back as the 1960 s, it has been obvious that, if we are to survive, everyone involved in the manufacturing process must explore their abilities to the limits. Otherwise, we must face a future of plant closings and soaring unemployment. The need for mutual participation is obvious in the new manufacturer-supplier relationships.

The success of the industry in the coming years is going to be based on four concepts: (1) quality and the use of statistical process control (SPC), (2) just-intime delivery, (3) long-term supplier contracts, and (4) mutual involvement in design and development. I would like to spend a few moments expanding on each of these.

(1) Quality has become a high priority, as well it should be. Consumers are demanding a quality product and will go elsewhere if it is not available from American manufacturers. With the influx of quality foreign cars into the United States, American automakers have had to seriously improve their quality in order to compete. The traditional U.S. manufacturing premise was low-cost, highvolume production and "make it to print." That philosophy, like blueprint tolerances, is no longer good enough. Requests for quotes from OEMs now ask for price, terms, delivery, and "What is your plan for SPC implementation?"

Using Dr. Deming's techniques for SPC, the Japanese learned an important premise: understanding manufacturing processes helps to control them. In this manner, products with repeatable and uniform dimensional and material characteristics can be manufactured.

Statistical process control is a highly important manufacturing tool. It provides a dependable means to improve the process and guarantee compliance of the part. Carmakers were quick to recognize the importance of SPC and no longer ask suppliers to "make it to print" but, rather, "make it right" and "make it the same every time." 
At Kelsey-Hayes, in order to control the product, we measure the dimensions automatically at a number of stations, feed them into a computer so that we will know which tools have to be changed, and change those tools at lunch or during coffee breaks, before they get out of tolerance. We also make twentyseven automatic measurements on a part to make certain that, when it arrives at the customer's plant, it can be directly placed on the automobile.

More and more, automakers are asking suppliers to take complete responsibility for their product quality. By returning this responsibility to the suppliers, OEMs contribute to their own cost effectiveness. More importantly, they place the responsibility for quality back at the point of origin, where error can be detected and corrected in the most time- and cost-effective way.

(2) Another idea borrowed from the Japanese is the concept of just-in-time delivery. Ideally, this will eliminate, or at least seriously reduce, the costs associated with carrying unnecessary inventory. The idea is that parts machined on Thursday are assembled into vehicles on Friday. Soon, suppliers will be implementing just-in-time deliveries with their own subsuppliers, and the final result will be inventory savings throughout the entire manufacturing process, right back to raw materials.

Major issues for all involved in just-in-time delivery include: production scheduling, dependable shipping methods, and, for some, locating plants near the sources of business. As the auto industry evolved in Japan, supplier companies were located next to the manufacturer's assembly plants. Japanese suppliers that are not next to car assembly plants are still relatively close to them, in comparison to the North American suppliers. Ideally, major suppliers would be located within one day of the automobile assembly plant, and in many cases they are. Kelsey-Hayes is fortunate because we are already located close to most of our customers.

Good communication is essential to just-in-time-whether the supplier is next door or miles away. It is also an important ingredient in the continuing process of working together to solve business-related problems. For example, when there are concerns that affect a particular industry, it is not unusual for various parties to work together to find a viable solution. A perfect example is the Automotive Industry Action Group (AIAG). This group, composed of members of middle management from the various car-manufacturing facilities, as well as their suppliers, is working on a number of projects, including the establishment of a common computer language for the entire industry, bar-coding parts, and a common packing list. As with other industries, there is movement to reduce paper flow at all levels and to electronically order parts and control inventory.

The AIAG is working on overcoming individual difficulties, which, without the effort of everyone, could not be solved. Individual companies also work together to solve problems inherent in developing new ways of doing business. For 
instance, in order to facilitate the constant deliveries of just-in-time suppliers, a more efficient unlogding and receiving system is essential. General Motors built an innovative receiving area at two of its new plants. Similar designs are being considered at Ford and Chrysler locations. These areas are designed to accommodate railroad cars, traditional end-unloading trailers, and (a new concept) sideunloading trailers.

With input about their needs from both suppliers and manufacturers, Fruehauf designed and made prototypes of two unique side-unloading trailers. These new trailers are designed for maximum access to cargo space so that the loading and unloading of parts can be accomplished with minimal effort and time. One has a gull-wing that opens up the entire side; the other has sliding side doors that allow access to any two-thirds of the cargo at one time, of ten decreasing unloading to a mere ten minutes. Additionally, the AIAG is setting up a project team to propose standard dimensions for parts containers, which would further streamline the unloading process.

By working together with a genuine concern for each other's needs, OEMs and suppliers should be able to create whole new methods for doing business, methods that will satisfy the needs of their particular industries as well as those of their customers. To protect their supply to the assembly plants, suppliers have traditionally carried a certain amount of inventory. Before they can benefit from just-in-time and confidently reduce that inventory, they will have to incorporate the cost and quality benefits of SPC in their manufacturing. It is becoming essential for suppliers to be able to produce top-quality parts at a "zero defect" level and to improve production at a low price. This will place new burdens on suppliers, which will tend to reduce their numbers.

(3) Just a few years ago, the prevailing theory was "the more suppliers, the better." We believed this forced our suppliers to be more competitive and more responsive to our needs. Then, we found ourselves in the middle of a terrible recession. Many suppliers simply could not hold out; they either closed down or shifted their focus to less-depressed fields. It soon became obvious that the suppliers who stuck it out were the strongest and most capable of the lot.

As OEMs became accustomed to dealing with this smaller group, they found they were getting better prices, dependable deliveries, and more consistent quality. Based on that experience, most manufacturers are concentrating on developing closer, more long-term positions with a much smaller circle of qualified suppliers. This alliance with the OEMs benefits the suppliers because it encourages longer-term contracts, and it benefits the manufacturer because it eliminates the complexities of multiple sourcing and the associated high costs of procurement.

Three- to five-year contracts offer the supplier a longer, more dependable market for his products and helps reduce his overall costs because he can tool 
properly. Longer-term contracts are also being offered by the U.S. military in purchasing their complicated weapons systems. The supplier benefits from a long-term contract since it definitely reduces his risk: he knows he is going to have business for a specific period of time. Naturally, this makes long-term planning much more accurate.

This reduced risk should also serve as an encouragement to suppliers to make capital investments in more productive facilities, improved quality, and innovative technology. To insure contract renewal, the vendor will have to produce and deliver the required quantity and quality of parts as needed. Automakers are asking for more supplier involvement in the design and development of produets, even at the earliest stages. Efforts from both teams working together should cut development time, reduce costs, and improve quality.

(4) As more intense OEM-supplier relationships take place, joint-venture and equity-participation programs will evolve. With suppliers participating in the costs associated with the launching of a new product, they will need to be sources very early in the product cycle. Gaining that critical lead time will be important. However, they will still need long-term contracts to guarantee a return on their development investment.

A number of challenges face the U.S. supplier in this atmosphere of "survival of the fittest." Any prolonged success will be dependent on the ability to meet rigid criteria. Suppliers will have to answer for their costs, as well as for their quality. It is imperative for the U.S. supplier to establish the capability to produce parts to a consistent norm, not just within the blueprint tolerances. The supplier will have to reduce costs through productivity increases, whether through design changes or processing improvements. Since there are quality suppliers throughout the world, the American supplier has to constantly focus on being competitive.

Manufacturing is no longer an American art, but a worldwide art. The successful supplier is going to have to widen his horizon to include doing business in other countries. In short, suppliers need to be able to meet the new challenges creatively and adapt to the changing needs of the auto industry around the world. OEMs can encourage these closer ties by recognizing that suppliers have limited capital resources, by communicating their real needs to suppliers (bearing in mind the important difference between desire and need), and by being selective when asking suppliers to participate in engineering programs so that only suppliers who have a reasonable chance to obtain the contract are asked. The traditional manufacturer-supplier business arrangement simply no longer works. This is a new ball game, with new rules and new goals.

There is no doubt in my mind that American industry, supported by the American worker, is as good as, or better than, any in the world. Given the proper 
equipment, management, and attainable goals, I am convinced that our industry will flourish. I believe we can change, and I believe we can meet any challenge to our traditional role as the world's industrial leader. 


\title{
RESPONSES OF CONFERENCE PANELISTS TO AUDIENCE QUESTIONS
}

\author{
Panelists for the second question and answer session were Harold A. \\ Poling and Edward J. Hayes. The moderator was Paul W. \\ MeCracken.
}

MCCRACKEN: Mr. Poling: You alluded to the fact that from 1980 to 1984 there has been an improvement in quality of 55 percent and 59 percent for cars and light trucks, respectively. Are those figures based on warranty claims?

POLING: No, they are based on consumer surveys of defects. In all, about 14,000 customers of all manufacturers were surveyed.

MeCRACKEN: That is not exactly a small sample.

POLING: No, it is a pretty reliable statistical survey.

McCRACKEN: Mr. Hayes: What steps can the U.S. auto industry take to improve scheduling, and how far into the future should schedules be stable?

HAYES: As I mentioned in my discussion, the OEMs are doing much better with stable schedules now, partially because their company-owned suppliers have directly profited from better scheduling. If production and schedules fluctuate drastically, the supplier has to stockpile excess parts. Consequently, any problem with those parts is not detected until a number have already been produced. In addition, there is the cost of carrying a larger inventory, and that cost eventually gets passed on to the end user. In our case, it is extremely important to know the production schedule three weeks in advance. Our parts are, in some cases, less complicated than others, and there are some suppliers who employ more extensive tooling and would need a longer period of time.

MeCRACKEN: Mr. Poling: Your remarks on Ford's efforts to improve quality were positive and upbeat. It is clear, however, that Ford has experienced difficulties in moving in this direction. Would you comment on one or two of the major difficulties and how these were or are being overcome? 
POLNG: I think the major difficulty was convincing our people that we really had changed and that quality was our number one priority. To dramatically demonstrate that change, we initiated a process for our 1981 Escort that determined whether the vehicle was ready for production. It was called $4 \mathrm{P}$ (Production Process Prove-out Program). The criteria for that program established that 300 separate parts had to be made off of production tooling. When it came time to go into $4 \mathrm{P}$, we were not ready. If we had followed historical practice, we would have proceeded. There was considerable debate within North America as to whether we should or not, and we elected not to proceed. We ended up, as a result, delaying $4 \mathrm{P}$ for a month and introduction for three weeks. Keep in mind, this was at a time when we were losing billions of dollars every year. Another change that we have implemented to improve quality is to initiate vacation shut-downs. For instance, we took a vacation shut-down last year at the time when the market was rising. We lost 100,000 vehicles, of which only 40,000 could be made up during the rest of the year. Thus, we lost 60,000 units in a rising market. Again, however, it was the right decision. If you do not take a vacation shut-down, then you use vacation replacements, and they are not as conversant with the work assignment as the people that are normally on that assignment. Quality will suffer. In addition, we have taken disciplinary action on employees who have removed reject tags and put parts on the line. All of these actions are attempts to convince people that we are truly concerned, that we are serious, and that we are not going to back off.

MeCRACKEN: Mr. Hayes: Has your company pursued supplying components to the new Japanese assembly operations in the U.S.-for example, Honda and Nissan-and how does their approach to supplier quality differ from Ford's approach, as has just been described?

HAYES: Yes, we certainly have pursued it, and in the Japanese companies where we have gotten some business, the approach to quality is very much the same as Ford's. We have also pursued business from European OEMs, and, in some cases, we have found that their demands are even greater. For instance, we were being asked to paint-with a very special paint-an area that normally in this country is not even painted. Yet it really did not have anything to do with the function of the component, so the cost ended up being more than it should have been.

MeCRACKEN: Mr. Poling: While Ford's quality improvement is significant, is not the gap between the U.S. auto industry, including Ford, and Japan still formidable? If so, will not the going get harder now that you have made most of the easy gains?

POLING: The answer to both questions is "No." We are very close to being competitive, not only with the Japanese, but also with the Europeans. As a matter of 
fact, we are now competitive with some of the high-volume Japanese manufacturers-Nissan for one, Mazda for another. We are not quite as good as a couple of the others, but we have made dramatic progress, and we will close that gap. We are also as good as some high-volume European imports-BMW, Volvoand are getting close to Mercedes. Closing the gap does not bother me as much as the problems that must be solved to give us a fair competitive environment. The yen-dollar relationship and the tax differential must be addressed.

McCRACKEN: Mr. Poling: Do you agree with Owen Bieber's earlier comments that the Japanese cost advantage is really less than $\$ 1500$ per car-the figure that at one time was bandied about so much?

POLING: I have a difference of opinion there. I think that on an Escort-size vehicle, the manufacturing cost difference is about $\$ 2000$, depending on the exchange rate. At the current exchange rate, it would be closer to $\$ 2000$, with about two-thirds of that difference attributable to the yen-dollar imbalance and the tax differential.

MCCRACKEN: What about on a Tempo-size vehicle?

POLING: The cost differential would be just about the same on the Tempo-size vehicle. If we look at the pickup truck, we get a better idea of the Japanese cost advantage. The Japanese are selling their compact trucks in this market by jumping a 25 percent barrier and running very extensive marketing programs. That gives us an indication of their advantage, even though, I might add, the quality of our Ranger pickup truck is as good as that of any pickup truck produced in the world.

McCRACKEN: Mr. Hayes: Another Japanese idea is to have very few independent suppliers like Kelsey-Hayes. Do you see a U.S. trend toward more vertical alliances between OEMs and their suppliers?

HAYRS: First, we definitely see a trend toward fewer suppliers. Second, in some cases we also see a trend toward OEMs helping a supplier with the production process or financing. At Fruehauf and Kelsey-Hayes, for instance, we made a decision to buy some beams. Unfortunately, we have to buy them in the length that the mill makes them because the supplier does not have the money to cut the beam to our specifications. We are now looking into the possibility of providing the supplier with the money to cut the beams so that we do not have to pay shipping costs on the excess. As far as the OEMs integrating, the trend so far has been in reverse. Some of our customers have given us business for parts that they were manufacturing themselves. It is still true, however, that we must produce a part at a lower total cost than the OEM can produce it. 
MeCRACKEN: Mr. Poling: Despite improvements in quality, Ford is continuing to move offshore, for example, Brazil. If the outlook for improved quality and cost reduction is positive, why move offshore?

POLING: We have purchased engines from Brazil for some period of time. We are also going to be shipping about 300,000 engines from our Dearborn engine plant to Europe starting in another couple of years and importing some small-volume vehicles from our European automotive operations, including the XR4 Sierra this fall (about 16,000 units), which will sell here as the Merkur XR4Ti. We believe that this process will be incremental and will not eliminate jobs in this country.

The operation in Mexico was the resolution of a Mexican problem. We have been doing business in Mexico for over fifty years, and we felt it was desirable to continue operations. Furthermore, the design vehicle that is produced down there is a U.S. design, and they use some of our components in the assembly of the vehicle. Our only alternative was to produce there or get out of business. We had been in Mexico for a long period of time, and we thought that we should stay in business there.

MCCRACKEN: Mr. Hayes: What is Kelsey-Hayes doing to meet competition from offshore-once again, for example, from Brazil or Japan? It appears virtually impossible to achieve the cost levels of these countries and meet the buying price of the OEMs.

HAYES: Well, one case comes to mind. We have competition from a wheel manufacturer in Brazil who receives a government payment for every wheel he ships. The only way we can beat him is to be able to automate-to more highly automate-so that we have lower labor costs per part, to beat them on quality, and to deliver the part in a more timely fashion. So far, we have been very successful. Low-cost offshore competition is a problem, but we have to live with it. To be competitive, we must have either a better-quality product or an equivalent price, as well as better delivery and service.

MeCRACKEN: Mr. Poling: How does Ford maintain quality in its offshore sourcing of parts and components?

POLING: We impose the same criteria on quality regardless of the source.

MeCRACKEN: Do you have the same program in those plants?

POLING: Yes, the same program and the same results. 
McCRACKEN: Mr. Hayes: It seems that the auto companies talk about long-term contracts but are very hesitant to grant them. How many long-term contracts has your company been able to obtain from the Big Three?

HAYES: It is true that the auto companies are hesitant to grant long-term contracts, but we have obtained some--I do not want to give the number, and am not sure I even know it. There is a trend toward long-term supplier contracts, and it is enabling us to tool a little better. I just hope that the OEMs do not change their minds, because we have spent a great deal of money trying to provide tooling for some of these contracts.

POLING: At Ford, the commitment to long-term contracts is real.

HAYES: I might mention one particular problem that can arise. We might design a part that contains certain components we have to purchase. Then, after we have indicated the price, another company might indicate to the OEM that they can make that particular component (and, therefore, the entire part) less expensively. No one knows whether their system will really work since they have not fully engineered or tested the product, but we get hit over the head with the price that they quoted. This puts a burden on us to reengineer and find another way of manufacturing the part. We also need a firm commitment from the OEMs that (1) when a contract is given, it will not be broken, and (2) if we cannot find a different way to make that total system, we can still protect some of the profit that we need for future capital investments.

McCRACKEN: Mr. Poling: Ford-U.S. versus Ford-Europe cars: Why is there such a difference in quality criteria between the two continents?

POLING: There is not a difference in quality criteria on the two continents. I was in Europe for six and one-half years and had responsibility for Ford-Europe, and $I$ think that the actions we were putting in place in Europe were directed toward the same end results that we have here. Of course, they have different driving conditions in Europe-we do not have many places in the United States like the Autobahn, where you floor the accelerator and drive 125 miles an hour-but, basically, the same attention to quality exists on both continents.

MCCRACKEN: Mr. Hayes: Do you anticipate a shakeout of Michigan suppliers, after which surviving firms in that more concentrated industry will be able to raise their prices? In other words, are you on the path to a monopoly?

HAYES: I do not think that will ever happen for two reasons. First, our customers manufacture some of the products that we do. Thus, they know what our material and labor costs are, how we manufacture, and how many we get per 
hour. Second, if we had too much profit margin, even if we had a monopoly, the customer would simply integrate the production of that part and make it himself. We do see a shakeout, and that is a problem, but also an opportunity.

MCCRACKEN: The next question is, in a sense, a sequel. Is this trend toward fewer suppliers an indication that we will end up with a few multifunctional megasuppliers at the expense of smaller ones?

HAYES: I think, frankly, that there will be fewer smaller suppliers because they cannot be as competitive as a supplier that is selling to four or five different firms and has the advantage of volume. For instance, we have a machine that can turn out six different valves every eighteen seconds. A small supplier can make some valves, but not that efficiently and in that quantity. In fact, we have bailed out a number of them. After the OEM has gone through that a few times, they are more likely to give us the entire contract.

MeCRACKEN: I have a question for both of you, and it is an amalgam of two or three questions. If we were to assume a trend toward a yen-dollar exchange rate of 190 to 200, would you then see the American automobile industry making sustained progress toward closing the cost gap vis-à-vis Japan in the years ahead?

POLING: I think that a more accurate assessment of the relative position of the yen-dollar exchange rate would be 180 to 190 . If the rate were 190 to 200 , we would make progress in closing the gap, but we would still have to contend with the tax differential.

MeCRACKEN: How much is that, would you guess?

POLnN: The tax differential is about $\$ 650.00$ per car, and the yen-dollar exchange rate is about $\$ 700.00$ per car. I would also take issue with the earlier comment indicating that the strength of the dollar was due to the high interest rates in the United States. In the past three years-and these are Secretary Regan's comments, not mine-the yen has weakened against the dollar by 70 percent even though our interest rates have come down from an extremely high prime rate of 19 percent to the present level of 11.5 percent. For some reason, the yen has not responded to all the positive economic factors that are the envy of most countries of the world: a very low interest rate, an extremely favorable balance of trade, and very high employment levels. In fact, it has weakened against the dollar, and that has caused increased pressure on not only our industry but all American industry. Thus, it is in the interest of this country to assure that we are playing by the same rules, and then we will have a fair chance to compete for the market. 
There are two large automotive markets in the world: the United States and Western Europe. Japan's market has been relatively stagnant for ten years. Every automobile-producing country in Western Europe has some form of control on Japanese imports; ours is the only relatively open market, with the exception of the restraints we have had in the past three years. Even with those restraints, the situation did not develop as expected. When the restraints were imposed, it was the intent to limit the Japanese share of the market to 18 percent. Yet our industry kept "walking away," and, as a result, their penetration increased substantially at a time when the U.S. industry was weakening and spending billions of dollars for new products. That situation resulted in the huge losses that we have experienced.

HAYES: I certainly agree with what Mr. Poling has said.

MCCRACKEN: That ends our second question and answer session. I wish to thank our panelists, and the audience, for their participation. 



\title{
A COMPACT FOR AUTOMOTIVE REVITALIZATION (C.A.R.)*
}

\author{
Gerald Greenwald
}

I feel honored to be invited to participate in the fourth annual U.S.-Japan Auto Industry Conference. Four years ago in 1980, when you had your first conference, I remember that we at Chrysler were frantically running around trying to figure out which hole we were going to plug with our first $\$ 500$ million of federally guaranteed loans, which we drew down in June of 1980 . We had enough leaks at that time to sink a battleship. In those days, we did not have much time for conferences or seminars, or for much else except the nitty-gritty of survival. If, for instance, anyone had the courage to make a long-winded presentation to any of us, inevitably someone would jump up in the middle of it and say, "Excuse me, I have a company to save," and then scoot right out the door.

We have come a long way since then. Chrysler's survival is now ensured, and, despite what Senator Gary Hart has had to say, I think we have become a pretty good example of good industrial policy for America. The record bears that out. We have paid off all $\$ 1.2$ billion of our federally guaranteed loans, and we did it seven years early. For its help, the federal government made a cool $\$ 311$ million in pure profit. More importantly, 600,000 American jobs were saved, including jobs at more than 16,000 supplier firms throughout the country. In addition, we have cut our costs, and our sales-like everyone else's-have taken off like a rocket. We have also reported record earnings.

Some people-outsiders mostly-are saying that all of us in Detroit are in Fat City again. And why not? The auto companies are rejuvenated; the UAW is warming up for its fall negotiations with GM and Ford with a renewed vigor the likes of which we have not seen since the days of Walter Reuther; and suppliers and dealers, who also sacrificed greatly to get to this point, are waiting (perhaps justifiably) in the wings. Recently, Commerce Secretary Malcolm Baldrige called

Gerald Greenwald is Vice Chairman of the Board, Chrysler Corporation, and Chairman of the Corporate Policy Committee.

*This article is reprinted by permission of the Chrysler Corporation. 
for an end to the voluntary restraints on Japanese cars, even before this year's restraints go into effect. In short, everyone is painting a bright future for the American auto industry.

Even though the industry is certainly in one of the most dramatic business rebounds in history, we would be making a tragic mistake if we believed our reviews. We may look good now, but this show has just opened. The important questions are: How long will it run, and will it run strong enough to allow the domestic industry and its constituents to recoup the devastating losses of the past decade? Those questions have not been answered yet, but, in the long run, they have as much an impact on the Japanese presence in this market as they do on the American presence.

Right now, everyone is focusing on profits, but that gives a false sense of optimism. For example, Chrysler lost nearly $\$ 3.5$ billion from 1978 to 1981 . In the last two years, we have made back $\$ 870$ million net. To break even we just have to make another $\$ 2.6$ billion. Put another way, Chrysler's record profit in 1983 of $\$ 700$ million, which was made by selling 1.5 million vehicles and employing an average of 81,500 people, was still $\$ 60$ million less than the $\$ 760$ million profit that $\mathrm{T}$. Boone Pickens and his corporate gunslingers at Mesa Petroleum stand to make in the Socal-Gulf Oil merger.

Of course, no new jobs will be created by that merger, just as no new jobs will be created by the mind-boggling $\$ 34$ billion being spent by oil companies on mergers and takeovers. There are jobs, however, in the auto industry, but many of those jobs-not only long-term, but also short-term-are still in danger. The reasons lie in a simple financial review of the U.S. auto industry in the last few years and a comparison with the Japanese industry:

(1) Japanese automakers entered the current sales recovery in the U.S. market from a strong financial position-a financial position based on several years of steady earnings. The U.S. auto companies, on the other hand, entered the recovery with over $\$ 8$ billion in long-term debt. (The debt service on that figure, by the way, is over a billion dollars a year.)

(2) In order to stay competitive with Japan (that is, to fund necessary quality and productivity improvements and needed $R \& D$ ) and to maintain employment, U.S. automakers will require an average of $\$ 15$ billion per year over the next three years for capital investment, a total of $\$ 45$ billion.

(3) Because of high interest rates, American automakers-under current conditions-will have to pay over three times as much for capital as their Japanese counterparts (according to an independent study sponsored by the free-trade American Business Council). 
(4) While the Japanese were steadily increasing productivity over the 1970 s, productivity in U.S. auto companies rode an economic roller coaster, rising in strong markets and falling in weak markets. Thus, there was no net increase in labor productivity in the U.S. auto industry from 1971 to 1981 , but real wages in the industry (adjusted for inflation) increased an average of 2 percent a year, and fringe benefits rose an average of 5 percent annually.

Of course, the industry has made dramatic leaps in productivity in the past eighteen months as production has increased. But we must ask ourselves, Are we on just another roller-coaster ride, heading for an even steeper plunge at the next inevitable cyclical downturn?

What all these facts point out is that the domestic auto industry in general -like Chrysler in microcosm-is not standing on a magnificent mountain of cash. Actually, it is digging itself ever so slowly out of a deep hole caused by the oil shocks of the $1970 \mathrm{~s}$, skyrocketing interest rates, a skyrocketing inflation rate, and a three-year auto depression.

Yet, not all of our problems are of our own making. In fact, our most serious competitive handicaps have resulted from governmental policies-both here and in Japan-over which we in the car business have no control except as individual voters. In this election year, it is important that we understand what those handicaps are.

Our first problem is the federal budget deficit. Although there is a lot of rejoicing in Washington this week about the president's decision to finally relent and cut defense spending in his revised budget plan, what a lot of people seem to be overlooking is that there is still a huge deficit. His program would cut 1985 's projected budget deficit by just $\$ 11$ billion. While that is a step in the right direction, it is, nevertheless, a tiny step. Even with the president's new plan, the government would still be in the red $\$ 169$ billion in 1987. And those are official administration numbers; other projections are much higher.

So, while we can applaud the president's first step and recognize that he can probably hold interest rates from rising dramatically for a while, we must also recognize that now is the time to use this temporary breathing space to really do something about the problem.* Interest rates are still 3 or 4 percent too high, based on historical averages, and until they come down, the future of cars and houses in this country will be in real jeopardy.

Second, our future is also clouded by what we at Chrysler have called the lack of a "level playing field" in international trade and, more specifically, in trade with Japan. Almost everyone recognizes that the yen-dollar disparity and

*Editor's Note: The prime rate stood at 11 percent on 19 March 1984 . By 15 August it had risen to 13 percent. 
the Japanese commodity-tax exemption on built-up vehicles sent to the United States translate into two very large trade advantages for Japanese automakers.

Regarding the tax issue, it is hard to really fault anybody for the Japanese advantage, but it is time to rectify it. The U.S. is practically the only country left in the world that relies primarily on income and property taxes for the bulk of its revenue. Since we are not going to change the tax code overnight, other solutions must be found to counter the structural cost advantage that the differences in our two tax systems inherently give the Japanese.

Again, it does little good to try to affix blame for the severe misalignment of the yen-dollar exchange rate. The effect, however, is very serious. With the advent of floating exchange rates in 1973, huge cross-border capital flows have become the norm. Since American interest rates have been high the last few years, the U.S. has become everyone's safe haven. In addition, the undervalued yen/overvalued dollar substantially reduces the cost of Japanese goods denominated in U.S. dollars-items like cars and trucks-and that advantage appears in the bottom-line profits for the Japanese.

While U.S. automakers were swimming in red ink, Japan's Big Four-Toyota, Nissan, Honda, and Tōyo Kōgyo-made a stunning $\$ 9$ billion in the last four fiscal years. Yet, according to an internal Chrysler study, without the yen-dollar imbalance and the Japanese tax advantage, they would have actually lost money. In other words, eliminate the disparity that exists between the yen and the dollar and cease the exemption of the Japanese commodity tax on cars headed for the U.S., and the seemingly invincible Japanese auto industry would have shown a loss in the last four years instead of reporting record profits.

Many feel these external obstacles, on top of our own internal obstaclesand we have a few-cannot be overcome. In fact, from daily readings of the Japan Times and weekly readings of the Japan Economic Journal, one gets the impression that the Japanese automakers think that Detroit is not worthy competition anymore. But I do not believe it. This year, the American auto industry will most likely regain its total production lead over the Japanese industry for the first time since we lost it in 1980. We also have the opportunity to plant the seeds for sustained, long-term growth. In order to do that, however, we in the industry must use 1984 to bargain on several fronts. We must use this pivotal election year to hammer out among several constituencies what I call a six-point "Compact for Automotive Revitalization," or "C.A.R." for short.

(1) We must, in this election year, demand that whomever we elect to federal office work to cut the deficit-cut it fast and cut it deeply. America, and the American auto industry, cannot live in a sea of red ink.

(2) We must move toward a level playing field by evening out the competitive differences that result from both the yen-dollar disparity and the lopsided 
differences between the U.S. and Japanese tax systems. (And, despite some highlevel meetings on this subject and a recent token strengthing of the yen, there has not been much real action.)

In fact, since November 9, 1983, the day when President Reagan and Premier Nakasone first got together in Tokyo, through today, the yen has strengthened only 4 percent-from 235 to 226 yen to the dollar. Until something is really done about moving toward a level playing field, restraints should be left in place.

(3) We must take further steps in this country to stimulate savings and investment. Since supply-side economics did not do the trick, we need to look down other avenues--perhaps expanded IRAs or Japanese-style tax-free savings accounts. Other options to aid industry might include taxing only the real part of capital gains, rather than including inflationary gains, or allowing faster depreciation on industrial investments that create jobs, paid for by eliminating the interest deduction on money borrowed for wanton corporate cannibalism.

(4) Management must do its part by having the discipline to invest in jobs and productivity, to keep toeing the line on quality even as production schedules increase, and to make a commitment to exercise restraint on pricing. Although many do not think that the auto industry has tried to keep prices down, data from the Bureau of Labor Statistics shows that, while the overall price of consumer goods has gone up 21 percent during the period of the voluntary restraints, the base prices of cars sold in America have gone up only 13 percent in the aggregate. Those higher numbers that some of our critics like to tout are average prices paid for new cars, and they are higher because the mix is richer today than it used to be. Put another way, people are now buying steak when they used to buy hamburger, but that does not mean we raised the price of either the steak or the hamburger.

(5) We must understand the wisdom of wage and benefit restraint at a time when the candy store looks ripe for the picking. A fair demand cannot be denied, but if the settlement in the upcoming UAW negotiations crosses that line, you can kiss the small-car business in this country goodbye.

(6) Finally, we must work to bring together a labor-managementgovernment partnership for competitiveness. Our friends in Japan have had such a partnership for a long time now, and their success is a testament to its effectiveness. Our success at Chrysler is just one small example of how it can also work on this side of the ocean. And the time to get moving is now. Too many American jobs depend on the continued health of the American auto industry. We cannot be so blasé about its long-term development and growth.

The elements of this "Compact for Automotive Revitalization" are of such importance that they almost scream to be campaign issues in the upcoming election. Some already are, but not always commensurate with their importance. If 
these issues are important to us-and I think they should be-then it is up to us to make them issues. It is up to us to put deficits and the level playing field on the front burner. It is up to us to get the politicians to listen.

And, I believe, it is also in the best interests of our friends in Japan to help out. After all, the lack of decisive action now will almost certainly spawn much more severe action later. If we can work together on these things, then I have no doubt that we can restore the U.S. auto industry to the world prominence that it deserves. 
PART II: ISSUES FOR DEBATE 



\title{
INDUSTRIAL POLICY FOR THE U.S. AUTO INDUSTRY: RECIPE FOR SUCCESS OR FAILURE?
}

\author{
James P. Womack
}

\begin{abstract}
"Industrial policy" is a fashionable term, but current debates about it seem to generate much smoke, some heat, and no light. Let me try to shed at least a little of the latter by defining this concept, tracing its origins, and examining the differing approaches to industrial policy currently being proferred by various groups in the U.S. This will be by way of background to a discussion of the prospects for devising a coherent and effective industrial policy for the U.S. auto industry.
\end{abstract}

A prime cause of confusion about the term itself is that different speakers have different things in mind. Those defining it most broadly include all actions of government that have any bearing on the health of industry, particularly in international competition. Thus, trade policy and macroeconomic policy (including government actions affecting interest rates, overall tax burdens, and exchange rates) are two key elements of industrial policy. A third element includes policies directly affecting products and the production process: sectoral tax burdens, product and process regulations, manpower and retraining policies, rules governing labor-management relations, rules governing industry structure, including vertical and horizontal integration and cooperation, and energy policy. However, many users of the term have only this third element in mind. They envision this set of government actions, if tailored to the specific needs of a sector, as a counterbalance to government policies-both domestic and foreign-that adversely affect the sector.

Industrial policy as a general concept, whatever its precise meaning, is yet another foreign import of recent years. The Japanese are commonly thought to. have devised sectoral strategies to build infant producers into world champions by means of targeted tax, trade, and credit policies. In Europe, each nation in the Common Market employs credit, tax, and manpower policies (often involving

James P. Womack is a Research Associate, Center for Transportation Studies, Massachusetts Institute of Technology. 
substantial subsidies) to keep its "national champions" from faltering in an integrated European marketplace where overt trade intervention to protect domestic firms is ruled out.

The various meanings of the term, its mixed origins, and the general lack of knowledge of the effects of foreign industrial policies can easily produce misunderstandings. For one, the role of Japanese industrial policy in pushing the Japanese auto industry beyond the take-off stage is easily overestimated. Much evidence suggests that, since the late $1960 \mathrm{~s}$, Japanese government policies toward the auto sector (including the desire to merge producers, government regulation of vehicle specifications, and sectoral tax policy) have been irrelevant or even harmful to the industry's export success. In Europe, while it is clear that industrial policy can make the shrinkage of a national industry more orderly, it is not clear that it can actually revitalize an industry slipping behind in competitiveness. (France provides the most recent examples where the steel and auto industries are being trimmed by a socialist government after massive subsidies and subtle market protections over many years failed to make their firms more competitive against European and Japanese competitors.) Thus, it is far from established that foreign "industrial policies" have ever demonstrated the efficacy that many American proponents of industrial policy attribute to them.

An additional, and perhaps the most important, source of misunderstanding about industrial policy lies in the widespread failure to assess proposed policies in light of the competitive weaknesses of U.S. industry. To take the auto case, the U.S. industry is in a far different situation from the infant Japanese industry or today's mature European industries. The Japanese government had a clean slate to work with as it sought to develop the Japanese industry, and a high-growth domestic marketplace in which to experiment. The Americans, in contrast, must deal with the vast scale of existing investments, the complex nature of automotive producers, the long period of time needed to learn new approaches to competition, and the maturity and volatility of the North American market. The European industry in the postwar period has been marked by brilliant product designs and significant export success in certain market segments. Strengths in these areas have bought time for European governments to deal with disadvantages in production costs and the need for rationalization in production systems. In the U.S., however, consumer demand over the past decade has shifted so dramatically away from both the traditional product size and design philosophy of the American producers that the industry must deal simultaneously with weaknesses in production systems and product designs.

In addition, taxes, exchange rates, and other macroeconomic policies are important competitive variables, but over the long term the internal functioning of an industry is surely more important in generating the dynamism and efficiency that ensure success. However, the competitive consequences of industry policies 
on industry structure, labor relations, and the types of products demanded by consumers, while crucial, are very hard to analyze, even when government officials and politicians know an industry well.

We must keep in mind, then, that the types of industrial policies we need may be very different from those of our competitor nations, and the challenge may be inherently greater in the U.S. if our national objective is to "catch up" or once more become dominant in automotive competition. Indeed, the mention of "catching up" raises an additional set of dilemmas for those who look to industrial policy for solutions because regaining competitiveness means different things and will have different consequences for the different groups involved in the debate over public policy.

For producers (defined broadly to include final assemblers, suppliers, distributors, bankers, and stockholders), the objective is to achieve an industrial revamping that restores profitability. This may mean production for the U.S. market in locations outside the United States, large-scale reductions in the domestic work force and its compensation level (even if production continues to take place domestically), or long-term protection. Thus, this definition of competitiveness centers on firms, but it does not necessarily have a national focus.

For labor, the purpose of industrial policy must be to preserve existing jobs, working conditions, and levels of compensation in the United States. This is without doubt a "national" focus, but it only represents one interest among many.

For government of ficials concerned with the industry revitalization, the objective of industrial policy will be to regain competitiveness by boosting productivity, spurring technical innovation, and improving product design and quality. This must be achieved, however, without the collapse of firms or massive employment reductions over the short term (either of which is politically intolerable). This is clearly a national focus, but only partially so since it may run contrary to the interests of consumers, other industrial sectors, unions, and environmentalists (as reflected in the sometimes contradictory actions of other government officials).

There is, thus, little indication of agreement about just how to pursue revitalization, and it is not just management at odds with labor or the industry as a whole at odds with government. Each assembler seems to have an approach of its own, and the various parts of government continue to emphasize very different goals. This is unfortunate, for the nature of American government is such that in order to establish a formal industrial policy, industry, labor, and the many divisions of government must be in broad agreement. 


\section{The Formal Policy Debate}

These conflicts of purpose and confusions about objectives, in combination with the strengthening American economy, no doubt account for the very modest range of formal industrial policy initiatives under active discussion in this election year. Nevertheless, the trauma of the period since 1979 has been such that the issue cannot simply be ignored, and the policy approaches likely to be embraced by the major parties in the general election are worthy of consideration.

The Reagan administration's primary proposal is a cabinet reorganization to produce a new Department of International Trade and Industry (or DITI) by merging functions of the existing Office of the Special Trade Representative and the Department of Commerce. The intent of the measure is to bring consistency to the current ad hoc policy rather than to create new government powers to guide industry. Thus, noncommercial responsibilities of the Department of Commerce, such as the Census and the National Oceanographic and Atmospheric Administration, would be sent elsewhere, and the Secretary of Commerce would double as the Special Trade Representative. The existing core of the Department of Commerce would be reorganized into an Office of Competitive Analysis. This office, in collaboration with sectoral councils of business, labor, and government representatives, would develop assessments of sectoral competitiveness and make suggestions (but only suggestions) on means of increasing competitiveness. Probably more important would be the "International Economic Competitiveness Impact Statements," prepared by the Office of Competitive Analysis for any federal regulation promising to have competitive consequences for American industry. These would presumably take their place beside environmental impact and costeffectiveness statements and would generally seem likely to constrain new government initiatives. Thus, the overall effect of this proposal seems to be that it would make government actions consistent and minimal for industries facing international competition.

The Democratic alternative is along the lines of House Resolution 4360, "The Industrial Competitiveness Aet of 1984." This bill is the legislative embodiment of the recommendations of the Industrial Policy Study Group, a committee including labor and "business Democrats" organized by Felix Rohatyn (an investment banker and the head of the Municipal Assistance Corporation in New York), Lane Kirkland (the AFL-CIO president), and Irving Shapiro (the retired chairman of DuPont). One element of the bill is a "Council on Industrial Competitiveness," which would be "quadripartite" (including business, labor, government, and public members appointed by the president and approved by the Senate) with a staff to perform competitiveness assessments of industrial sectors. These would presumably be similar to those of DITI's Office of Competitive Analysis but would go a step further by including plans for sectoral development. However, the Council 
would have no line authority and function only as an advisor to government on the competitive consequences of contemplated actions.

A second element of the bill is a "Bank for Industrial Competitiveness" that would be a market-rate lender dealing with situations where transaction costs and risks are high or "where no one in the financial community wants to crack heads" (in the words of the bill's drafter). In other words, it would function as a permanent loan board that would endeavor to revitalize faltering producers, or even a whole sector, by obtaining concessions from management, stockholders, lenders, suppliers, and labor in order to reach agreement on a restructuring plan in return for additional lending or loan guarantees.

Neither approach has any prospect for passage this year, and, in any case, one may wonder about their significance for the competitiveness of American industry. Both approaches are remarkably modest in comparison with the comprehensive industrial policies often ascribed to foreign governments. Industrial policy in its most comprehensive sense would tailor trade, credit, manpower, and tax policies to the needs of each sector. Even in its narrower sense as defined above, industrial policy would assess product and process regulations, energy policy, the rules of labor relations, and the rules of industry structure (including antitrust and organization of the financial system) in light of the competitive needs of domestic producers. At a minimum, this comprehensive policy process would endeavor to provide the fabled "level playing field" upon which the home team could compete against foreign rivals. Going further, it might even provide a home-team advantage in the case of industries viewed as particularly important to the national economy. By contrast, the DITI proposal only links trade policy to regulatory policy, and in a way not clearly specified. House Resolution 4360 seems only to link credit policy with intrasectoral agreements on restructuring plans. Trade, manpower, energy, regulatory, and structural policies fall quite outside its purview.

\section{The Unnoticed Evolution of de facto Industrial Poliey}

Given the lack of basic agreement in American society on means and objectives, it seems unlikely that "industrial policy" as a formal process will significantly affect the American auto industry, at least for many years. However, this is not to say that a de facto American industrial policy does not continue to evolve or, indeed, that it cannot help in a modest way to revitalize the U.S. auto industry even if its elements are not tightly coordinated. Over the next decade, this de facto policy will address three key issues: energy (mostly through adjustments to CAFE), trade (through the evolution of the VRA), and industry structure (through interpretation of the Clayton Act and other antitrust statutes). 
Energy policy looms as a key issue because the present structure of the Corporate Average Fuel Economy (CAFE) regulations interferes with the need and desire of the American-based producers to fully exploit their continuing advantage in the large-car segment of the market. This is the case, of course, only if current energy prices continue for another five or ten years, as many observers now believe they will. From the perspective of many in government, the abandonment of fuel-economy regulations would signal the end of a strategy for energy adaptation. For labor, CAFE in its present form is the key factor that would bar domestic producers from quickly moving to offshore sources for their small-car lines if the VRA is dropped or greatly relaxed in 1985. Thus, a complex negotiation will be needed to revise CAFE in a way that gives the industry the freedom it needs while acknowledging other concerns as well.

Trade policy is equally difficult to adapt to changing conditions. Domestic producers want the freedom to use offshore sources but worry about being innundated by foreign competition. Any sort of trade protection, however, becomes harder to defend as the industry begins to recover and produce high profits. Many members of the executive branch and Congress are determined to send, simultaneously, a signal to foreign producers that there is a limit to import penetration, or at least its rate of increase, and a signal to the domestic industry that it will be necessary to continue catch-up efforts. For labor, however, the problem is that the Voluntary Restraint Agreement is not enough. Its cap on finished units seems only to invite Fremonts, Smyrnas, and Marysvilles, plus component imports. That is, it protects some jobs at the assembler level but can offer little long-term help for most employees in the industry. In addition, the new Nissan and Honda assembly operations present a strong challenge to the UAW's ability to organize the industry. Local content is much preferred, but a workable scheme that does not touch off a trade war with the Europeans yet effectively blocks the Japanese and that can garner widespread political support has been elusive.

Rules on industry structure are perhaps the most complex policy issue. They are potentially far reaching in their impact, and yet their consequences are difficult to predict. However, with the approval of the GM-Toyota joint venture by the Federal Trade Commission, a proliferation of similar arrangements can be predicted. It seems likely, therefore, that the American auto industry will follow a path of internationalization in the years immediately ahead.

Although there is nothing in statute or even in American experience to connect these policy foci, my strong sense is that whether or not DITI or the Council on Industrial Competitiveness come into being, there will be a strong trend toward an ad hoc weighing of the competitive implications of government policy, especially in these three areas, in the years ahead.

If one believes, as I do, that the effectiveness of most foreign industrial policies is vastly overrated and that what goes on within the production system is 
more important to the long-term competitiveness of American industry than government twisting the knobs (including interest and tax rates) outside the industrial black box, then this newly emerging eagerness for government to think carefully about how its sector-specific regulations affect competitiveness of the American industry may be quite important. In addition, one of the characteristics of American government is that officials with different functions and at different levels are reasonably free to entertain such considerations, even when they do not find an explicit mandate in statute. A quick reading of the recent FTC decision on the GM-Toyota joint venture clearly shows this. Those commissioners favoring the venture justified it in terms of its ability to enhance the competitiveness of U.S. industry, even though there is nothing in the Clayton Act about "international competitiveness." The intellectual tide in this direction is now so strong that the commissioners opposing the measure found it necessary to treat this issue at length in their dissenting opinions-that is, to argue that the venture would not enhance American competitiveness. Whatever the merits of the FTC decision, it seems very likely that a similar mind-set will be applied to CAFE and the VRA. This can quickly yield a reasonably coherent, procompetitive policy without any central coordination or formal agreement among all parties about national aims.

Much evidence in recent American history suggests that broad movements of this sort do occur. The educational reforms in response to Sputnik (carried out largely at the local level without central direction) and the all-pervasive environmental movement of the early 1970 s are two prime examples. Thus, the prospects for the evolution of an implicit industrial policy that is more supportive of the American auto industry in its efforts to become competitive are bright. Having said this, however, let me close with the ancillary observation that even in the presence of a supportive, de facto industrial policy, the American industry's effort to once more become competitive in the world auto industry (an effort I believe to be well under way) will succeed or fail largely on the basis of what happens inside the industry; government policy will play only a supporting role. And if the American industry does succeed in self-revitalization, its success may well bring into question the efficacy of the automotive industrial policies of its competitor nations. 



\title{
THE JAPANESE TAX SYSTEM AND AUTOMOBILES
}

\author{
John Creighton Campbell
}

There is a prevailing impression in the American automobile industry, one well reflected by several remarks at the 1984 U.S.-Japan Automotive Industry Conference, that the Japanese tax system gives an unfair advantage to Japanese automakers. This impression is mostly based on false premises.

This brief report will set forth some basic facts about how the Japanese tax system affects automobiles. It does not attempt to draw a complete picture and is not based on original research or detailed data. Our overview will begin with the most frequently mentioned issue, the commodity tax, and will go on to discuss the overall shape of the Japanese tax system, tax burdens on corporations, estimates of the "tax differential" between Japanese and American cars sold in the United States, and the implications of high Japanese taxes on auto ownership.

\section{The Commodity Tax}

The Japanese national government charges a tax of from 5 to 30 percent on a varied list of items, including jewelry, appliances, musical instruments, boats, and automobiles. The current tax rate for automobiles is 23 percent for large cars, 18.5 percent for small cars, and 15.5 percent for midget cars, plus an additional tax on auto air conditioners. This tax is charged on all automobiles sold in Japan, on the basis of the manufacturer's selling price for domestic cars and the price at receipt for imports. It is not charged on exports.

Several arguments have been advanced to explain how the commodity tax system provides an advantage for Japanese exported automobiles. The simplest argument states that, because of the commodity tax, it is cheaper to produce cars for overseas than domestic markets, or that production for export is more profitable. Accordingly, the marketing patterns of Japanese automakers are "distorted" so that they export more cars than they would if there were no commodity tax.

John Creighton Campbell is Associate Professor of Political Science and Director, Center for Japanese Studies, The University of Michigan. 
This is not a logical proposition. Although the commodity tax is paid by the manufacturer as a matter of convenience in collection, its effect is identical to a sales tax. In fact, it is essentially the same as the U.S. liquor and tobacco taxes. The tax is passed on directly to the Japanese consumer. The price a manufacturer charges for a car leaving his factory is no different whether the car is sold in Japan or overseas, at least not for any reason connected with taxes. Export sales may indeed be more profitable, but that is simply because the Japanese domestic market is more price-competitive than overseas markets, partly due to quotas and partly to the fact that much of the competition overseas is with less-efficient manufacturers. A Japanese automaker will produce as many cars as he can sell profitably in the domestic market and as many as he can sell profitably overseas.

The apparent confusion about this point may result from an inaccurate understanding of import and export shares. It is true that the commodity tax causes a larger share of Japanese auto production to go to exports. If the system were abolished today, the price of all new automobiles in Japan would suddenly drop substantially. More Japanese could afford to buy a car, so total domestic sales would go up, and the export share would correspondingly drop. However, if one makes the safe assumption that the Japanese auto industry has or could quickly develop sufficient capacity to meet this new demand, there is no reason why its absolute number of exported cars would fall at all. Shares of domestic and export production in Japan are irrelevant to American automakers; it is only the absolute quantities of exports and their cost that matter.

\section{The Structure of the Japanese Tax System}

A more sophisticated argument about the commodity tax holds that the United States is disadvantaged because it relies more on direct taxes on individual and corporate income, which add to production costs, while the rest of the industrialized world has moved to indirect taxes on consumption. That means that American exports get taxed heavily once during production and again when consumed overseas; conversely, imports to the United States bear lighter productionrelated taxes overseas and lighter consumption taxes here. As the UAW testified before the House Ways and Means Committee in March 1983:

Under the GATT rules, indirect taxes can be rebated on exports and imposed on imports. Since these rules were written, taxes have risen substantially the world over. The U.S. tended to add to its direct tax burden while the Europeans and Japanese tended to increase indirect taxes. 1

${ }^{1}$ Quoted in materials provided by the UAW. 
This argument may or may not make good economic sense or be an important factor in American trade with Europe. However, it simply is not true for Japan. In the early postwar period, Japan experimented with both a "turnover tax" and a value-added tax, but both were abandoned primarily because of complaints from small business. The share of indirect taxes in total tax revenues has actually declined continuously, from 49 percent in 1955 to 29 percent in $1981 .^{2}$ More importantly, Japan's overall tax structure is much closer to that of the United States than to Europe in its reliance on direct taxation (see table 1). Since the mid-1970s, there has been considerable discussion about imposing a valueadded or other consumption tax, but nothing has been instituted so far.

The fact that the Japanese tax system relies on direct taxes to roughly the same extent as in the United States indicates that the commodity tax is unlikely to have a gross impact on economic behavior. This is not surprising: the commodity tax on automobiles amounted to just 1.1 percent of total tax revenues in fiscal year 1983, too small an amount to have much significance. Still, particularly given the widespread impression that Japanese government policy favors big business, the question of whether the tax burden shouldered by corporations is larger in the United States or Japan is worth investigating. Three sorts of data are available.

\section{Corporate Taxation in Japan}

As is of ten the case, data at the most macro level is the easiest to collect and interpret. As table 1 indicates, the Japanese rely much more heavily on the corporate income tax as a source of revenue than do other advanced nations. In some years, most recently 1978, the corporate tax has actually produced more revenue than the individual income tax, which would be unthinkable in the United States. Economists debate the extent to which corporate taxes are really passed on to consumers, and it is true that dividend income receives favorable tax treatment in Japan, but, despite these qualifications, there can be little doubt that a higher proportion of the costs of government is covered by business in Japan than in the U.S.

Corporate tax rates are a somewhat different matter. The higher share of taxes paid by companies in Japan is partially due to two factors: Japanese income tax rates are somewhat lower than in the U.S., at least at the lower and moderate income levels, and in many years Japanese companies have made higher profits. However, the rate at which those profits were taxed were very similar in the two countries, at least until recently. A 1981 calculation by the Japanese Ministry of Finance puts the average rate at 51.55 percent for Japan and 51.18 percent for

${ }^{2}$ Ministry of Finance statistics: Zaisei Tōkei, 1983 ed. 
Table 1

Sources of Tax Revenues, 1980

(percent of total tax revenue)

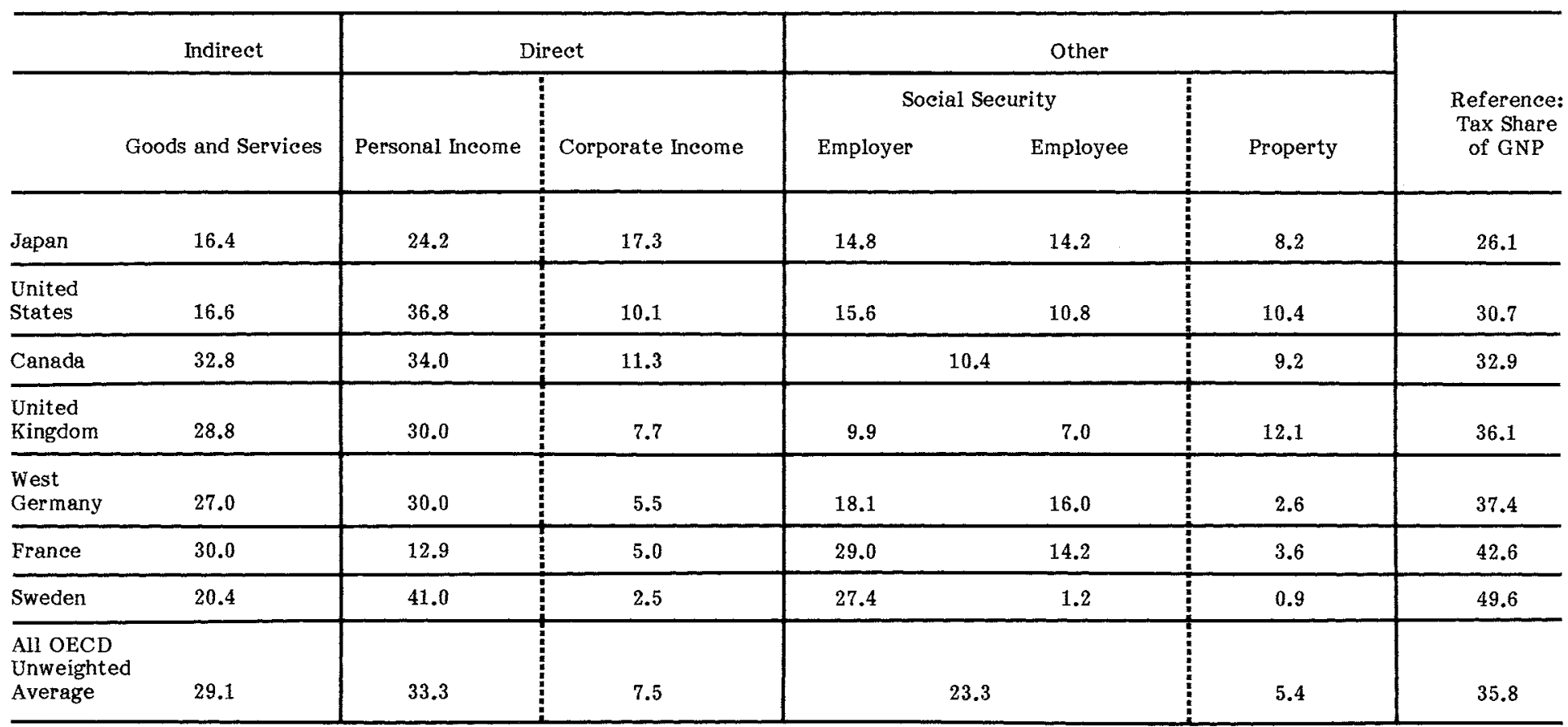

Source: Organization for Economic Cooperation and Development, "Revenue Statistics of OECD Member Countries, 1965-1981." 
the United States. ${ }^{3}$ These figures must be treated with caution. The accounting rules that determine what is a profit for tax purposes differ, corporate tax rates are lower for smaller firms in Japan (important in an industry like automobiles where much of the value is contributed by parts suppliers), and tax laws change rather frequently-Japanese corporate tax rates have been raised and American rates lowered since this estimate. Nonetheless, there is certainly no evidence here for a lighter burden in Japan.

Another angle on corporate taxation, covering the manufacturing sector only, is provided by a new study by the Congressional Research Service. ${ }^{4}$ The CRS used "discounted cash flow analysis," which defines the effective tax rate not as a percentage of profits but as the difference between the pretax and posttax return on investment (divided by the pretax return). The study itself is largely concerned with various rates of depreciation. In 1977, looking at national taxes only, the effective tax rate in Japan was indeed lower than in the U.S., 33.8 percent to 37.5 percent. After changes in the tax law, however, the most recent estimate is 35.8 percent for Japan and 25.3 percent for the United States. When state and local taxes on corporations are added in, the gap becomes much wider: 50.5 percent in Japan and 27.7 percent in the United States. As far as taxes are concerned, a dollar invested in manufacturing in the United States will bring a much greater return than in Japan-a point that should be of interest to Japanese auto firms.

It is beyond the scope of this article to wrestle with the implications of these three different analyses of corporate taxation. We observe only that the argument that consumption taxes have substituted for taxes on production in Japan, so that competing American companies labor under a cost disadvantage, does not appear to hold water.

\section{Auto Industry Taxes}

The figures cited above are averages for all corporations or for the entire manufacturing sector and do not necessarily apply to a specific industry such as automotive manufacturing. If the auto commodity tax were "rebated" in the sense that those revenues were somehow credited or refunded specifically to the

${ }^{3}$ Ministry of Finance figures cited in Jimmy W. Wheeler, Merit E. Janow, and Thomas Pepper, Japanese Industrial Development Policies in the 1980s: Implications for U.S. Trade and Investment (Croton-on-Hudson, NY: Hudson Institute, October 1982), p. 91.

${ }^{4}$ Jane Gravelle, "Comparative Corporate Tax Burdens in the United States and Japan and Implications for Relative Economic Growth," Congressional Research Service Report 83-117 E (6 September 1983). 
automotive industry, clearly automakers' costs would be reduced, and they would have a competitive advantage.

One way to investigate this possibility would be to compare effective tax rates in the automotive industry with other industries, but, unfortunately, the necessary data are not available. Another way is to examine the tax laws to see if there are specific provisions benefiting the auto industry directly or indirectly. Most taxes, of course, apply equally to all industries, but Japan has long had a system of targeted "special tax measures" to accomplish specific policy objectives.

If one looks at the history of government policy toward the automobile, several such "special tax measures" can be found. From 1955 to 1970, the automotive parts industry was a legally targeted industry and, as such, received certain tax concessions. Automakers themselves took advantage of tax breaks on certain kinds of machinery investment and of measures that temporarily deferred taxation on a portion of export earnings. Even today, there is a special tax provision to encourage robotization in small and medium industry that probably is helpful to smaller parts suppliers. ${ }^{5}$

In general, however, the importance of special tax measures has declined dramatically since the late 1960s. According to one estimate, the revenue loss from such measures amounted to 9.0 percent of total corporate taxation in 1972 , but just 1.9 percent in $1981 .^{6}$ Moreover, by and large the policy objectives have been switched from encouraging investment or exports to combating pollution and conserving energy. In short, under Japanese tax law, no mechanism exists by which commodity tax revenues could be transferred back to the automotive industry, directly or indirectly.

It might be noted that the proposal to institute an auto commodity tax in the United States, which has lately gained some currency among automotive industry executives, calls for a direct rebate. In a well-known 1983 article in the Harvard Business Review, John J. Nevin of Firestone Tire and Rubber called for a 17.5 percent excise tax on all cars sold in the U.S., which domestic makers could credit against their other taxes, including employee income and social security tax withholdings. ${ }^{7}$ This scheme amounts simply to a tariff. It would be a clear

$5_{\text {It }}$ is generally agreed, however, that tax policy was not a major factor in the diffusion of robots in autos and other industries. See U.S. General Accounting Office, "Industrial Policy: Case Studies in the Japanese Experience," GAO/ID 9311 (20 October 1982), pp. 24-29.

${ }^{6}$ Wheeler, Janow, and Pepper, op. cit., p. 98. See also the list of currently applicable tax measures on pp. 100-1. pp. 88-95.

7 "Doorstop for Free Trade," Harvard Business Review (March-April 1983), 
violation of GATT rules and, in any case, is unjustified as an "equalization" measure vis-à-vis Japan because, as we have seen, the Japanese commodity tax is in no sense rebated.

\section{Taxes Per Vehicle}

There is another, more direct approach to the question of the alleged Japanese tax advantage that has been taken both by Nevin and the Chrysler Corporation. ${ }^{8}$ This is to look into company accounts to determine the total taxes paid at every stage of producing and selling an automobile so that the tax burdens of American cars and of Japanese cars sold in the United States can be compared. Nevin compares small cars with a $\$ 5900$ factory price in the U.S. and concludes that the American car would carry $\$ 1550$ in U.S. taxes and a Japanese car only $\$ 920$ in combined Japanese and U.S. taxes - a difference of $\$ 630$. Chrysler includes sales and other taxes and finds that the burden on the average American car is $\$ 2500$, while the burden on the average Japanese car is $\$ 1850$, producing a $\$ 650$ difference. If these calculations are correct, the Japanese cost advantage would indeed be significant.

I do not have the necessary data to make an independent estimate of tax per vehicle. However, it is possible to raise questions about the methods employed in these two studies. Such an analysis of the Chrysler argument was carried out by Remy Haimet for the Joint U.S.-Japan Automotive Study at the University of Michigan, and his conclusions, plus a few additional observations, may be summarized here. First, it is questionable whether it makes sense to include the individual income tax and social security contributions paid by workers as part of the tax burden of the companies that employ them. Most objective analysts would simply call these wage costs. If employee-paid taxes were not counted in, the Japanese tax advantage as estimated by Nevin would drop to zero even before the tariff is collected on the Japanese import. Eliminating the employee-paid taxes from the Chrysler estimates still leaves a $\$ 350$ Japanese advantage in the tax burden before the tariff, or $\$ 200$ after the tariff.

The latter figure must further be qualified by a second observation. Chrysler's analysis is based on data collected from 1980 , which was a terrible year for the U.S. auto industry, and the Chrysler Corporation in particular. Sales and production were very low, and, since fixed costs (including various taxes) do not decline proportionally when production drops, manufacturing costs per vehicle rose. In practice, such increased costs are offset to some extent by the fact that in a year when there are no profits, no corporate income tax is paid, and tax Break," n.d.

${ }^{8}$ Ibid. and the Chrysler Corporation, "U.S. Tax Poliey Gives Japan an Unfair 
credits are earned for any losses incurred. In 1980, Chrysler received a tax credit of $\$ 39.5$ million, which amounts to almost $\$ 45$ for each car it produced in that year. However, in its estimates of the tax burden per American vehicle, not only did Chrysler neglect to subtract this $\$ 45$ tax credit, it added $\$ 200$ as an estimate of corporate tax in a "normal" year. ${ }^{9}$ Averaging corporate taxes over several years is a reasonable procedure, but these and other tax costs should then be applied to a normal year's volume of production.

However, Chrysler chose to examine 1980 , so those figures can be appropriately modified. If we use Chrysler's own estimate of $\$ 900$ in manufacturer's taxes, subtract the $\$ 200$ added in to represent the corporation tax in a normal year, and then subtract the $\$ 45$ corporate tax credit Chrysler actually received in 1980 , the burden of manufacturing taxes becomes $\$ 655$ per vehicle. Adding the dealer and sales tax of $\$ 550$, the total burden becomes $\$ 1205$. For a Japanese car, the total of manufacturing, import, and dealer and sales taxes is $\$ 1300$. A comparison shows a $\$ 95$ tax advantage for the American car.

Even granting the legitimacy of the Chrysler and Nevin approach, which is to include individual income and social security taxes paid by auto workers (in both assembly firms and parts suppliers) in the calculation of the total tax burden, serious problems remain. Chrysler finds that American auto workers pay about $\$ 1050$ in these taxes for every car they produce, and Japanese workers about $\$ 550-\mathrm{a} \$ 500$ difference and, thus, the greater part of the cost advantage. This "gap" is ascribed to differences in the tax system of the two countries. However, in the same calculations, Chrysler also estimates that only 40 manhours are required to build a car in Japan, compared to 90 manhours in the United States. This means that the Japanese firm can employ less than half as many workers as the American firm, so that, even if it paid exactly the same tax per worker, the employee tax bill per auto would be less than half of what it is in the U.S. Note also that American auto wages are higher, resulting in higher taxes even if rates are identical. If we wished to include employee-paid taxes in the burden but adjust these figures simply to take out the effect of higher Japanese productivity, leaving aside higher wages, it turns out that the Japanese tax advantage dwindles to only about $\$ 75$, even accepting Chrysler's handling of the corporate tax problem.

It is apparent that the much heralded $\$ 650$ Japanese tax advantage is really the product of a very special method of calculation. What would seem to be more reasonable approaches-either looking only at actual corporate taxes or at least assessing the impact of the tax system as if productivity in the two countries were the same-indicate that the Japanese "advantage" is negligible at most.

${ }^{9}$ Data supplied by the Chrysler Corporation to the Joint U.S.-Japan Automotive Study. 
I might add that these conclusions are generally consistent with the estimates made by Dr. Blaine $M$. Gordon, a financial expert formerly at General Motors, in an article published by the Japan Automobile Manufacturers' Association. ${ }^{10}$ Gordon examined the taxes paid by Japanese auto manufacturers in the 1976-79 period (excluding employee-paid taxes) and compared these with estimated taxes for American firms, adjusting for lower taxes paid by parts suppliers. He concluded that manufacturing taxes on a $\$ 10,000$ (U.S. retail) vehicle would be $\$ 720$ in Japan and $\$ 880$ in the U.S. This difference would be more than offset by the 3 percent American import tariff (here estimated at $\$ 195$ ), resulting in a slight tax advantage for the American car.

It must be emphasized that these matters are very complicated, and I make no claim for the reliability of these estimates. It is the Chrysler Corporation, John Nevin, and others connected with the American automotive industry who have argued that differences in the tax systems of the two countries have given the Japanese an unfair advantage and who call for revisions in American tax law to redress the inequity. Their own figures, however, reveal that the differences in taxes paid in the two countries are caused not by differences in the tax system but primarily by differences in wages and productivity, and even that calculation is based on questionable assumptions. The Japanese tax advantage is a non-issue.

\section{Tax Burdens on Automobiles in Japan}

Finally, one tangential but interesting point might be added. Japanese automotive executives were startled by these American allegations of a tax advantage because they have long perceived themselves as laboring under a grossly unfair tax burden within Japan. According to JAMA estimates, in 1983 almost 10 percent of total Japanese tax revenues was generated by taxes on automobiles, and this figure does not even count the corporate income and other taxes paid by manufacturers, parts suppliers, and dealers, let alone their employee's income taxes. It refers only to revenues from the fuel tax, the various sales, registration, and inspection taxes, and highway tolls. An individual buying an ordinary $1600 \mathrm{cc}$ car for $¥ 1.0$ million (about $\$ 4350$ at $¥ 230$ to the dollar) would pay an estimated $¥ 353,000$ (over $\$ 1500$ ) in taxes and fees for his first year of ownership, and a total of $¥ 1.343$ million (almost $\$ 6000$ ) over eight years. ${ }^{11}$ I lack comparable data for the U.S., but the Japanese figure is unquestionably much higher.

$10 "$ "A Comparison of the Tax Burden on Japanese vs. American Cars," The JAMA Forum 2.3 (1984): 23-26.

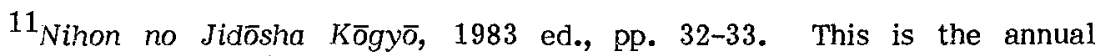
statistical yearbook of JAMA. Note that Japanese auto-related taxes subsequently were raised in Spring 1984. 
As indicated briefly in the discussion of the commodity tax, these high taxes borne by Japanese auto owners amount to a substantial disincentive to drive (as opposed to, for example, riding on the heavily subsidized railroads). These taxes, therefore, dampen the demand for automobiles in the Japanese domestic market, which is why Japanese automakers have consistently called for reducing these taxes and have bitterly complained when they were increased. If lower taxes allowed them to sell more cars in Japan, economies of scale would mean that their unit costs for every car produced, whether for the domestic or the export market, would be lowered. In this indirect sense, the differences between the Japanese and the American tax systems give American cars a slight competitive edge.

\section{Conclusion}

This article was provoked by the widespread argument that differences between the Japanese and American tax systems provide an unfair competitive advantage to Japanese cars sold in the American market. I have not collected new data: this analysis is simply a report and critique of information and arguments provided by other researchers. The findings may be summarized as follows:

1. The proposition that a commodity tax charged on domestic sales somehow leads to more exports is fallacious.

2. Unlike Europe, Japan does not rely heavily on consumption taxes.

3. Corporate tax rates are either about the same or higher in Japan than the U.S., depending on how they are measured.

4. The purported $\$ 620$ to $\$ 650$ tax advantage of Japanese imports is almost entirely due to wage and productivity differences-the individual employee taxes paid per vehicle are higher in the U.S. simply because employees are paid more and there are more employees per vehicle, not because of differences in the tax system.

5. If corporate taxes are properly included in the calculation, most of the advantage disappears.

6. If anything, Japanese automakers are disadvantaged by their tax system, in that the high taxes associated with owning an automobile in Japan have suppressed demand.

This article is not intended to be the final word on taxation in the American and Japanese auto industries. More complete data would allow detailed and consistent comparisons of tax burdens on the two industries and on the automotive "sectors" of the two societies. I have not dealt with the question of whether the higher taxes charged on large cars in Japan constitute an unfair nontariff barrier against American imports. Nor have I assessed the extent to which benefits may 
have aided the Japanese auto industry in the era when it was developing most rapidly, twenty to thirty years ago. Important questions about the implications of differences in tax systems for decisions about the location of production remain to be explored, as does the issue of whether further tax revisions to aid the American auto industry (such as by reducing the cost of capital) are justified regardless of what the Japanese do. Nonetheless, the issue most discussed today is the alleged tax advantage of Japanese imports. In my view, the considerations outlined above should be enough to dismiss that particular argument in the search for explanations of Japanese competitiveness. 



\author{
CURRENCY MISALIGNMENTS: \\ THE CASE OF THE DOLLAR AND THE YEN*
}

\author{
Shafiqul Islam
}

The dollar's dramatic rise in the last three years has initiated an international debate involving sharply conflicting views. The strong dollar has been largely behind the substantial loss of U.S. competitiveness in world markets, which has importantly contributed to the large and still growing U.S. trade and current account deficits. As a result, many analysts assert that the dollar is "overvalued." By contrast, some analysts focus their attention on the growing U.S. trade deficit with Japan and on the large and rising Japanese current account surplus. They conclude that the yen is "undervalued." Still others argue that terms like overvaluation and undervaluation are meaningless in a floating rate system because exchange rates are basically determined by market forces.

The purpose of this paper is to shed some light on this debate. Theory and empirical evidence both suggest two major conclusions. First, it does make sense to talk about the possible overvaluation or undervaluation of a currency even in a freely floating system. However, these concepts mean different things to different people. Therefore, unqualified use of these terms can lead to confusion and unnecessary argument. Second, empirical evidence on changes in international competitiveness as well as on the behavior of trade and current accounts suggests that the dollar is unusually strong but the yen is not especially weak.

\title{
Some Conceptual Issues
}

When is a currency in disequilibrium? To arrive at a sensible and operationally useful answer, it is first necessary to make a distinction between the

Shafiqul Islam is Senior Economist, International Research Department, Federal Reserve Bank of New York.

*This article is reprinted from the Federal Reserve Bank of New York Quarterly Review 8.4 (Winter 1983-84): 49-60. Reprinted by permission of the publisher. 
concepts of short-run or temporary equilibrium and long-run or what may be called fundamental equilibrium.

A sequence of short-run equilibrium exchange rates is determined by continuously shifting forces of supply and demand in the foreign exchange market. Although trade in goods and services contributes to changes in the balance of supply and demand of foreign exchange, trade in financial assets, often speculative in nature, dominates the short-run dynamics of this market. And market rates change constantly as market participants assess and reassess all relevant new information. Since transaction costs are small and buying and selling go on at all times of the day, the foreign exchange market is in the process of clearing virtually continuously. Thus, for all practical purposes, it is a close approximation to treat market exchange rates as short-run equilibrium exchange rates, although we know that strictly speaking not every rate quoted during a trading day represents an equilibrium.

A long-run equilibrium exchange rate, by contrast, is determined only when the world economy as a whole is in equilibrium and all other economic variables are also in equilibrium. In this kind of general equilibrium, markets for assets, goods, and labor all clear in the sense that supply equals demand. In addition, all expectations are realized and all relative prices remain constant.

This notion of equilibrium, although useful in theory, does not have a counterpart in the real world. The world economy is continuously adjusting, but of ten slowly, to new shocks, and therefore it is questionable whether it could ever be in an overall long-run equilibrium. For example, slow and lagged adjustments in the goods markets and in the current account of ten lead to swings in market exchange rates that may persist over extended periods at times. In addition, the long-run equilibrium values of all economic variables, including exchange rates, are also changing over time, sometimes very sharply. Market exchange rates are, therefore, almost always overshooting or undershooting long-run equilibrium exchange rates which are changing as well.

Thus, deviations from long-run equilibrium represent a normal state of affairs, and they could be persistently large at times. These deviations may simply reflect slow adjustments in other markets rather than any malfunctioning of the exchange market per se.

But there are times when some may consider the short-run volatility or even the medium-term swings in market exchange rates as excessive and not consistent with changes in underlying economic and financial conditions (fundamentals). Exchange rate swings may also reflect a relative absence of stabilizing speculation or even the presence of destabilizing speculation. In extreme cases, 
market exchange rates may behave like speculative "bubbles." 1 Admittedly, it is often difficult to determine whether the market is being driven by destabilizing speculation or is just responding, with some uncertainty, to so-called economic fundamentals. This is so because the foreign exchange market is essentially a speculative market, and there is no consensus, even among economists, which variables represent fundamentals, let alone how to assess their linkages with exchange rates. ${ }^{2}$

The distinction between the two concepts of equilibrium helps shed light on a number of aspects of the current currency debate. For example, it appears that those who believe that the dollar cannot be in disequilibrium in the current floating rate system are essentially arguing that the dollar is almost always in shortrun equilibrium. They are also expressing the view that the market rate reflects all available information and the market assessment of economic fundamentals is more accurate than that of anyone else. ${ }^{3}$

${ }^{1}$ Market observers and policy practitioners of ten voice their concern with bandwagon and other destabilizing speculative behavior in the exchange market. Academic economists have also recognized this possibility long before the advent of the current float. Nurkse, for example, wrote in 1944: ". . a anticipatory purchases of foreign exchange tend to produce or at any rate to hasten the anticipated fall in the exchange value of the national currency, and the actual fall may set up or strengthen expectations of a further fall ... Exchange rates in such circumstances are bound to become highly unstable, and the influence of psychological factors may at times be overwhelming." R. Nurkse, International Currency Experience: Lessons of the Interwar Period (League of Nations, Princeton, New Jersey, 1944).

Recently, Dornbusch expressed a similar view, "The idea of a bubble is worth recognizing because it emphasizes that there is no tendency for efficient capital markets to force a rate toward its fundamental value ... There is no reason to assume that the present value of the dollar does not represent such a speculative trap" (page 7). R. Dornbusch, "U.S. International Monetary Policies," a paper presented to the Board of Governors of the Federal Reserve System, September 30,1982 .

${ }^{2}$ James Tobin has aptly summarized the problem, ". . no one has any good basis for estimating the equilibrium dollar-mark parity for 1980 or 1985, to which current rates might be related. The parity depends on a host of incalculables-not just the future paths of the two economies and the rest of the world but the future portfolio preferences of the world's wealth owners..... In the absence of any consensus on fundamentals, the markets are dominated-like those for gold, rare paintings, and-yes, often equities-by traders in the game of guessing what other traders are going to think." See J. Tobin, "A Proposal for International Monetary Reform" (Cowles Foundation Paper No. 95, Yale University, New Haven, 1980).

${ }^{3}$ A recent expression of this view comes from Treasury Secretary Donald Regan: "In a floating exchange rate system, there can be no correct value to any currency other than the value given to a currency through market transactions" (quoted in Washington Post, February 23, 1984). Secretary Regan, however, also believes that ". . . it is confused thinking to describe the dollar as overvalued." 
Those who believe that the dollar is overvalued do not necessarily dispute the view that the dollar is almost always in short-run equilibrium. But they stress the point that the dollar may be severely out of line with the likely range of longrun equilibrium values. Although this concern sometimes focuses on the persistence of deviations from long-run equilibrium per se, and some may have misgivings about the market assessment of fundamentals, the real issue is of ten the macroeconomic and distributional costs that these deviations induce. The focus of the concern and the assessment of the costs involved, however, vary a great deal, and so do the qualitative judgment and quantitative assessment of currency misalignments.

Thus, terms like "overvalued" and "undervalued" in and of themselves are nebulous, but they do reflect someone's judgment that the going rate is undesirable for one reason or another. To some, the dollar is overvalued because it has led to a substantial loss of international competitiveness of U.S. manufacturing. Certainly, the industries that have been adversely affected consider the dollar overvalued. The large and deteriorating trade deficit and the loss of jobs resulting from this erosion of U.S. competitiveness are seen as confirmation of the view that the dollar is overvalued even from a national standpoint.

Many European analysts and officials consider the dollar overvalued because of the increased import costs and the inflationary impact of the associated depreciation of their currencies. The argument that the dollar deepened the European recession by inducing the authorities to raise interest rates is sometimes advanced as further evidence indicating the overvaluation of the dollar. The heavily indebted less developed countries (LDCs) view the dollar as overvalued because it has increased the burden of debt servicing substantially since most of their debt is denominated in dollars.

Thus, there are many groups at home and abroad that have been adversely affected by the current strength of the dollar, and hence they consider the dollar overvalued. However, significant exchange rate changes-equilibrating and disequilibrating ones-are always going to induce costs for some groups and lead to the complaint that one currency or another is misaligned. In the recent period, the concept of an overvalued dollar, for some, simply expresses the fact that a strong dollar is costly to them in one way or another.

The strong dollar, however, generates not only costs but benefits as well. The main beneficiaries of the strong dollar are consumers in the United States and foreign competitors of U.S. producers. The strong dollar has also significantly contributed to the achievement of one of the major policy objectives in the United States-the reduction of inflation. These examples again illustrate the distributional aspect of changes in exchange rates. 
There is, however, a second and quite different way of looking at the concept of currency misalignment. Some analysts may consider the dollar overvalued from the standpoint of resource allocation costs rather than a distributional concern.

In their view, the current strength of the dollar is unsustainable, and hence resource allocations and global adjustments resulting from the strong dollar are temporary and likely to be reversed when the dollar declines. They believe that the strong dollar has been causing hardship in otherwise profitable industries in the United States and perhaps providing incentives for inefficient industries to spring up abroad. These resource allocations and reallocations are, therefore, unnecessarily costly and should be prevented.

An associated theme is the following. If the current levels of the dollar are ultimately unsustainable (because the large and growing U.S. current account deficits cannot be financed indefinitely) but nevertheless persist over the medium term, there may be a protectionist fallout in the United States. A variety of protectionist measures may be sought that would undermine the progress made over the past three decades toward a liberal global trading environment. Thus, persistent currency misalignments can impose real costs by reducing the economic efficiency that stems from a global expansion of free trade.

If unsustainable exchange rate movements are costly from the standpoint of efficient allocation of international resources, then it is important that these movements be detected and their magnitude be estimated. This is, in fact, the way most economists view the issue of currency misalignments. Although they usually define misalignments in exchange rates as deviations from long-run equilibrium values, many conceptual and practical problems have discouraged the use of general-equilibrium models of the world economy for calculating long-run equilibrium exchange rates. Instead, simple rules of thumb involving the concept of purchasing power parity (PPP) and considerations of current account balance are widely used to detect currency misalignments and sometimes to offer quantitative estimates. These approaches are, however, beset with many conceptual and practical problems as well, especially if they are used mechanically.

\section{Assessment of Currency Misalignments}

Attempts to detect disequilibrium in current exchange rates through PPP calculations must assume that, while the economy is suspected to be in long-run disequilibrium today, it was in long-run equilibrium or at least much closer to it in the chosen base period. In other words, PPP methodology essentially ignores two crucial insights that emerge from theory, namely, (1) observed rates are almost never in long-run equilibrium and (2) long-run equilibrium real exchange rates do 
change over time. This methodology also requires the use of a price or a cost index, and estimates of misalignments are of ten very sensitive to this choice.

A second approach is to define an approximately balanced current account, sometimes over a business cycle, as a long-run equilibrium condition. It has some practical appeal because it implies an absence of any net inflow or outflow of savings, and hence an absence of a redistribution of wealth between the country and the rest of the world. However, this notion of long-run equilibrium neither holds up to historical serutiny, nor is based on first principles of economics. The United Kingdom, for example, ran surpluses in its current account continuously between 1870 and 1914. Between 1946 and 1970, the U.S. current account was in surplus in all but three years. These persistent "imbalances" did not necessarily point to any serious macroeconomic disequilibrium.

In principle, any current account imbalance is sustainable and optimal if it reflects the saving-investment decisions of rational individuals and profitmaximizing firms. In other words, if current account deficits and surpluses result from or lead to matching and voluntary private trade in assets, then those external "imbalances" are both sustainable and optimal. This implies that there need be no macroeconomic problem if a country with a higher propensity to save or with a lower rate of return on investment at home runs current account surpluses for long periods of time.

Although mechanical applications of PPP and current account considerations can lead to misleading conclusions, judicious use of information on changes in international competitiveness, as well as careful analysis of current account behavior, can prove very useful in assessing currency misalignments. From a practical point of view, it is more tractable to view currency misalignments as deviations from currency values that are sustainable over the medium term rather than as deviations from the elusive long-run or fundamental equilibrium exchange rates.

A sustainable exchange rate can be thought of in a very broad manner: it is a rate that can be sustained over the medium term by policies that are appropriate from the point of view of efficient allocation of international resources. It is important to consider the appropriateness of policies. Even if a currency value can be sustained by inappropriate policies, it could be considered unsustainable because inappropriate policies themselves should be viewed as unsustainable.

A sustainable currency value is, therefore, one that can be maintained by government policies that are appropriate and sustainable in the sense of being consistent with such common national goals as stable economic growth, low inflation, and low unemployment. Assessing whether an exchange rate is sustainable from this point of view is not an easy matter, especially if distributional considerations-both intranational and international-are brought to bear on this 
judgment. For example, policy goals or policy mixes of a large country, even if deemed appropriate by its residents, may well be considered undesirable by its trading partners.

A careful analysis of changes in international competitiveness and the behavior of relative current accounts, however, can help detect extreme deviations from sustainable exchange rates. In less obvious situations, these types of information can contribute importantly to public discussion of, and private negotiations on, currency misalignments even if noneconomic considerations ultimately determine the nature of government policies. For example, if currency appreciation leads to substantial losses in a country's international competitiveness, it may suggest that the current value of the currency is unsustainable.

A narrow focus on conventional measures of international competitiveness, however, could be misleading. Changes in competitiveness may reflect structural shifts in the economy and hence may not indicate that the going exchange rate is unsustainable. Thus, it is necessary to supplement this type of information with a more comprehensive analysis of the country's "underlying" external payments position.

This requires a judgment on how large a current account surplus or deficit can be considered sustainable, given the medium-term saving/investment behavior of the country in relation to its trading partners. It is also necessary to take into account temporary and cyclical factors that may be influencing the present and prospective behavior of the current account and the capital account of the country's balance of payments. If the present and future current account balance of the country appears unsustainable over the medium term, even after accounting for factors other than the exchange rate, then the going exchange rate can be considered unsustainable.

Again, a thorough analysis of this type, especially if it is to be consistent on a multilateral basis, requires modeling the linkages among major economic variables as well as a great deal of judgment. However, less formal analysis can prove useful in extreme cases. For example, a rapidly deteriorating current account deficit is unsustainable if it points to a rising foreign debt/GNP ratio that the country will be unable or unwilling to maintain after a certain point. Or, if a large and deteriorating current account deficit reflects policies that are inappropriate and unsustainable from the standpoint of the medium-term objectives of the country and/or the international community, then the external imbalances can be viewed as unsustainable.

The rest of the paper is devoted to an assessment of the current exchange rates of the dollar and the yen along these lines. Particular attention is paid to the view that the yen is undervalued. Our assessment relies on an examination of various available measures of international price and cost competitiveness 
supplemented by an informal, albeit careful, analysis of the behavior of the current accounts of Japan and the United States.

\section{The Yen Problem}

There are two versions of the argument that there is a yen problem. One version simply claims that the yen is undervalued. The other version is more specific; it holds that the dollar is more overvalued against the yen than any other major currency. That is, there is a special yen-dollar imbalance that cannot be explained solely by the dollar's overall strength.

Japan's large and rising trade and current account surpluses are seen as prima facie evidence for an undervalued yen. Japan's gains in international competitiveness against the United States as well as the large and growing U.S. trade deficit with Japan are interpreted as evidence suggesting a special yen-dollar imbalance.

For example, in April 1983, Fred Bergsten of the Institute of International Economics (IIE) stated,

Quantitatively the dollar-yen misalignment is more severe than the misalignment between the dollar and any other major currency. . . . U.S. international price competitiveness deteriorated against Japan by over 70 percent in four years. Is it any wonder that the U.S.Japan trade imbalance has soared to record levels and that a major crisis exists in economic relations between the two countries? . . . the dollar is overvalued against a number of important currencies, but it is more overvalued against the yen than against the others. ${ }^{4}$

More recently, The Economist (December 3, 1983, page 15) expressed its view in this way.

Overprotected farmers and an undervalued yen both anger Japan's trading partners, especially the Americans. . . . This cheapness of the Japanese currency and dearness of the American one can go a

${ }^{4}$ Testimony before the Senate Foreign Relations Committee, pages 6-7. However, John Williamson, also of the IIE, did not identify the yen as particularly weak in the subsequent monograph, "The Exchange Rate System" (October 1983).

The Organization for Economic Cooperation and Development (OECD), in its December 1983 Economic Outlook (page 8), comes close to identifying a separate yen problem: "Exchange rates, assessed on the basis of current account prospects, have seemed out of line, with the dollar high and the yen, in particular, low." 
long way towards explaining why Japan is headed for a currentaccount surplus of $\$ 25$ billion this year and America a deficit of $\$ 40$ billion.

In what follows, these views on the dollar and the yen exchange rates are assessed on the basis of the data on changes in competitiveness and on movements in the current account. The major conclusion is that the dollar appears to be unusually strong, but the yen is not particularly weak. Japan's recent gains in competitiveness against the United States have resulted from an overall strength of the dollar, and not from any overall weakness of the yen.

\section{Changes in Competitiveness}

Changes in international competitiveness are examined in a number of different ways. These changes are estimated for both the economy as a whole and for the manufacturing sector. Data on both price competitiveness and cost competitiveness are used. The calculations are performed for the United States, Japan, and to facilitate comparison Germany and France. Changes in competitiveness are computed on a trade-weighted (effective) basis for all four countries as well as vis-à-vis the United States for the other three countries.

The nominal trade-weighted dollar started its current upward swing in late 1980. But the average trade-weighted value of the dollar did not rise in 1980 from its level in 1979. Rather than choosing 1980 as a reference period, we take a long-run view and compare recent levels of exchange rates and competitiveness with their corresponding averages for the entire 1974-80 period. This averaging minimizes the effects of peculiarities of particular years on the broad conclusions of this analysis.

The year 1983 is chosen as the terminal period for the aggregate economy. For manufacturing, data availability dictates that we use 1983-II as the terminal period. Later we argue that our principal qualitative conclusions are essentially invariant with respect to any reasonable choice of these base and terminal periods.

Chart 1 presents some preliminary evidence in support of the view that the yen is not weak but that the dollar is strong. The appreciation of the inflationadjusted trade-weighted dollar that began in late 1980 continued through 1983 and the value of the dollar in 1983 was much higher than its 1974-80 average level (top panel). ${ }^{5} \quad$ By contrast, the inflation-adjusted trade-weighted yen appreciated

5 This index uses weights from the IMF's multilateral exchange rate model (MERM) for 11 major countries. Wholesale price indexes (WPI) are used in measuring inflation. 
Chart 1

\section{Real Exchange Rates}

Index $1974-80=100$
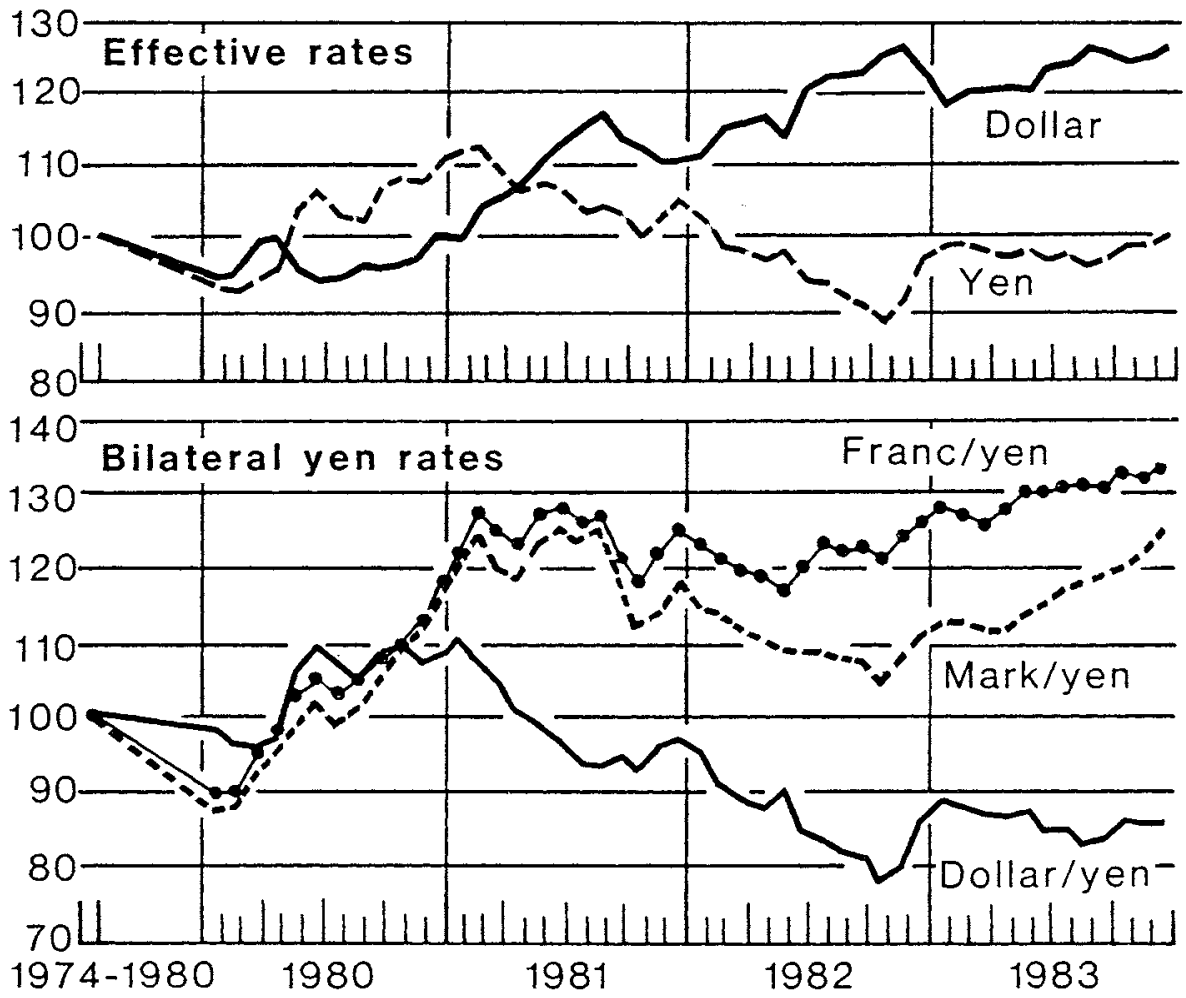

Wholesale prices have been used to adjust for inflation differentials. Weights for effective rates are derived for eleven major countries from the IMF's multilateral exchange rate model (MERM). 
sharply in 1980 and then more than offset this appreciation by depreciating until late 1982. The substantial depreciation of 1981-82 has been partly responsible for the international concern on the weakness of the yen. The yen, however, appreciated sharply in late 1982 and, in contrast to the dollar, remained in 1983 near its average during 1974-80.

The bottom panel of the chart points to the overall strength of the dollar rather than to any overall weakness of the yen as a source of Japan's recent gains in competitiveness against the United States. The chart shows that, when compared with 1974-80 averages, the yen is significantly weak in inflation-adjusted terms vis-à-vis the dollar (because of the overall dollar appreciation), but it is very strong against the German mark and the French franc. These observations are confirmed and further elaborated by additional evidence summarized in the table.

Bilateral competitiveness. The major observations on bilateral exchange rates and bilateral competitiveness of Japan vis-à-vis the United States can be summarized as follows:

In 1983, the yen was 4 percent higher against the dollar than in 1974-80 on average. The German mark, however, was 15 percent lower and the French franc was 40 percent lower.

When adjusted for wholesale price inflation differentials, the yen does show a depreciation of 13 percent against the dollar. The mark, however, depreciated over 25 percent and the franc over 30 percent. Thus, Japan's gain in overall price competitiveness against the United States has been substantially less than that of Germany and France.

In manufacturing, Japan and Germany made substantial, but similar, gains against the United States both in terms of export price competitiveness (30 percent) and labor cost competitiveness ( 20 percent). France's gains have been even greater. But note that, while France's and to a lesser extent Germany's competitive advantage against the United States can be attributed to the depreciation of their currencies, Japan's advantage is more than accounted for by the relatively slow growth of its prices and costs. For example, if currency values remained at their 1974-80 averages, Japan's gains in export price competitiveness would have been even greater than 30 percent, whereas Germany's and France's gains would have been a great deal less.

Effective competitiveness. The evidence on changes in exchange rates and competitiveness on a trade-weighted basis (table) can be summarized as follows:

Relative to 1974-80 averages, the yen was, in fact, as strong as the dollar in 1983. Both currencies had appreciated around 23 percent. By contrast, the mark was over 10 percent stronger and the franc was around 27 percent weaker. 
Changes in Exchange Rates and Competitiveness: Aggregate Economy (1983) and Manufacturing (1983-11)

In percent; $(+)$ indicates a loss of competitiveness

\section{Changes from $1974-80$ period}

United

States

France

France

States

Japan Germany

France

\section{Bllateral competitiveness}

\section{Aggregate economy:}

Nominal exchange rate (dollar price of the currency)

* Real exchange rate

$\begin{array}{lrrr}- & 6.3 & -14.7 & -40.5 \\ - & -13.4 & -25.7 & -33.6 \\ & & & \\ - & -29.6 & -31.9 & -35.3 \\ - & -20.6 & -21.7 & -28.1\end{array}$

$\begin{array}{llll}- & -6.5 & -28.5 & -44.2 \\ - & -16.7 & -30.2 & -35.3 \\ & & & \\ - & -27.8 & -35.4 & -37.5 \\ - & -16.2 & -29.1 & -34.1\end{array}$

+Export price competitiveness

$\ddagger$ Labor cost competitiveness 
As far as nominal rates are concerned, it is the strength of the yen rather than its widely perceived weakness that clearly emerges from the data.

When the relatively low inflation in Japan is taken into consideration, Japan's gains in aggregate price competitiveness in 1983 turn out to be negligible (1 percent). During the same period, the United States incurred a loss of 23 percent in overall price competitiveness. Germany and France, on the other hand, show substantial gains in competitiveness, about 8 percent and 20 percent, respectively.

The comparisons above refer to price competitiveness for the aggregate economies. But what about manufacturing competitiveness on a trade-weighted basis? According to the IMF index on manufacturing price competitiveness, Japan in 1983-II was where it was on average during 1974-80, while Germany had gained 5 percent and France 9 percent. According to the Morgan Guaranty index, ${ }^{6}$ however, the manufacturing sectors of all three countries appear to have made similar gains (between 6 to 8 percent) in price competitiveness. By contrast, manufacturing price competitiveness in the United States declined by over 20 percent.

Finally, as regards changes in labor cost competitiveness in manufacturing, Germany and especially France again come way ahead of Japan, whose gains in competitiveness turn out to be minor. Again, the United States shows a dramatic loss, over 25 percent.

Sensitivity of the results to the choice of the base and terminal periods. It could be argued that the base period 1974-80 goes too far back in the past, that it biases the conclusions by including information of little relevance today. Instead, it would be more instructive to see how competitiveness has changed since the dollar began its rise in 1980. Further investigation, however, suggests that the principal qualitative conclusions of the above analysis do not depend on the choice of $1974-80$ as the base period although the quantitative estimates are sensitive to such a choice.

The table summarizes the data taking 1979-80 (the period immediately preceding the rise of the dollar) as the base period. This change in the base period does not affect any of the above qualitative conclusions. The loss of U.S. competitiveness now looks even more dramatic, and Japan's gains in competitiveness appear even less significant. Germany and France continue to show substantial gains in competitiveness.

${ }^{6}$ Of the two Morgan Guaranty indexes, this one takes into account competition in third markets (World Financial Markets, August 1983). Morgan Guaranty regularly publishes another index which shows Japan to be slightly more competitive than Germany. This latter index does not take into account competition in third markets. 
To provide a sense of the robustness of these conclusions, two other sets of computations were carried out by using period intervals unfavorable to our principal conclusions. First, an attempt was made to see how weak the yen was vis-àvis the dollar in 1982-III, compared with the 1974-80 average. The 1982-III quarter was characterized by the weakest yen against the dollar since 1980 . We find that the real exchange rate of the yen was 18 percent lower in 1982-III than the 1974-80 average, whereas the mark and the franc were around 28 percent lower.

On a trade-weighted basis, the pattern is the same-the yen shows a depreciation of 8 percent in real terms against a depreciation of 12 to 14 percent for the other two currencies. Thus, even when the yen hit its low of the recent period, Japan's gain in overall price competitiveness against the United States and on a trade-weighted basis was smaller than that of Germany and France.

The other computation involves measuring the extent of depreciation of the yen since 1978-III, the quarter characterized by the strongest real effective exchange rate of the yen during the last decade. Between 1978-III and 1983, the yen depreciated around 28 percent against the dollar in real terms. The corresponding figure is about the same for the mark and is around 33 percent for the franc.

In real effective terms, however, the yen depreciated around 13 percentslightly less than the franc (15 percent) but slightly more than the mark (10 percent). So, measuring from the yen's peak in the floating period, the yen is somewhat weaker in real terms than the mark on a trade-weighted basis but not vis-àvis the dollar. However, it would be misleading to use this evidence from a period as brief as one quarter to argue that the yen has become a relatively weak currency. It is especially unwarranted in this case because the yen was unusually strong in the third quarter of 1978 , a period of great speculative instability in the exchange markets.

Evidence on competitiveness, therefore, does not support the view that there is any overall weakness of the yen or that the yen is undervalued. It does, however, suggest the dollar is unusually strong. This implies that the yen's weakness against the dollar (or, more precisely, Japan's gains in competitiveness against the United States) reflects the overall strength of the dollar rather than any overall weakness of the yen.

This assessment implicitly assumes that the yen was not seriously undervalued on average during 1974-80. It could be argued, however, that the yen was already undervalued during the broad sweep of 1974-80.

When the base period is shifted to the sixties, evidence on competitiveness does not point to any undervaluation of the yen during 1974-80. In fact, conventional measures point to an overall loss of competitiveness for Japan during the 
seventies. It is possible that the available measures of competitiveness are faulty and do not capture the "true" changes in competitiveness. Besides, as argued earlier, changes in competitiveness-manufacturing or economy wide-do not tell the whole story about currency misalignments. A broader macroeconomic perspective on the yen can be obtained from considering the behavior of the Japanese current account.

\section{Current Account Considerations}

As explained earlier, current account imbalances by themselves are, at best, an imperfect guide to detecting the presence of currency misalignments. One needs a judgment as to how large an external surplus or deficit can be considered normal or sustainable, given the pattern of the country's saving and investment as well as policy objectives over the medium term.

Thus, a persistent surplus in the Japanese current account per se does not suggest any undervaluation of the yen. In fact, many argue that by the early seventies Japan became a natural capital-exporting country, and a persistent underlying, if not actual, current account surplus is normal for such a country. ${ }^{7}$

Although a current account surplus in and of itself may not point to an undervalued currency, a rapidly growing and/or persistently large surplus may. This was, however, not the case in Japan during the seventies. Japan's current account was neither persistently in surplus nor growing every year but went through wide swings between surpluses and deficits. During 1974-80, Japan had surpluses in three years and deficits in four years.

Moreover, the average size of the Japanese surplus was not very large. Japan had an average surplus in its current account of only 0.13 percent of GNP during 1974-80. This was moderately higher than the U.S. figure (0.03 percent) and substantially less than that of Germany ( 0.57 percent) and that of the United States during the sixties ( 0.73 percent).

Thus, the behavior of Japan's current account during 1974-80 does not suggest that the yen was undervalued during that period.

${ }^{7}$ After the midsixties, Japan turned from being a capital importer to being a capital exporter in its long-term capital account. In addition, since the first oil shock, the private investment rate as well as overall economic growth has declined significantly in Japan. The decline in the private saving rate, however, has been much smaller. For fuller discussions, see R. I. McKinnon, "Exchange Rate Instability, Trade Imbalances, and Monetary Policies in Japan and the United States," in P. Oppenheimer (ed.), Issues in International Economics (Stocksfield, England: Orill Press Ltd., 1980); and M. Yoshitomi, "An Analysis of Current Account Surpluses in the Japanese Economy," in E. R. Fried, P. H. Trezise, and S. Yoshida (eds.), The Future Course of U.S.-Japan Economic Relations (The Brookings Institution, Washington, D.C., 1983). 
Does the yen appear undervalued now if viewed in light of the current and future path of the Japanese current account? Since the Japanese current account surplus is expected to be much larger than that of any other industrial country in 1983-84, it could be argued that the yen is now more undervalued relative to other major nondollar currencies in the sense that its current account surplus is large, it is growing, and it is unsustainable.

A number of facts may help put this view in proper perspective. First, the Japanese current account surplus was around 0.5 percent of its gross domestic product (GDP) in 1981-82, and it rose to around 2 percent of its GDP in 1983. In 1984 , the surplus is likely to rise somewhat in dollar terms, but not significantly as a percentage of GDP. The perception that the recent increase in the Japanese surplus results from a boom in Japan's exports helped by an overall weakness of the yen is, however, incorrect.

The dollar value of Japan's exports increased 18 percent in 1981 (without a matching increase in imports), turning the 1980 current account deficit of over $\$ 10$ billion into a surplus of $\$ 5$ billion. But in 1982 , a year in which the global criticism of Japanese trade practices as well as its financial and exchange rate policies became intense, Japan's exports declined 8 percent in dollar terms, leading to a slight shrinkage of its trade surplus. Both global recession and growing protectionism appear to have contributed to this drop in Japanese exports.

In 1983, exports recovered sharply, in both volume and dollar terms. But the dollar value of Japanese exports was still lower in 1983 than it was in 1981. Viewed in light of Japanese trade performance in 1981 and 1982, what appears remarkable about the 1983 bulge in Japanese trade surplus is not a surge in exports but an unusually low level of dollar imports. This decline in import value appears to have resulted from cyclical weakness of the Japanese economy, lower oil prices, and pure valuation effects of exchange rate changes. Volume of imports was slightly higher in 1983 than in 1981, but the dollar value of imports was, in fact, $\$ 17$ billion lower in 1983 than in 1981 .

Second, Japan's 1983-84 surplus can also be viewed as partly resulting from substantial liberalization of international capital flows in Japan at the end of 1980 and hence may reflect a one-shot but slow portfolio adjustment to an increase in capital mobility at a time when U.S. yields have been very high. The sharp rise in capital outflows resulting from this portfolio adjustment was partly responsible for the 1981-82 depreciation of the yen and appears to be counteracting upward pressure on the yen that may have come from large current account surpluses of Japan in 1983-84.

Some have suggested that Japan still maintains capital controls that depress the value of the yen by discouraging capital inflows. It is true that capital inflows into Japan are still not completely free. For example, foreign ownership 
of Japanese companies is still constrained by many regulations. But there are regulations that deter capital outflows as well. On balance, it is difficult to establish that the remaining capital controls significantly bias capital flows in the outward direction. ${ }^{8}$

Third, a shift has been taking place in the fiscal position of Japan relative to the United States during 1982-84 (Chart 2). A measure of this relative fiscal shift can be obtained from estimates of discretionary changes in general government budget balances. According to the December 1983 Economic Outlook of the OECD, the United States is expected to provide a fiscal stimulus of 2.5 percent of GDP over 1982-84 while Japan is likely to contract fiscally by a similar magnitude.

In light of this information, it does not seem unusual that over the same period the current account would deteriorate by 2 percentage points of GDP in the United States while improving by 1.5 percent of GDP in Japan.

Fourth, the relative cyclical position of Japan and the United States may also have temporarily aggravated their current account imbalances. While the U.S. economy is experiencing a rapid homegrown recovery, Japanese growth has been modest and appears to have been led by the pickup in export demand.

Finally, if the overall strength of the dollar is partly responsible for the deterioration of the U.S. current account deficit, then the improvement in Japan's external surplus can be traced partly to the same factor as well. Japan is the second largest trading partner of the United States which itself happens to be the largest trading partner of Japan.

This close trade relationship dictates that some of the U.S. deficit will show up as the Japanese surplus. Between 1982 and 1983, the U.S. trade balance deteriorated by $\$ 25$ billion. Japan picked up less than $\$ 3$ billion of this directly in the form of an increase in its bilateral trade surplus with the United States. However, the strength of the dollar may also have enabled Japan to outcompete the United States in some third markets, such as Western Europe and East Asia.

When these various special and cyclical factors are considered together in assessing the behavior of the Japanese current account, Japan's large and growing current account surplus does not point to any overall weakness of the yen. A significant part of the surplus appears to be resulting from temporary factors and from the overall strength of the dollar.

${ }^{8}$ Many argue that the elimination of all remaining capital controls may, in fact, encourage further net capital outflows and weaken the yen in the short run. See, for example, W. A. Niskanen, "Issues and Nonissues," in E. R. Fried, P. H. Trezise, and S. Yoshida (eds.), The Future Course of U.S.-Japan Economic Relations. 
Chart 2

Budget Deficit and the Current Account: 1970-84

in percentage of gross domestic product

\section{General government financial balance}

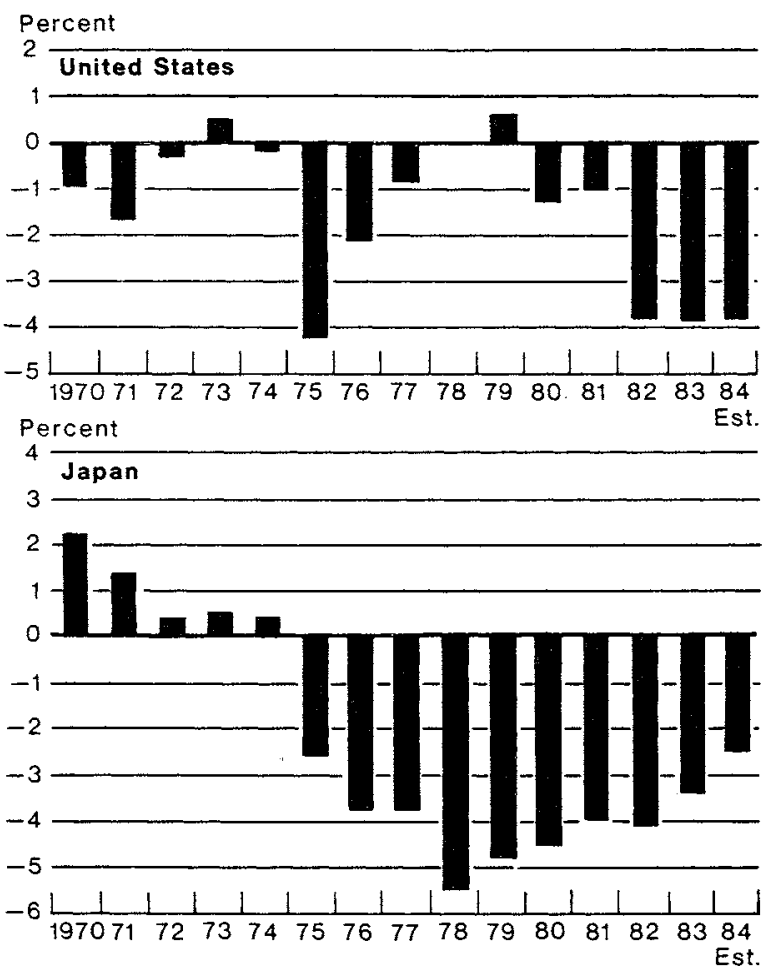

Current account balance

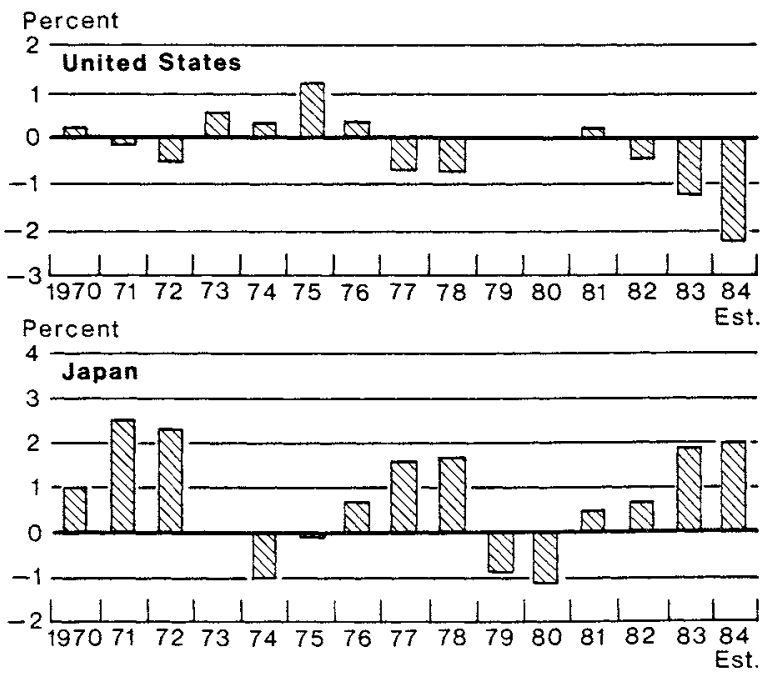


Indeed, once these factors are taken into account, Japan's underlying current account surplus does not appear to be very large or to be growing rapid1y. A persistent surplus in the Japanese current account may or may not lead to an overall appreciation of the real exchange rate of the yen. That will depend on the joint future interaction between the private portfolio preferences of international investors and the public policy choices of national governments. But the recent behavior of the Japanese current account does not suggest that the yen is particularly weak.

The dollar appears too strong, however, if the behavior of the U.S. current account is analyzed. Whereas the Japanese current account surplus as a share of its GDP is not likely to rise appreciably in 1984, the U.S. current account deficit is expected to rise from over 1 percent of its GDP in 1983 to over 2 percent in 1984.

Although a significant part of the deterioration of the U.S. deficit can be accounted for by the relative eyclical position of the United States and the decline in demand for U.S. goods from the heavily indebted countries, especially those in Latin America, the strength of the dollar is still the single most important factor. ${ }^{9}$ If the dollar remains at the current level, the U.S. current account is expected to continue to deteriorate. By end-1985, according to recorded statisties, the United States is likely to turn from a net creditor country to a net debtor country.

One implication of this shift in U.S. wealth will be a gradual change in the composition of the U.S. current account. Net investment income, which peaked at $\$ 33$ billion in 1981, has already started declining and will continue to do so in the foreseeable future. Thus, the large service account surplus of the seventies will continue to shrink in the eighties. To achieve a balanced current account, the U.S. merchandise trade deficit must be significantly smaller during the eighties than it was in the seventies. Because of this dynamic effect, the longer the current account deficit persists, the larger is the depreciation of the real exchange rate of the dollar required to eliminate the deficit.

But what is of greater concern about the present situation is the fact that such large current account deficits are unprecedented in recent U.S. history, and there is a great deal of uncertainty as to how the dollar, and more generally the world financial markets, will react as the United States continues to demand a greater proportion of world savings.

9 According to staff estimates, if the real effective exchange of the dollar were held constant from 1980 to 1983 at its average 1973-80 level, the U.S. merchandise trade deficit would have been over $\$ 30$ billion lower in 1983 , all other things remaining the same. 
Because of the current high return and the relatively low political and economic risk that characterize U.S. assets, international investors have so far financed the growing U.S. current account deficit. However, as the U.S. current account deficit grows bigger, the perceived exchange rate risk of holding financial dollar assets may begin to dominate the attraction of high U.S. yields, and market assessment may increasingly turn against the dollar. The weakening of the dollar since mid-January may be reflecting such a change, but how far the dollar will fall and how fast depends on how international investors and speculators will assess and reassess their expectations of the future course of the dollar in light of new events and new information.

To sum up, an assessment of the behavior of the U.S. current account supports the view that the current strength of the dollar may not be sustainable indefinitely but the precise dynamies of the dollar decline is still impossible to predict.

\section{Interest Rates}

Another factor often cited in support of the view that the yen is undervalued is the low level of Japanese interest rates. 10

A closer look at the facts, however, reveals that Japanese interest rates were not particularly low in 1983. For example, throughout 1983, the three-month Euroyen deposit rate (as reported in Morgan Guaranty's World Financial Markets) remained somewhat higher than the comparable Euromark rate. Chart 3 provides additional evidence by taking into account differential inflation rates. Throughout 1983 the United States clearly emerges as the country with the highest level of short-term real interest rates, but Japan's short-term real interest rates were higher than those of most major industrial countries. ${ }^{11}$ An examination of longterm real rates suggests the same conclusion.

There could be disagreements on the details of the measurement of these real interest rates, but the central conclusion is clear: the United States has very high interest rates but Japan does not have very low interest rates. Therefore, the weakness of the yen vis-à-vis the dollar cannot be attributed to low Japanese interest rates but appears to be partly a result of high U.S. interest rates.

${ }^{10}$ A recent expression of this view can be found in the October 19,1983 issue of The Economist (page 77). An article entitiled "How Japan Cheapens the Yen" maintains that Japan "contributes to the yen's weakness by still rigging interest rates."

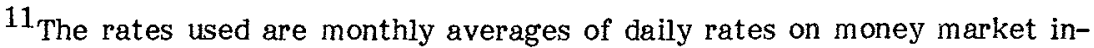
struments with maturity of about three months. Expected inflation in month $t$ is proxied by the twelve-month rate of CPI inflation in month $t+6$. 
Chart 3

Real Short-term Interest Rates*

January 1980-November 1983

\section{Real interest rates}

Percent per annum

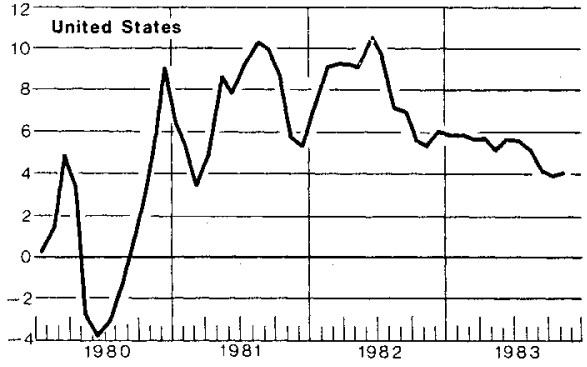

Percent per annum

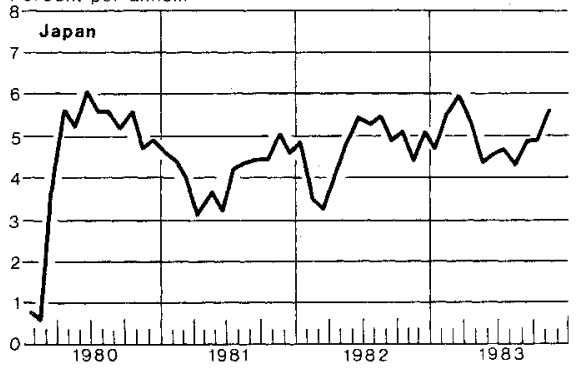

Real differentials: local minus U.S. real interest rate

Percent per annum

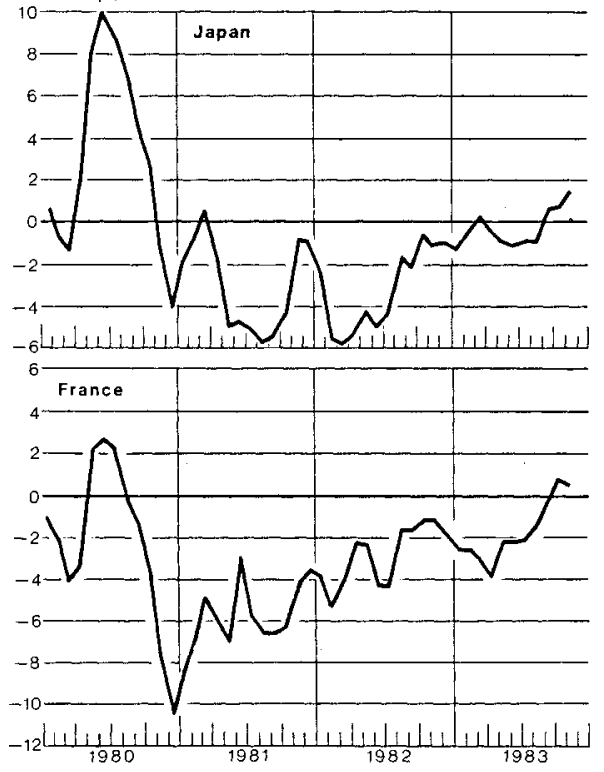

Percent per annum
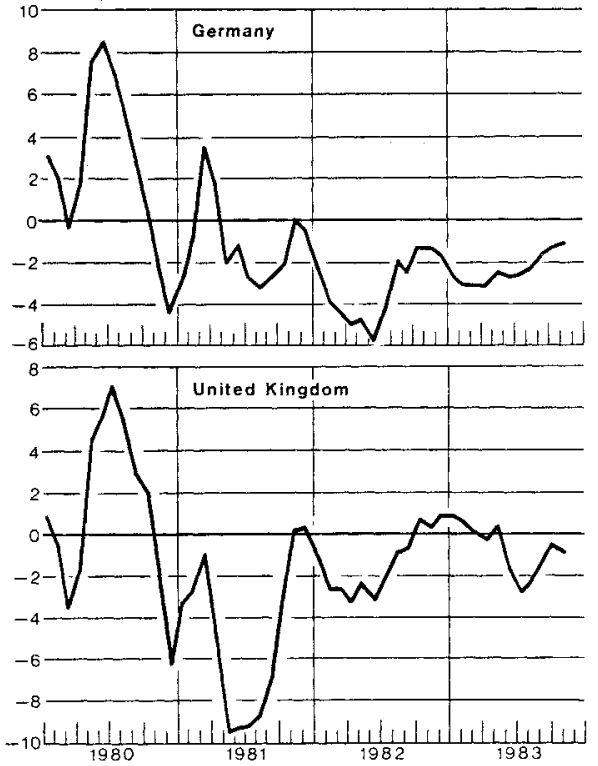

* The rates shown are monthly averages of daily rates on money market instruments of about ninety days maturity adiusted by an estimate of expected inflation. The rate for Japan is the discount rate on two-month (private) bilis. 


\section{Concluding Remarks}

The central conclusion of this article is that, from a macroeconomic and trade point of view, the dollar is too strong but the yen is not particularly weak. Japan's recent gains in competitiveness against the United States have resulted from an overall strength of the dollar and not from any overall weakness of the yen. In other words, there is no special yen-dollar imbalance. Evidence on changes in international competitiveness as well as an assessment of the present and prospective current account movements both point to such a conclusion.

The conclusion that Japan's present and prospective current account surpluses are not excessively large once temporary and cyclical factors are taken into account can, however, be criticized from an international point of view. Since Japan is the world's second largest economy, a current account surplus that may not be large from its national point of view may be considered to be unduly large by the rest of the world. Japan's trading partners may not wish to incur matching current account deficits for economic or political reasons.

If this is the issue, it needs to be clearly spelled out. This will open an international debate on how large a Japanese current account surplus is considered undesirable by her trading partners and why. Is a Japanese current account surplus on the order of 1.0 percent of its GDP on average too large from the point of view of Japan's trading partners? Should Japan run a balanced current account on average? Why is a small Japanese surplus desirable? Is it to keep the forces of protectionism in the United States and in Europe on a leash?

Similar questions can be raised about the size of the U.S. current account deficit. Since the dollar is the major international currency and the United States is the world's largest and richest economy, a large and growing U.S. demand on world savings may create unique adjustment problems for the international financial system.

These are important questions. But they do not focus narrowly on exchange rates. Rather they direct public attention to the broader issue of the international implications of different mixes of monetary, fiscal, financial, and trade policies. Ultimately, the question of what constitutes correct values of exchange rates can be understood only in that broader context. 